Aus der Klinik für Allgemein-, Viszeral- und Kinderchirurgie

(Prof. Dr. med. B. M. Ghadimi)

im Zentrum Chirurgie

der Medizinischen Fakultät der Universität Göttingen

\title{
In vivo Optical Imaging zum Nachweis der \\ Leberrepopulation nach Konditionierung der \\ Empfängerleber und Hepatozytentransplantation
}

\section{INAUGURAL-DISSERTATION}

zur Erlangung des Doktorgrades

der Medizinischen Fakultät

der Georg-August-Universität zu Göttingen

vorgelegt von

Ali Seif Amir Hosseini

aus Teheran

Göttingen 2013 
Dekan:

1. Berichterstatter/in:

2. Berichterstatter/in:

3. Berichterstatter/in:

Tag der mündlichen Prüfung:
Prof. Dr. rer. nat. H. K. Kroemer

Prof. Dr. med. S. König

Prof. Dr. med. F. Alves

Prof. Dr. hum. biol. M. Schön

18.06.2014 


\section{Inhaltsverzeichnis}

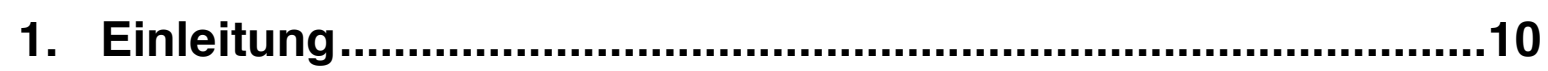

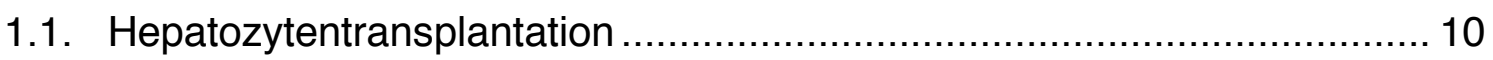

1.1.1. Historische Aspekte der Hepatozytentransplantation ........................ 10

1.1.2. Indikation der Hepatozytentransplantation .................................. 11

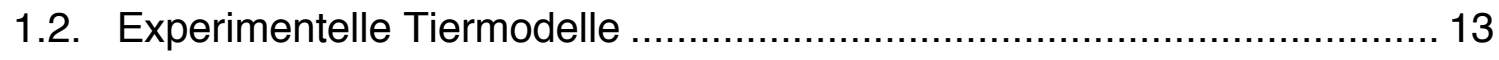

1.2.1. Nachweismethoden transplantierter Hepatozyten .......................... 13

1.2.2. Dipeptidylpeptidase-IV-Fischer-344-Ratten-Transplantationsmodell .. 15

1.2.3. Hepatische Präkonditionierung zur selektiven Leberrepopulation nach Hepatozytentransplantation ................................................ 16

1.2.4. Applikationswege der Hepatozytentransplantation............................ 18

1.3. In vivo Optical Imaging .......................................................... 20

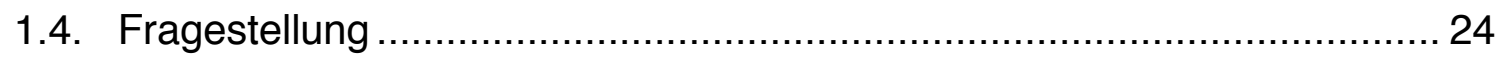

2. Material und Methoden .........................................................25

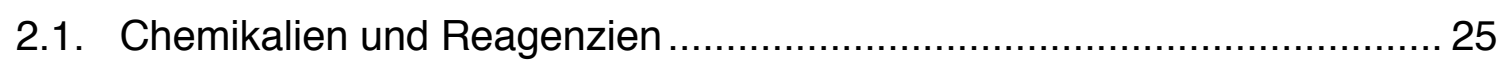

2.2. Verbrauchsmaterialien ................................................................... 28

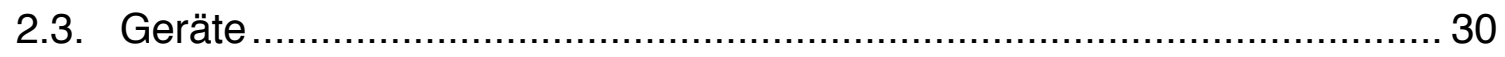

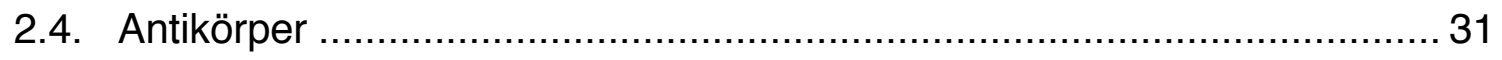

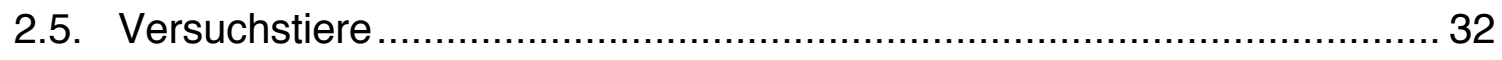

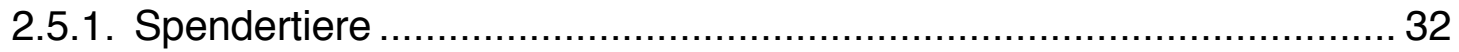

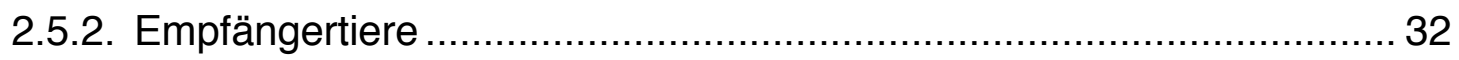

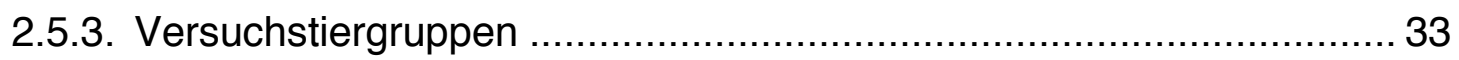

2.5.4. Behandlungszyklus der Versuchstiere ........................................ 33

2.6. Selektive Bestrahlung der Rattenleber .......................................... 35

2.7. Isolation und Aufbereitung der Hepatozyten......................................... 35

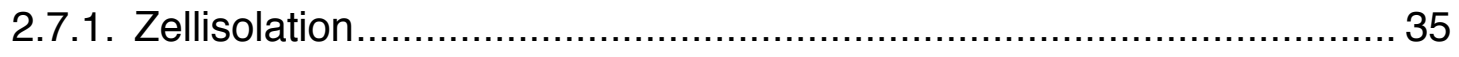

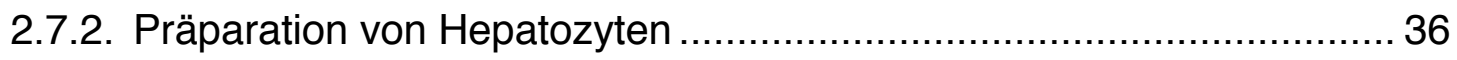




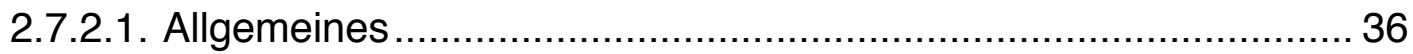

2.7.2.2. Herstellung der Perfusionslösung.............................................. 36

2.7.2.3. Gewinnung isolierter Hepatozyten............................................. 38

2.7.2.4. Reinigung der Zellsuspension .................................................. 39

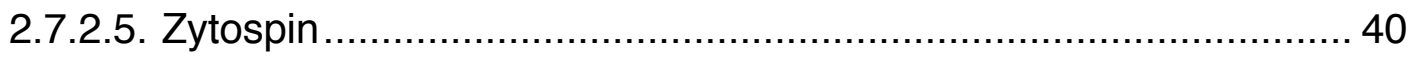

2.8. Leberteilresektion und intrasplenale Transplantation von Hepatozyten ... 40

2.9. Histologische Aufarbeitung der Gewebeproben ................................... 41

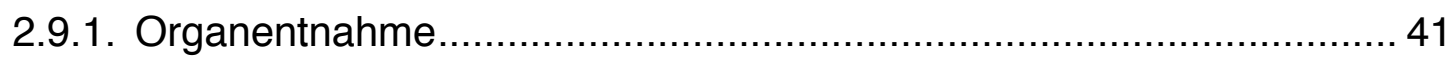

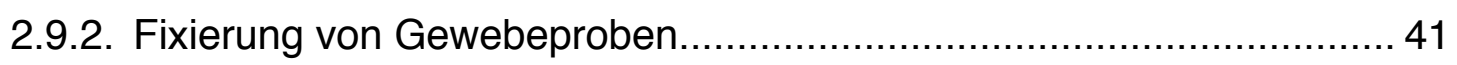

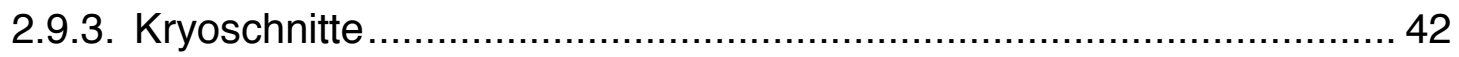

2.10. Immunfluoreszenzfärbungen .......................................................... 42

2.10.1. Fluoreszenzmikroskopische Untersuchung .................................. 42

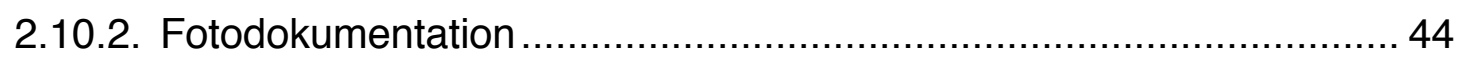

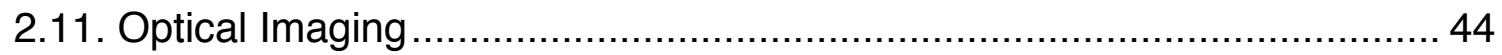

2.11.1. Cy5.5-gekoppelter DPPIV-Antikörper ........................................... 44

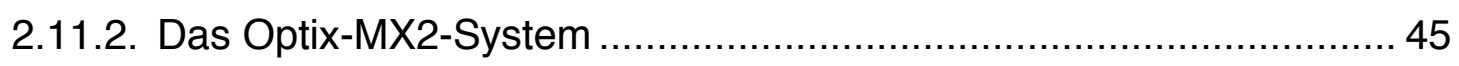

2.11.3. Bestimmung der Gesamtleuchtkraft ........................................... 48

3. Ergebnisse.....................................................................50

3.1. Nebenwirkungen und Toxizität der Vorbehandlung und des Optical

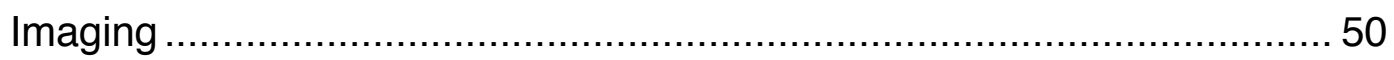

3.2. Beurteilung präparierter Spenderhepatozyten vor Transplantation ...........50 50

3.3. Feststellung der optimalen Aufnahmebedingungen und des Messzeitpunktes im Optical Imaging ...................................................... 51

3.4. Optical Imaging der Leberrepopulation in vivo.......................................... 55

3.5. Bestimmung der Gesamtleuchtkraft der Leber ..................................... 58

3.6. Nachweis der hepatischen Repopulation durch Immunfluoreszenzmikroskopie 


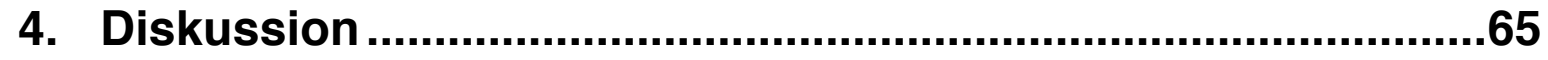

4.1. Hepatozelluläre Transplantation im DPPIV-Fischer-344-Tiermodell ........65

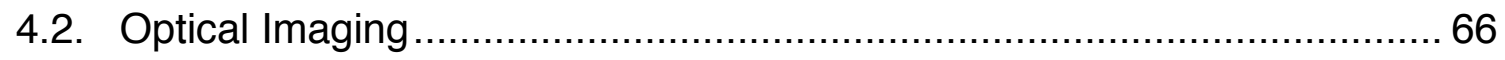

4.2.1. Optical Imaging im DPPIV-Fischer-344-Tiermodell .........................66

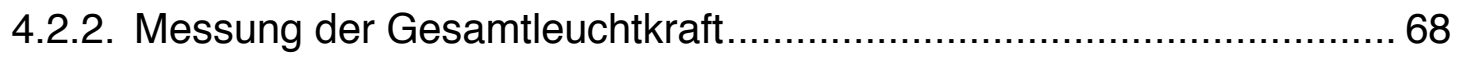

4.2.3. Derzeitiger Status und Perspektiven des Optical Imaging...................70

4.2.4. Intravitale Bildgebung im klinischen Kontext ............................... 72

4.3. Hepatozytentransplantation als Perspektive .................................. 73

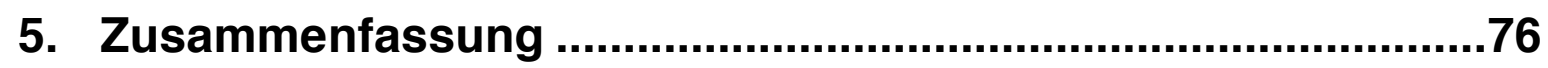

6. Tabellen- und Abbildungsverzeichnis .................................79

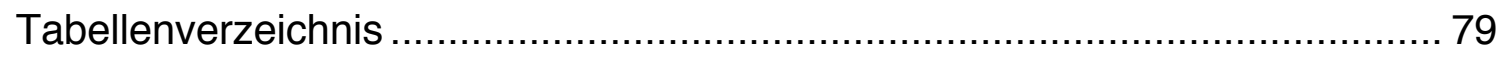

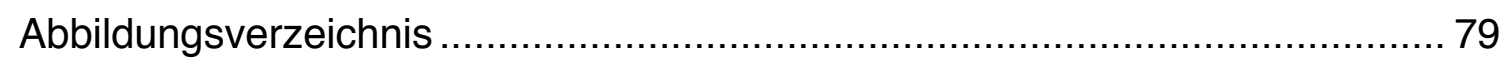

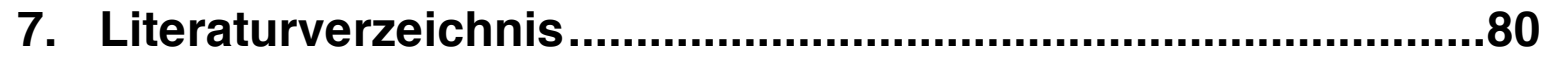




\section{Abkürzungsverzeichnis}

Abb.

AK

AZ.

ap

bzw.

CCD

CD26

$\mathrm{cm}$

Cx32

CT

DAPI

Dil

DPPIV
Abbildung

Antikörper

Aktenzeichen

anterior-posterior

beziehungsweise

charge-coupled device

(ladungsgekoppeltes Bauelement)

cluster of differentiation 26

Zentimeter

Connexin 32

Computertomographie

4‘,6-Diamidino-2-Phenylimdol

Dioctadecyl-tetramethyl-indocarbocyanin-perchlorat

Dipeptidylpeptidase IV

$\mathrm{Fa}$.

Firma 
FDA

FITC

FMT

G

g

GLK

Gy

HBsAg

HEPES

$\lg G$

IU

Kap.

$\mathrm{kDa}$

KG

$\mathrm{kg}$

$\mathrm{mg}$
Food and Drug Administration

Fluoresceinisothiocyanat

Fluoreszenz-Molekular-Tomographie

Gauge

Gramm

Gesamtleuchtkraft

Gray

Hepatitis-B-surface-Antigen

Hydroxyethylpiperazinethansulfonsäure

Immunglobulin G

international units

Kapitel

Kilodalton

Körpergewicht

Kilogramm

Milligramm 
Min

Mio.

$\mathrm{ml}$

$\mathrm{mm}$

MRT

MV

$\mu \mathrm{m}$

NC

$\mathrm{nm}$

ns

o.g.

OLT

pa

PET

p.i.
Minute

Million

Milliliter

Millimeter

Magnetresonanztomographie

Mega-Elektronenvolt

Mikrometer

normalized counts

Nanometer

Nanosekunde

oben genannt

orthotope Lebertransplantation

posterior-anterior

Positronen-Emmisions-Tomographie

post injectionem 
rel.

$\mathrm{ROI}$

SELICA

SPECT

Tab.

TCSPC

TPSF

UDP

$\mathrm{U} / \mathrm{min}$

vgl.

z.B.

z.T. relativ

Region of Interest

(Bereich von Interesse)

Safety and Efficacy of Liver Cell Application

single-photon emission computed tomography

(Einzelphotonen-Emissionscomputertomographie)

Tabelle

time-correlated single-photon counting

(Zeitkorrelierte Einzelphotonenzählung)

temporal point spread function

(Fluoreszenzphotonenlaufzeithistogramm)

Uridindiphosphat

Umdrehungen pro Minute

vergleiche

zum Beispiel

zum Teil 


\section{Einleitung}

\subsection{Hepatozytentransplantation}

\subsubsection{Historische Aspekte der Hepatozytentransplantation}

Die Idee der Transplantation von Zellen oder Organfragmenten zur Therapie von Lebererkrankungen bewegt die Wissenschaft seit Beginn des 20. Jahrhunderts. Die Forschung auf diesem Gebiet hielt sich über Jahre bedeckt und lange Zeit galt die orthotope Lebertransplantation (OLT) als einzige Möglichkeit der Therapie des akuten und chronischen Leberversagens. Die enormen Kosten und das hohe Risiko der Ganzorgantransplantation zwangen jedoch zum Umdenken und rückten das Prinzip der Übertragung einzelner Zellen oder Zellfragmente in den Mittelpunkt. Organfragmente wurden erstmals in den 30er Jahren des vergangenen Jahrhunderts verpflanzt (Markus und Becker 1999). Die enzymatische Isolation von Hepatozyten gelang zuerst Howard et al. im Jahre 1967 (Howard et al. 1967). Den Grundstein für die Hepatozytentransplantation legten schließlich Berry und Friend (Berry und Friend 1969) und die Arbeitsgruppe von Seglen (Seglen 1976) mit ihren optimierten Verfahren zur Isolation von Leberzellen. Die damals neu eingeführte Technik der In-Situ-Kollagenaseperfusion erlaubte es, eine große Anzahl von Hepatozyten mit einem hohen Reinheitsgrad zu gewinnen (Markus und Becker 1999). Gleichzeitig verliehen weitere Publikationen über neue Transplantationstechniken von Hepatozyten diesem Gebiet der Forschung neuen Auftrieb. Die Arbeitsgruppen von Rugstad (Rugstad et al. 1970), Matas (Matas et al. 1976), und Groth (Groth et al. 1977) zeigten, dass nach intraportaler Infusion von Hepatozyten in Gunn-Ratten (Hyperbilirubinämieratten) die Bilirubinkonzentration erheblich gesenkt werden konnte. Dadurch war der Beweis erbracht, dass transplantierte Hepatozyten in der Lage sind, in den hepatischen Stoffwechsel des Empfängerorganismus einzugreifen und diesen, nach Entgleisung, auch zumindest partiell zu korrigieren. Obwohl es bereits 1967 technisch gelang, im Tiermodell Leberzellen zu transplantieren, fand die humane Applikation erst im Jahre 1992 statt (Mazaris 
et al. 2005). Erste Versuche der Hepatozytentransplantation beim Menschen wurden von Mito durchgeführt, dessen Arbeitsgruppe autologe Hepatozyten zur Behandlung von Patienten mit chronischem Leberversagen eingesetzt hat (Mito et al. 1992). Habibullah et al. führten anschließend erfolgreich eine Transplantation mit allogenen fötalen Hepatozyten bei Patienten mit akutem Leberversagen durch (Habibullah et al. 1994). Die ersten Versuche, hepatische Stoffwechselstörungen zu therapieren, wurden bei Patienten mit familiärer Hypercholesterinämie durch die Arbeitsgruppe um Grossman durchgeführt (Grossman et al. 1994). Einige Jahre darauf wurden allogene Hepatozyten erfolgreich zur Behandlung des CriglerNajjar-Syndroms Typ 1 eingesetzt, einer angeborenen, monogenen Stoffwechselerkrankung der Leber, bei der das Enzym Bilirubin-UDPGlucoronosyltransferase vollständig fehlt, welches für die Bilirubinausscheidung verantwortlich ist (Fox et al. 1998).

Während Teilerfolge in der Therapie von Stoffwechselerkrankungen mit temporärer klinischer Stabilisierung der behandelten Patienten dokumentiert werden konnten, bleibt es weiterhin schwierig, den exakten Therapieerfolg nach Hepatozytentransplantation zu messen. In der sogenannten Bridging-Therapie ist sie erwiesenermaßen effektiv. Hierbei konnte gezeigt werden, dass Patienten bis zum Erhalt einer neuen Leber erfolgreich therapiert und schwerwiegende lebensbedrohliche Stoffwechselentgleisungen vermieden werden können (Hughes et al. 2012).

\subsubsection{Indikation der Hepatozytentransplantation}

Die Hepatozytentransplantation wird als vielversprechende therapeutische Option für Patienten mit Stoffwechselstörungen der Leber betrachtet (Serra et al. 2012). Es bestehen zwei primäre Indikationen zur Zelltherapie: zum einen angeborene Stoffwechselerkrankungen der Leber, zum anderen das akute Leberversagen. Angeborene metabolische Erkrankungen sind selten und treten in Europa und in den USA mit einer Inzidenz von 1:1500 auf (Raghuveer et al. 2006). In der Regel sind betroffene Patienten gezwungen, sich an strenge Diäten zu halten. Zudem 
müssen sie sich medizinischen Prozeduren und einer medikamentösen Langzeittherapie unterziehen, um chronische Komplikationen bzw. akute metabolische Entgleisungen zu vermeiden. Diese medizinisch notwendigen Behandlungsmaßnahmen können sich in hohem Maße einschränkend auf die Lebensqualität des betroffenen Patienten auswirken. Die einzige endgültige Behandlungsoption ist die OLT, die über 90 \% Langzeitüberleben bei Kindern mit Stoffwechselerkrankungen der Leber bietet (Sokal 2006). Dennoch ist der operative Organersatz bezogen auf die Gesamtpopulation mit Risiken sowie mit einer gewissen Morbidität und Mortalität verbunden (Watt et al. 2010). Bei Erwachsenen liegen die 1-Jahres-, 5-Jahresund 10-Jahres-Überlebensrate bei $84 \%$, respektive $68 \%$ und $54 \%$ (Singh und Watt 2012).

Eine weitere Patientengruppe, bei der die Hepatozytentransplantation als Therapieoption in Betracht gezogen werden kann, ist das akute oder fulminante Leberversagen. Dieses Versagen kann derzeit, abgesehen von den Fällen bei denen es zu einer hepatischen Rekompensation kommt, nur durch eine Lebertransplantation therapiert werden (Baccarani et al. 2003). Virale Hepatitiden und medikamentöse Überdosierung sind die häufigsten bekannten Ursachen für das akute Leberversagen. Meistens bleibt jedoch die Ursache ungeklärt (Otsuka et al. 2007). Das akute Leberversagen kann ebenfalls bei Patienten auftreten, bei denen ein signifikanter Anteil der Leber reseziert und nur eine geringe hepatozelluläre Organmasse zurückgelassen wurde (Garcea und Maddern 2009). Ferner ist das Risiko für das Auftreten des akuten Leberversagens nach einem hepatischen Eingriff bei Patienten mit einer präexistentiellen Lebererkrankung als nicht gering zu betrachten (Smets et al. 2008).

Nicht zur Verfügung stehende Organe, eine akute Verschlechterung des klinischen Zustandes sowie präexistente Kontraindikationen für eine Transplantation führen in vielen Fällen zu einem frühzeitigen Versterben dieser Patienten (Bilir et al. 2000). Die Hepatozytentransplantation könnte für viele der o.g. Szenarien eine mögliche Behandlungsalternative bieten, z.B. als sog. Bridging-Therapie, um die Wartezeit bis zur Erlangung eines geeigneten Organs zu überbrücken oder sogar, 
um die Stoffwechselleistung der Leber soweit zu korrigieren, dass von einer OLT abgesehen werden kann.

Für Patienten mit einer schweren Leberzirrhose ist die Ausgangssituation ungleich schwieriger und die Durchführbarkeit einer zellulären Therapie problematischer. Neben dem Pfortaderhochdruck im Empfängerorgan trägt die gestörte hepatische Architektur zur Dysfunktion der Leber als Stoffwechselorgan bei. Durch intrahepatische porto-portale venöse Shunts verschiebt sich das physiologische Gleichgewicht bei der nutritiven und oxygenen Versorgung der Hepatozyten, sodass ihre erfolgreiche Ansiedlung ohne das Vorhandensein einer physiologischen Leberarchitektur fraglich bleibt (Soltys et al. 2010). Patienten mit fortgeschrittener Leberzirrhose gehören damit nicht zur primären Indikationsgruppe der Hepatozytentransplantation.

\subsection{Experimentelle Tiermodelle}

\subsubsection{Nachweismethoden transplantierter Hepatozyten}

Um die humane Applikation der Hepatozytentransplantation besser zu ergründen, ist es notwendig, geeignete Tiermodelle zu entwickeln. Die wissenschaftliche Grundlage hierfür wurde vor über 40 Jahren anhand von tierexperimentellen Modellen geschaffen (Seppen et al. 2009). In den 1960ern belegten die ersten Transplantationsstudien mit Hepatozyten in verschiedenen Tiermodellen ihre grundsätzliche Durchführbarkeit (Starzl et al. 1966). Bei funktioneller Einschränkung der Leber, z.B. auf dem Boden eines genetischen Defizits oder bei toxischer Leberschädigung, konnten transplantierte, gesunde Zellen einen Überlebensvorteil gegenüber den nativen und erkrankten Zellen im Empfängerorganismus unter Beweis stellen. Es kam zur präferenziellen Organrepopulation durch die Spenderzellen. Dieses Phänomen konnte insbesondere in einer transgenen Maus mit einer genetisch bedingten Urokinase-Plasminogen-Aktivator-Defizienz gezeigt werden. Die Mäuse in diesem Tiermodell entwickelten ein chronisches Leberversagen, bedingt durch den Gendefekt. Eine Transplantation von gesunden Hepatozyten führte zu 
einer fast vollständigen Neubesiedlung der Empfängerleber und zu einer Rekonstitution der Leberfunktion (Rhim et al. 1994). Im Laufe der vergangenen 20 Jahre wurden zahlreiche Tiermodelle mit genetisch defizienten Tieren etabliert. Die besondere klinische Relevanz dieser Tiermodelle konnte 2006 eine Arbeitsgruppe um Stephenne beweisen. Sie lieferte valide Daten, dass genetisch bedingte Leberfunktionsstörungen im menschlichen Organismus ebenfalls durch eine Applikation von gesunden Hepatozyten korrigiert werden konnten (Stephenne et al. 2006).

Für den regelhaften klinischen Einsatz sind sichere Nachweismethoden transplantierter Hepatozyten für ein erfolgreiches Therapie-Monitoring im Empfängerorganismus erforderlich. Ein früher Ansatz, transplantierte Hepatozyten im Empfängerorgan zu verfolgen, war die exogene Zellmarkierung, d.h. Spenderzellen wurden vor Transplantation mit Farbstoffen markiert. Hierbei kamen verschiedene Färbetechniken zum Einsatz, u.a. der Fluoreszenzfarbstoff Dil (Dioctadecyl-tetramethylindocarbocyanin-perchlorat) oder das Carboxyfluorescein (Fujioka et al. 1994). Auf diese Weise gelang es, Spenderhepatozyten nach Markierung mit Dil noch bis zu 6 Wochen in der Leber des Empfängertieres nachzuweisen (Markus et al. 1997). Bislang konnte jedoch ein erfolgreicher Einsatz bei humanen Hepatozytentransplantationen nicht dokumentiert werden (Fisher und Mas 2009). Eine nicht zu vernachlässigende Problematik dieser Form der Zellmarkierung ist die, dass die exogenen Marker metabolischen Abbauprozessen im Organismus unterliegen und sich die Konzentration des Farbstoffes faktisch mit jedem Zellzyklus vermindert (Deliolanis et al. 2007).

Es gab weitere Ansätze, in denen HBs-Antigen-exprimierende, transgene Maushepatozyten zum Einsatz kamen (Gupta et al. 1990). Mit Hilfe dieser Modelle konnte gezeigt werden, dass die zuvor in das Milzparenchym implantierten Hepatozyten über das Pfortadersystem in die Lebersinuoiside abwanderten und sich dann weiter in den Periportalfeldern der Leber ansiedelten. Mit Verbesserung der Nachweisverfahren waren diese Zellen noch mehr als 8 Wochen nach Transplantation in der Empfängerleber nachweisbar (Luker und Luker 2008).

Das Überleben der Hepatozyten nach Transplantation und ihr Beitrag zur funktionellen Verbesserung der Leber sind nur schwer objektivierbar. Die oben aufgeführ- 
ten Nachweismethoden sind jedoch sehr komplex und technisch anspruchsvoll. In den letzten Jahren ist die intravitale Bildgebung in den Fokus der Forschung gerückt. Sie erlaubt es, die eingebrachten Zellen im Empfängerorganismus nichtinvasiv wiederholt zu identifizieren und ihre Integration zu visualisieren. Neue Magnetresonanz-Tomographie-Verfahren (MRT-Verfahren) unter Verwendung von Eisenoxid-Partikeln zur In-Vivo-Bildgebung werden derzeit entwickelt. Ihre potenziell toxische Wirkung sowie eine nur geringe Spezifität der Marker stellen jedoch die größte Hürde dar (Huang et al. 2008). Auch die EinzelphotonenEmissionscomputertomographie (SPECT) und die Positronen-EmissionsTomographie (PET) sind eine mögliche Option, sind jedoch aufwendig (Koenig et al. 2009). Hier bieten Optical-Imaging-Verfahren - wie das hier vorgestellte OptixMX2-System - eine vielversprechende Alternative. Hierbei handelt es sich um eine Bildgebungsmodalität, die darauf basiert, Licht zu detektieren, welches von vitalen Zellen oder Gewebe emittiert wird. Als Signalquelle wird hierbei in der Regel Fluoreszenz oder Biolumineszenz verwendet (vgl. Kap. 1.3) (Muller et al. 2013).

\subsubsection{Dipeptidylpeptidase-IV-Fischer-344-Ratten- Transplantationsmodell}

DPPIV (Dipeptidylpeptidase IV) ist eine membrangebundene Exopeptidase, die als Bestandteil von CD26, einem 110-kDa Oberflächenprotein, auf fast allen Gewebearten des Körpers exprimiert wird. Initial wurde das Enzym 1966 als glycyl-prolylb-naphthylamidase (Hopsu-Havu und Glenner 1966) beschrieben und später zu DPPIV umbenannt (Tanaka et al. 1992). Neben seiner Funktion als Marker für die T-Zell-Aktivierung (Fleischer 1994) steht CD26 in Verbindung mit der Signaltransduktionskette von T-Zellen als Ko-Stimulator (Morimoto und Schlossman 1998) und ist beteiligt an diversen anderen Funktionen der T-Zellen, u.a. der Zytokinproduktion (Dang et al. 1990) sowie der Zellmigration (Morimoto et al. 1989). Eine hohe Gewebskonzentration von DPPIV liegt im Nierengewebe, im Dünndarm sowie in der Leber vor. Insbesondere die Hepatozyten und die Gallencanaliculi weisen einen hohen Grad der Expression auf (Gossrau 1981). 1991 konnte eine 
spontane Mutation im Gen des Enzyms DPPIV an einem Zuchtstamm der Fischer344-Ratten nachgewiesen werden (Thompson et al. 1991), was zu einem Funktionsverlust der katalytischen Untereinheit des Proteins führte. Trotz der funktionellen Einschränkung des Enzyms zeigten die betroffenen Tiere gegenüber dem Wildtyp eine normale Lebenserwartung. Die Verfügbarkeit eines solchen syngenen Zuchtstammes von Fischer-344-Ratten mit und ohne DPPIV-Aktivität bot die ideale Grundlage für die Entwicklung eines Transplantationsmodells. 1995 stellten Gupta et al. zum ersten Mal ein solches syngenes Transplantationsmodell vor. Hierbei wurden DPPIV-positive Wildtyp-Hepatozyten in DPPIV-defiziente Ratten transplantiert (Gupta et al. 1995). Die Darstellung der DPPIV-positiven Zellen erfolgte durch histochemische Färbung. Mit Hilfe dieses neu entwickelten Tiermodells konnte zum ersten Mal der Integrationsmechanismus transplantierter $\mathrm{He}$ patozyten in die Empfängerleber detailliert beschrieben werden. Dieses Tiermodell bildete ebenfalls die experimentelle Grundlage für das vorgelegte Dissertationsprojekt.

\subsubsection{Hepatische Präkonditionierung zur selektiven Leber- repopulation nach Hepatozytentransplantation}

Die Hepatozytentransplantation zeigt ein enormes therapeutisches Potenzial für zahlreiche hepatische Stoffwechselstörungen, ob auf genetischer oder auf erworbener Basis. Um die Effektivität transplantierter Hepatozyten für die klinische Applikation zu bestimmen, ist es zunächst erforderlich, die spezifischen Eigenschaften der Hepatozyten im Tiermodell zu charakterisieren. Das Zell-Engraftment sowie das proliferative Potenzial der transplantierten Zellentitäten stellen einen notwendigen Gegenstand dieses Charakterisierungsprozesses dar.

In verschiedenen Tiermodellen ist die hepatische Präkonditionierung des Empfängertiers vor Transplantation ein unersetzlicher Bestandteil zur Verbesserung des Zell-Engraftments sowie zur Stimulierung der Proliferation der Empfängerleber nach Transplantation. Es ist bekannt, dass sich bei fehlender Präkonditionierung nur 15 bis $20 \%$ der transplantierten Hepatozyten erfolgreich im Leberparenchym 
des Empfängertiers ansiedeln (Ponder et al. 1991) und pro Sitzung nicht mehr als $1 \%$ des gesamten Lebervolumens durch transplantierte Hepatozyten ersetzt werden können (Gupta et al. 1991). Wiederholte Hepatozytentransplantationen können die Fraktion der transplantierten Zellen der Leber auf ein Maximum von 5 bis $7 \%$ erhöhen. Jedoch erfordert eine effektive Zelltherapie deutlich höhere Raten der intrahepatischen Ansiedelung. Daher müssen Strategien entwickelt werden, die ein optimales hepatisches Milieu erzeugen, um die Spenderzellen im Empfängerorganismus nach Transplantation zu vermehren.

Zwei sich ergänzende Bedingungen müssen vorliegen, um die Hepatozytentransplantation zu optimieren. Die Grundidee besteht darin, zum einen die Proliferationskapazität der transplantierten Zellen zu erhöhen (Yuan et al. 2003), zum anderen gleichzeitig einen Überlebensnachteil für die nativen Hepatozyten im Empfängerorganismus bzw. einen Vorteil für die transplantierten, DPPIV-positiven Zellen zu schaffen (Christiansen et al. 2006). Ersteres kann durch eine hepatische Teilresektion erreicht werden, bei der eine Regenerationsantwort durch die verbliebene Leber induziert wird (Grompe 2001). Der somit geschaffene Proliferationsstimulus wirkt gleichermaßen unselektiv sowohl auf die endogenen Hepatozyten als auch auf die Spenderzellen ein. Der selektive Proliferationsstimulus der Spenderzellen resultiert aber erst dann, wenn das Wachstum der endogenen Hepatozyten blockiert wird und folglich die transplantierten Zellen die Empfängerleber repopulieren können. Ein bereits etabliertes Modell, welches die partielle Hepatektomie sowie die Applikation des Alkaloids Retrorsin vorsieht, erfüllt die genannten Bedingungen (Koenig et al. 2005). Darüber hinaus existiert ein weiteres Tiermodell, das auf dem Alkaloid Monocrotalin basiert (Joseph et al. 2006). Jedoch erlauben die potenziell hepatotoxischen Nebenwirkungen dieser systemisch applizierten Pyrrolizidinalkaloide sowie ihr onkogenes Potenzial keinen regulären klinischen Einsatz. Eine geeignete Alternative bietet die lokale Bestrahlung der Leber. Sie ist eine in der Humanmedizin lang etablierte Therapiemodalität und kann auf Grund der kalkulierbaren lokoregionären und fehlenden systemischen Nebenwirkung potenziell für einen klinischen Einsatz in Erwägung gezogen werden (Christiansen et al. 2006). Durch Schädigung der Hepatozyten-DNA kommt es im Bestrahlungsgebiet zu einem 
Proliferationsstopp der Hepatozyten (Blockierung des Zellzyklus). Bestrahlung kann sowohl in vitro (Nikolaou et al. 2012) als auch in vivo (Christiansen et al. 2006) Zellwachstum hemmen und ist daher auch im Tiermodell als Verfahren für die hepatische Präkonditionierung vor Zelltransplantation geeignet (Yamanouchi et al. 2009) (vgl. Kap. 2.6).

Neben den oben genannten Bedingungen ist die Qualität der transplantierten Zellen für das Transplantationsergebnis besonders wichtig. Primäre Hepatozyten sind grundsätzlich die erste Wahl. Aufgrund ihrer Knappheit werden dennoch alternative Zellressourcen erforscht (Le Blanc et al. 2003). Autologe Stammzellen, z.B. aus dem Knochenmark, stellen eine mögliche Quelle dar (Lysy et al. 2008), aber auch fötale Vorläuferzellen (Schmelzer et al. 2007), embryonale Stammzellen (Agarwal et al. 2008), mesenchymale Stammzellen aus dem Knochenmark (Lagasse et al. 2000), mesenchymale Stammzellen aus dem peripheren Blut, Nabelschnurblut (Nonome et al. 2005) sowie Fettgewebe (Banas et al. 2008). Diese Zellentitäten sind jedoch aufgrund ihres nicht vollständig erforschten Nebenwirkungsspektrums wie z.B. das fibrosierende Potenzial von mesenchymalen Stammzellen oder das kanzerogene Potenzial von embryonalen Stammzellen für einen regelhaften klinischen Einsatz nicht ohne Vorbehalt geeignet. Dagegen liegt die höchste Expertise in präklinischen Modellen und ersten humanen Anwendungen mit primären Hepatozyten vor. Diese besitzen nachweislich die beste Funktionalität im Vergleich zu den oben genannten, alternativen Zellentitäten (Fitzpatrick et al. 2009). Im vorgelegten Dissertationsprojekt haben wir uns daher für diesen Zelltyp entschieden.

\subsubsection{Applikationswege der Hepatozytentransplantation}

Bei Stoffwechselstörungen der Leber sowie im Falle von akutem Leberversagen, beides Erkrankungen, bei der die Architektur der Leber erhalten bleibt, bieten eine physiologische Matrix und eine regelrechte portale Blutversorgung die ideale Voraussetzung für die Hepatozytentransplantation. Es existieren verschiedene Ansätze des Applikationsweges zur Hepatozytentransplantation beim Menschen. Die 
vielleicht am häufigsten zum Einsatz kommende Methode ist die direkte intraportale Injektion (Bilir et al. 2000). Die Zellen wandern dabei idealerweise über das Pfortaderstromgebiet in die Lebersinusoide ein und besiedeln nach Durchquerung der sinusoidalen Endothelzellbarriere das Empfängerorgan. Im Falle eines zirrhotischen Lebergerüstumbaus kann jedoch die Transplantation der Zellen eine portale Hypertension auslösen und ultimativ zu einer pulmonalen Translokation von Hepatozyten führen (Strom et al. 1999). Somit ist die Menge an Zellen, die innerhalb einer Sitzung transplantiert werden kann, durch ihren Effekt auf die intraportalen Druckverhältnisse limitiert. Der klinischen Erfahrung nach ist die Komplikationsrate bei intraportaler Transplantation allerdings hoch. Neben der transienten portalen Hypertension, die im humanen Organismus bis zu 3 Stunden nach Injektion der Zellen noch anhalten kann, gibt es eine Reihe weiterer Nebenwirkungen, die bedacht werden müssen (Strom et al. 1997). Als weitere Komplikationen zählen Blutungen, hämodynamische Instabilität während der Infusion sowie Embolisation pulmonaler Arterien durch Translokation der infundierten Zellen in die Lunge (Muraca et al. 2002). Bei Obduktionen verstorbener Patienten, die zuvor eine Zelltransplantation erhalten hatten, konnten Hepatozyten in den Alveoli nachgewiesen werden (Baccarani et al. 2003). Die Pfortaderthrombose ist ein weiteres Risiko und kann dadurch minimiert werden, dass die Zahl der innerhalb einer Sitzung infundierten Hepatozyten reduziert und eine gewichtsadaptierte Heparinisierung therapiebegleitend durchgeführt wird (Fox et al. 1998).

In der Literatur werden weitere potenzielle Transplantationsorte beschrieben. Die intraperitoneale Transplantation hat in Studien gezeigt, dass die ektope Zellmasse im Falle eines akuten Leberversagens unterstützend in den Lebermetabolismus eingreifen kann und Entgleisungen des Leberstoffwechsels zu korrigieren vermag (Habibullah et al. 1994). Um eine Abstoßungsreaktion zu verhindern, untersuchen neuere Ansätze die Möglichkeit der Immunoisolation der Zellen. Mit diesen entkapselten Zellen, den sogenannten Hepatozyten-Microbeads, konnte in vitro gezeigt werden, dass sie autonom eine Albumin- und Faktor-VII-Synthese leisten können (Hughes et al. 2012). 
Die Nierenkapsel stellt eine weitere Möglichkeit der ektopen Transplantation von Hepatozyten dar. In verschiedenen Versuchsreihen überzeugte diese Methode insbesondere dadurch, dass sie ein repetitives und einfach durchführbares Monitoring der Zellen mittels Biopsie ermöglicht (Papalois et al. 1994). Jedoch bietet das relativ kleine Volumen der Nierenkapsel nicht genügend Raum für eine größere Zellmasse, die signifikant in den Lebermetabolismus einzugreifen in der Lage wäre.

In zahlreichen Tierversuchen hat sich die Milz unter allen nicht-hepatischen Organen als geeignetste Alternative für die Hepatozytentransplantation bewährt (Cai et al. 2002). Im Rattenmodell gelang es durch repetitive Infusion bis zu $12,5 \%$ der ursprünglichen Lebermasse des Empfängerorganismus über die Milz zu transplantieren, wobei die Milz als Suspensorium dient und sukzessiv Hepatozyten in das portale Venensystem entlässt. Bei dieser Methode wurde eine nur vorrübergehende portale Hypertension beobachtet. Mit Hilfe von radioaktiv markierten Hepatozyten gelang es, die Distribution der Zellen nachzuweisen: Schätzungsweise $26 \%$ verblieben in der Milz, $72 \%$ wurden in der Leber lokalisiert und nur $2 \%$ gelangten in die Lungen (Gupta et al. 1994). Der unkomplizierte Zugangsweg und die relativ geringe Komplikationsrate haben uns überzeugt, im vorgelegten Dissertationsprojekt die Milz als Zugangsweg für die Implantation in die Leber zu verwenden.

\subsection{In vivo Optical Imaging}

Das interdisziplinäre Forschungsgebiet der intravitalen Bildgebung fokussiert sich auf die nicht-invasive Darstellung von Prozessen im lebenden Organismus (Hilderbrand und Weissleder 2010). Um genauer zu sein, ermöglicht sie die Untersuchung physiologischer Prozesse im Kontext eines lebenden Organismus und kann ein umfassenderes Bild der Krankheitspathologie und Krankheitsentwicklung zur Verfügung stellen (Pittet und Weissleder 2011). Wiederholte Überwachung der Reportergenexpression in lebenden Tieren ist für viele Anwendungen entscheidend, z.B. für Gentherapiestudien und transgenetische oder syngene Tiermodelle 
(Ray et al. 2001). Zurzeit werden mehrere Verfahren der nicht-invasiven Bildgebung und Quantelung der Genexpression in lebenden Tiermodellen untersucht. Von den derzeit klinisch verfügbaren funktionellen bildgebenden Verfahren weisen nur die PET und die SPECT eine hinreichende Sensitivität auf (Solomon et al. 2011), und trotzdem ist es schwierig, die Oberflächenrezeptoren der Zellen und die Reportergene zu erkennen und darzustellen (Räty et al. 2007). Zudem verlangen diese Verfahren die Verwendung von Radionukliden (Lecchi et al. 2007). An dieser Stelle könnte das Optical Imaging eine wichtige Rolle übernehmen (Weissleder und Pittet 2008), z.B. wäre eine potenzielle klinische Anwendung in Kombination mit markierten Antikörpern sowohl für die Tumordetektion als auch zur Einordnung der Tumore in Untergruppen gemäß ihrer Rezeptorexpression denkbar (Koyama et al. 2007).

Eine vielversprechende Methode der nicht-invasiven Bildgebung stellen OpticalImaging-Systeme dar. Sie messen Licht, welches durch Fluoreszenz oder durch Biolumineszenz im untersuchten Tier erzeugt wird (Napp et al. 2010). Das Prinzip bei der Fluoreszenzbildgebung besteht darin, dass Licht zunächst Gewebe von außen penetriert, ein spezifisches Rezeptormolekül in vivo anregt und hierdurch die Emission von Lichtwellen im Niedrigenergie-Bereich verursacht. Diese Lichtwellen können mit Hilfe von speziellen Kameras, die mit einem sogenannten charge-coupled device (CCD) ausgerüstet sind, registriert werden (Nikolaou et al. 2012). In der Biolumineszenzbildgebung hingegen wird Licht durch eine enzymatische Reaktion erzeugt und ebenfalls mit einer dezidierten CCD-Kamera registriert (Nikolaou et al. 2012). Optical-Imaging-Verfahren erlauben die spezifische Darstellung von Zellen und Geweben mittels antikörpergekoppeltem Farbstoff und bieten überdies eine ausreichende Sensitivität und die Vorteile einer erhöhten räumlichen Auflösung sowie das Fehlen schädlicher lonisierungsstrahlung wie bei PET, SPECT und CT (Choy et al. 2003).

Die Fluoreszenzbildgebung kann somit für eine nicht-invasive Quantifizierung und Visualisierung von molekularen Prozessen in vivo eingesetzt werden. Entscheidend in dieser Hinsicht sind dabei Sonden, die durch ein dezidiertes OpticalImaging-System detektierbar sind. Fluoreszensfarbstoffe spielen hierbei eine wich- 
tige Rolle. Sie können grob in zwei Kategorien eingeteilt werden: Reporter-Gene (fluoreszente Proteine) und injizierbare exogene Fluorophore. Die Entwicklung der Nah-Infrarot-Fluophore (NIR-Fluophore) und Nanomaterialien über die letzten zehn Jahre hat den Übergang der Fluoreszenz-Bildgebung von der mikroskopischen (Epifluoreszenz, konfokale und multifokale Mikroskopie, und mesoskopische Optical Projektion Tomographie) zur makroskopischen Bildgebung ermöglicht. Neue Entwicklungen im Verständnis von spezifischer Anbindung, der Aktivierung, der Pharmakokinetik, der Biokompatibilität und der Photophysik der Sonden sowie die Ausreifung multimodaler Techniken sind für eine Verbesserung der NIRSonden notwendig. In Verbindung mit dem verbesserten Design der Sonden haben grundlegende Arbeiten, die sich auf die Entwicklung sensibler Instrumente insbesondere Fluoreszenz-Molekular-Tomographie (FMT) und die Reduzierung von Artefakten konzentrierten, wesentlich zur Effektivität der molekularen Bildgebung beigetragen (Hilderbrand und Weissleder 2010).

Eine Limitierung des Optical Imaging stellt jedoch die eingeschränkte Gewebepenetration durch das Anregungs- bzw. Fluoreszenzlicht dar. Biologische Chromophore, besonders Hämoglobin, absorbieren sichtbares Licht in hohem Maße und setzen so der Tiefenpenetration bei kurzen Wellenlängen bereits bei einigen Millimetern eine Grenze. Andere biologische Komponenten - wie Wasser und Lipide - sind im Bereich des Sichtbaren bis zum Nah-Infrarot-Licht optisch transparent, im Infrarotbereich jedoch stark lichtabsorbierend. Die kombinierte Absorption dieser Komponenten bedeutet ein Fenster von 600 nm bis 1000 nm für das Optical Imaging, in dem der Absorptionskoeffizient des Gewebes minimal ist. Außerdem sind Lichtstreuung und Autofluoreszenz im Nah-Infrarot-Licht reduziert. Die Autofluoreszenz von Elastin (Boumaza et al. 2001), Kollagen (Lee et al. 1993) und anderen biologischen Fluophoren weist eine Emission im sichtbaren Bereich $(<600$ $\mathrm{nm}$ ) auf und kann Sonden im Kurzwellenbereich stark beeinflussen, führt jedoch im Nah-Infrarot-Bereich nicht zu Interferenzen. Der Schlüssel zu effektiver Bildgebung in tieferen Gewebeschichten ist somit das Nah-Infrarot-Licht. NIRFluoreszenzfärbungen können bei sorgfältiger Vorbereitung und Anwendung sen- 
sibler Nachweismethoden $2 \mathrm{~cm}$ Gewebe oder mehr durchdringen (Leevy et al. 2006).

Studien haben gezeigt, dass die NIR-Optical-Imaging-Technologie zur Überwachung von Zelloberflächenrezeptoren (Ke et al. 2003) oder Antigenen (Moore et al. 2004) verwendet werden kann. In dem vorgelegten Dissertationsprojekt wurde der Fluoreszenzfarbstoff Cy5.5 eingesetzt. Dieser kann an einen Antikörper gekoppelt und einem lebenden Nagetier appliziert werden, z.B. durch intravenöse Injektion. Der markierte Antikörper erkennt das Ziel-Antigen DPPIV in vivo. Nach Anregung des Antikörper-Farbstoff-Komplexes kann die Fluoreszenzintensität detektiert und gemessen werden. Dieser Ansatz, bei dem das Ziel die Identifikation und Nachverfolgung genetisch kodierter Hepatozyten vor einem negativen Hintergrund ist, stellt eine vielversprechende Methode dar (Christiansen et al. 2006).

In der hier präsentierten Arbeit wurden aus Wildtyp-Fisher-344-Ratten isolierte Hepatozyten DPPIV-defizienten Fischer-344-Ratten implantiert, die nach Vorbehandlung mit perkutaner Bestrahlung mit 25 Gy eine 30-prozentige Hepatektomie erhielten. Das Optical Imaging wurde eingesetzt, um zum einen die Repopulation der Leber qualitativ zu beurteilen, zum anderen, um die Kinetik der Leberrepopulation darzustellen. 


\subsection{Fragestellung}

Das Ziel des vorgelegten Dissertationsprojektes war die Entwicklung einer Methode zur In-Vivo-Bildgebung von transplantierten Spenderhepatozyten, die sich in der Empfängerleber vermehren. Die Hepatozytentransplantation wurde im Dipeptidylpeptidase-IV-Fischer-344-Ratten-Transplantationsmodell nach Präkonditionierung mittels partieller Leberbestrahlung und Leberteilresektion durchgeführt. Ziel war es, mit Hilfe des Optix-MX2-Systems der Firma ART, Montreal, Kanada, die Leberrepopulation zu visualisieren und deren Kinetik über einen längeren Zeitraum zu analysieren. Im Anschluss wurden die Ergebnisse durch Immunofluoreszenzanalysen validiert. Das Projekt befasst sich im Detail mit folgenden Fragen:

Determinierung der Messparameter und des idealen Messzeitpunktes

1. Zu welchem Zeitpunkt sind die Signale spezifisch für die Leber und wann ist der optimale Messzeitpunkt für das Optical Imaging?

2. Treten Messfehler auf und wie können Messfehler eliminiert werden?

Verlaufsbeurteilung der Repopulation im Empfängerorganismus

1. Zu welchem Zeitpunkt beginnt die Proliferation?

2. Lässt sich anhand des Optical Imaging eine eindeutige Kinetik der Leberrepopulation erstellen?

3. In welchem Maße korrelieren die Ergebnisse aus dem Optical Imaging mit denen aus den im Anschluss durchgeführten ImmunofluoreszenzKolokalisationsstudien an Gewebeschnitten nach Organentnahme? 


\section{Material und Methoden}

\subsection{Chemikalien und Reagenzien}

In den nachfolgend beschriebenen Versuchsdurchführungen wurden die hier aufgeführten Reagenzien verwendet (übliche Bezeichnung der Reagenzien in alphabetischer Reihenfolge):

Material

AEC 3-Amino-9-

Ethylcarbazol

Alkohol: Ethanol 99,8 absolut, $M=46,07 \mathrm{~g} / \mathrm{mol}$

ALTROMIN 1324: Haltungsdiät für Ratten

Aqua dest.: gefiltertes Leitungswasser, Filtersystem Mill-Q® Reagent Water System

Aquamount
Firma

Firmensitz

Darmstadt, Deutschland

Deventer, Niederlande

Lage, Deutschland

Millipore

Molsheim, Frankreich
Aceton
3,3'-Diaminobenzidin-
Tetrahydrochlorid x $2 \mathrm{H} 2 \mathrm{O}$
Merck
Darmstadt, Deutschland
Heidelberg,
Serva
Deutschland

Deisenhofen, Deutschland

Sigma-Aldrich 
DAPI 4‘,6-Diamidino-2-

Phenylimdol

Diethylether: reinst

EDTA Ethylendiamin tetra-acedic acid $99 \%$

EGTA Ehylene glycol-bis ( $ß$-aminoethyl ether) N, N, N', N'tetraacetic acid

$$
\begin{gathered}
\text { GLP } 3893 \\
\text { (Nafag 890) }
\end{gathered}
$$

Glucose: D(+)-Glucose (Monohydrat), $\mathrm{M}=198,17$ $\mathrm{g} / \mathrm{mol}$

Hämatoxylin: Kristallpulver

Heparin: Liquemin ${ }^{\circledR} \mathrm{N}$ 2500, Heparin-Natrium $5000 \mathrm{IE} / \mathrm{ml}$

HEPES N-(2-

Hydroxyethyl)piperazineN'-(2-ethanesulfonic acid): sodium salt C8H17NaO4Sna
Sigma Chemicals

St. Louis, MO, USA

Darmstadt, Deutschland

Sigma Chemicals

St. Louis, MO, USA

Sigma Chemicals

St. Louis, MO, USA

Provimi Kliba

Kaiseraugst, Schweiz

Darmstadt, Deutschland

Darmstadt, Deutschland

Novo Nordisk

Mainz, Deutschland

Sigma Chemicals
St. Louis, MO, USA 
Hostaket $\AA^{\circ}$ : Ketaminhydrochlorid

Kaninchenserum

$\mathrm{KCl}$

Kollagenase

$\mathrm{NaCl}$ : isotone Kochsalzlösung $0,9 \%$

NaHCO3: Natriumhydrogencarbona, $\mathrm{M}=84,01$ $\mathrm{g} / \mathrm{mol}$

PBS: Dulbecco's phosphate buffered saline

Percoll

Rattenserum

Rompun®: Xylozinhydrochlorid, 2 \%ige Lösung

Trypanblau
Intervet

Boxmeer, Niederlande

DAKO Corporation

Merck

Darmstadt, Deutschland

St. Louis, MO, USA

Sigma Chemicals

Braun

Melsungen, Deutschland

Merck

Heidelberg,

Deutschland

Gibco BRL

Pharmacia/LKB

Uppsala,

Schweden

Carpinteria, CA, USA

Leverkusen, Deutschland
Bayer

Merck
Darmstadt,

Deutschland 
Tris/

Maleate

Vectashield® Mounting Medium

Ziegenserum
Sigma-Aldrich

Vector Laboratories

DAKO Corporation
Deisenhofen,

Deutschland

Carpinteria, CA, USA

\subsection{Verbrauchsmaterialien}

Material

Firma

Firmensitz
Auslaufpipetten $10 \mathrm{ml}$

Braunüle ${ }^{\circledR}$

Vasofix®: (20G und 17G)

50 ml Falcon Röhrchen

Einmalspritzen Injekt ${ }^{\circledR}(2$,

$5,10,20 \mathrm{ml}$ )

Infusionssysteme mit

Blasenfalle
Sarstedt

Braun

Sarstedt

Braun

Braun
Nümbrecht,

Deutschland

\section{Melsungen,}

Deutschland

Nümbrecht,

Deutschland

Melsungen, Deutschland

Melsungen, Deutschland 

Heidelberger Verlänge-
rungen

Kanülen Sterican®

Nalgene Cryoware $®$ :

Cryogenic Vials

Neubauerzählkammer

Perfusorleitungen

Petrischalen

Super Frost ${ }^{\circledR}$ Plus Objektträger und Deckgläser
Braun

Braun

Nalge Nunc

International

Brand Gläser

Braun

Greiner Labortechnik

Menzel Gläser
Melsungen,

Deutschland

Melsungen,

Deutschland

Rochester, NY, USA

Wertheim, Deutschland

Melsungen,

Deutschland

Frickenhausen, Deutschland

Braunschweig, Deutschland

Vicrylß 3-0 resorbierbares Johnson \& Johnson MediNahtmaterial

cal Products $\mathrm{GmbH}$

Wien, Österreich 


\subsection{Geräte}

Material

Zentrifuge

Shandon Cytospin II

Mikroskop

Ultramikrotom: Cryo-

Ultramikrotom

Optix MX2

Computertomograph Somatom Balance
Firma

Hettich Rotaxia/KS

Shandon, Inc.

Zeiss Axioskope

Leica

ART

Siemens

Varian Clinac 600 C Beschleuniger

Varian Medical Systems, Inc.

\section{Firmensitz}

Nümbrecht, Deutschland

Pittsburg, PA, USA

Oberkochen,

Deutschland

Wetzlar, Deutschland

Montreal, Canada

Erlangen, Deutschland

Tabelle 1: Geräte 


\subsection{Antikörper}

Die verwendeten Primärantikörper und deren Bezugsquellen sind der Tabelle 2 bzw. Tabelle 3 zu entnehmen. Hinsichtlich der für die Optical-Imaging-Versuche benötigten DPPIV-Antikörper (Maus, monoklonal) und dem unspezifischen Kontroll-IgG (Maus, monoklonal) wird auf Kapitel 2.11.1 verwiesen.

\begin{tabular}{cccc}
\hline Antigen & Spezies & Verdünnung & Bezugsquelle \\
DPPIV (CD26) & $\begin{array}{c}\text { Maus, } \\
\text { monoklonal }\end{array}$ & $1: 100$ & BD-Pharmingen \\
Connexin 32 & $\begin{array}{c}\text { Kaninchen, } \\
\text { polykonal }\end{array}$ & $1: 5000$ & Sigma C3595 \\
\hline
\end{tabular}

Tabelle 2: Verwendete Primärantikörper

\section{Antigen}

Ziege-anti-Maus-lgG;

Alexa 568-gekoppelt

Ziege-anti-Kaninchen-lgG,

Alexa 488-gekoppelt
Verdünnung

$1: 400$

$1: 400$

\section{Bezugsquelle}

Molecular Probes

(Deutschland)

Molecular Probes

(Deutschland)

Tabelle 3: Verwendete Sekundärantikörper 


\subsection{Versuchstiere}

Sämtliche Versuche sowie die im folgenden beschriebenen Tierexperimente wurden in Übereinstimmung mit den geltenden Tierschutzbestimmungen beantragt und durch den Präsidenten der Bezirksregierung in Braunschweig genehmigt (AZ.: 33.42502-090/06 vom 11.09.2006). Alle Zucht- und Pflegevorgänge fanden innerhalb der Zentralen Tierexperimentellen Einrichtungen (ZTE) der Universitätsmedizin Göttingen unter der Leitung von Dr. med. vet. S. Kimmina statt. Die Haltung unter standardisierten Bedingungen wurde von der ZTE gewährleistet. Die Ratten erhielten neben dem Standardfutter „alltromin-1324-Haltungsdiät für Ratten“ drei Wochen vor dem Optical Imaging ein spezielles Futter, GLP 3893 (Nafag 890) von Provimi Kliba, Kaiseraugst, Schweiz, um Autofluoreszenz zu vermeiden. Ferner erhielten die Versuchstiere Wasser ad libitum.

\subsubsection{Spendertiere}

Zur Gewinnung von primären Hepatozyten (DPPIV-positiv) für die hepatozelluläre Transplantation wurden etwa zwei bis drei Monate alte Wildtyp Fischer-344-Ratten männlichen Geschlechts (Charles River, Deutschland) mit einem Körpergewicht von 190-200 g verwendet.

\subsubsection{Empfängertiere}

Als Empfängertiere wurden 2 Monate alte, weibliche DPPIV-defiziente Fischerratten mit einem Körpergewicht von 140-160 g verwendet. Das Etablieren des Zuchtstammes erfolgte in der ZTE der Universitätsmedizin Göttingen mit Elterntieren, die von Dr. Ezio Laconi (Institut für experimentelle Pathologie der Universität Cagliari, Italien) stammen. 


\subsubsection{Versuchstiergruppen}

Im folgenden sind die einzelnen Tiergruppen tabellarisch aufgeführt, die zu unterschiedlichen Zeitpunkten der Versuche zum Einsatz kamen:

\begin{tabular}{|l|l|c|c|}
\hline Evaluationsgruppe A & 1 Tier: TX, spez. AK & $\begin{array}{c}\text { 1 Tier: TX, unspez. } \\
\text { AK IgG }\end{array}$ & $\begin{array}{c}\text { 1 Tier: nicht TX, } \\
\text { spez. AK }\end{array}$ \\
\hline Messgruppe B & 3 Tiere: TX, spez. AK & $\begin{array}{c}\text { 1 Tier: TX, unspez. } \\
\text { AK IgG }\end{array}$ & $\begin{array}{c}\text { 1 Tier: nicht TX, } \\
\text { spez. AK }\end{array}$ \\
\hline $\begin{array}{l}\text { Referenzgruppe C } \\
\text { (histologische Refe- } \\
\text { renz) }\end{array}$ & 2 Tiere: 3d nach TX & $\begin{array}{c}\text { 2 Tiere: } 4 \text { Wo nach } \\
\text { TX }\end{array}$ & $\begin{array}{c}\text { 2 Tiere: } 16 \text { Wo } \\
\text { nach TX }\end{array}$ \\
\hline
\end{tabular}

Tabelle 4: Verwendete Versuchstiere

Zu den in der Studie verwendeten Tieren zählten transplantierte Tiere (TX), die jeweils einen spezifischen Antikörper (AK) oder einen unspezifischen AK (IgG) erhielten. Ferner kamen nicht transplantierte Tiere mit spezifischem AK zum Einsatz. Die Tiere der Evaluationsgruppe A dienten der Bestimmung der Messparameter (vgl. Kap. 3.4). Die Tiere aus der Referenzgruppe $C$ dienten als histologische Referenz und wurden ausschließlich histologisch ausgewertet. Die Tiere der Messgruppe B wurden sowohl dem Optical Imaging zugeführt als auch im Anschluss nach 16 Wochen histologisch ausgewertet (vgl. Kap. 3.4).

\subsubsection{Behandlungszyklus der Versuchstiere}

Die Versuchstiere wurden unter 12/12 Stunden Hell/Dunkel-Zyklen mit StandardNagetierfutter und Wasser ad libitum gehalten. Bestrahlung und operative Prozeduren wurden unter Anästhesie mit Sevofluran durchgeführt. Nach Vorbehandlung mit perkutaner, CT-geplanter, partieller Leberbestrahlung wurden die weiblichen Empfängertiere 4 Tage später einer partiellen Hepatektomie und der Hepatozytentransplantation zugeführt (Testgruppe). Zwei Kontrolltiere durchliefen die gleiche Prozedur, aber ohne nachfolgende Hepatozytentransplantation. Drei Ratten aus der Testgruppe wurden mittels Optical Imaging zur Dokumentation der Leberrepopulation 1, 4 und 11 Tage sowie 4, 8, 12 und 16 Wochen nach der Hepatozytentransplantation untersucht. Danach wurden die Tiere getötet und ihre Lebern der 
Gewebeanalyse zugeführt. Gewebeproben beider Leberlappen wurden exzidiert und in 2-Methylbutan bei $-70^{\circ} \mathrm{C}$ langsam runtergekühlt. Gefrierschnitte von $5 \mu \mathrm{m}$ Dicke wurden für 10 min in eiskaltes Aceton zur Konservierung überführt.

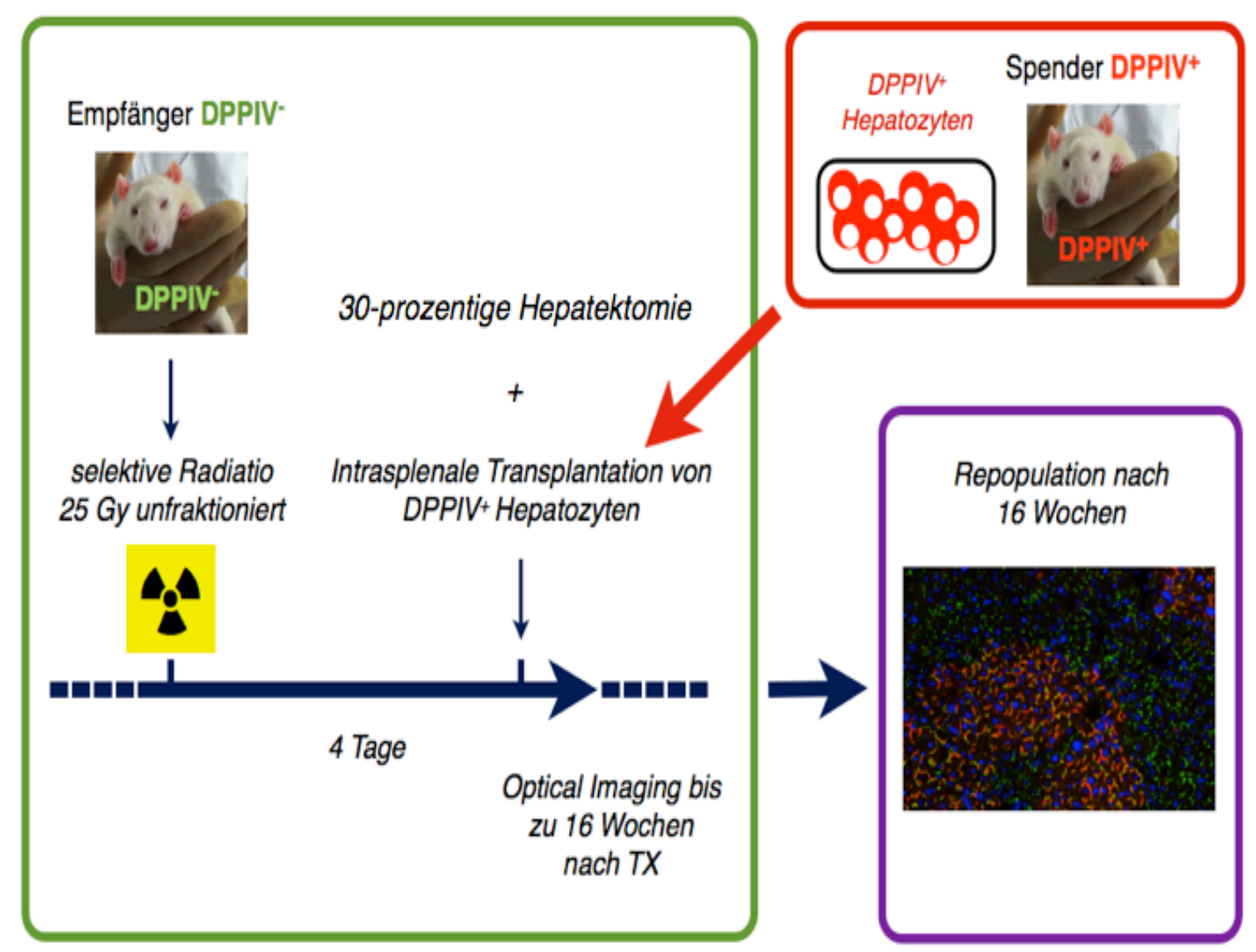

\section{Abbildung 1: Transplantationsmodell}

DPPIV-negative Tiere wurden einer selektiven Bestrahlung der Leber unterzogen. 4 Tage später erfolgten die partielle Hepatektomie und die Hepatozytentransplantation. Optical Imaging wurde bis zu 16 Wochen nach Zelltransplantation durchgeführt. In Immunfluoreszenz-Kolokalisationsstudien wurden die Ergebnisse nach der letzten Optical-Imaging-Messung nach 16 Wochen validiert. 


\subsection{Selektive Bestrahlung der Rattenleber}

Alle Ratten erhielten ein Planungs-CT (Somatom Balance, Siemens, Erlangen) in Bauchlage, um die kraniale und kaudale Lebergrenze zu bestimmen. Diese Grenzen wurden auf der Haut der Tiere gekennzeichnet und dienten als obere bzw. untere Feldgrenze des Bestrahlungsfeldes. Als mediale Grenze des Bestrahlungsfeldes wurde der Rand der Columna vertebralis definiert, wodurch das Rückenmark geschont werden konnte. Die seitliche Grenze wurde neben der Körperkontur der Ratte festgesetzt. Auf der Grundlage des Datensatzes des Planungs-CTs sowie der festgelegten Feldgrenzen erfolgte dann in jedem Fall, nach entsprechender elektronisch berechneter Dosisverteilung (CadPlan, Varian, Palo Alto, USA) unter Verwendung eines Varian Clinac 600 C Beschleunigers, die Bestrahlung in ap/pa-Technik mit 6 MV Photonen mit einer Einzeldosis von 25 Gy (Dosisleistung 2,4 Gy/min). Zur Schonung des Rückenmarks sowie des Gastrointestinaltraktes wurde eine so genannte Half-Beam-Technik verwendet (Lage des Isozentrums: caudo-medial).

\subsection{Isolation und Aufbereitung der Hepatozyten}

\subsubsection{Zellisolation}

Die Hepatozyten wurden mittels zweistufiger In-Situ-Kollagenaseperfusion isoliert (Seglen 1976). Mit Hilfe dieser Technik wurde das Lebergewebe zunächst enzymatisch verdaut, anschließend aufbereitet und zentrifugiert. Die Vitalität der isolierten Hepatozyten wurde mittels Trypan-Blau-Exklusion ermittelt. Diejenigen Zellen, die eine Vitalität von über $90 \%$ sowie eine Zellanhaftung von über $70 \%$ aufwiesen, wurden als geeignet für eine weitere Transplantation eingestuft. Für die Zytospin-Aufbereitung wurden $3 \times 10^{4}$ Zellen auf einen Objektträger zentrifugiert und für 10 min in eiskaltes Aceton überführt. 


\subsubsection{Präparation von Hepatozyten}

\subsubsection{Allgemeines}

Zur Gewinnung von primären Hepatozyten als Spenderzellen wurde das bereits in Kapitel 2.7.1 erwähnte Verfahren der In-Situ-Perfusionstechnik nach Seglen eingesetzt. Sämtliche Arbeitsschritte erfolgten unter aseptischen Bedingungen. Dieses galt sowohl für die Sterilfiltration als auch für das Autoklavieren der eingesetzten Geräte. Das Aufarbeiten der Zellen erfolgte unter einer Sterilbank (Steril gard Hood Class II, The Baker Company, Sanford, Maine, USA).

\subsubsection{Herstellung der Perfusionslösung}

Zur Gewinnung von DPPIV-positiven Spenderhepatozyten wurden verschiedene Lösungen benötigt. Eine Auflistung über Art und Zusammensetzung dieser befindet sich unter Tabelle 6. Zur Präparation der Zellen wurden letztlich drei Perfusionslösungen angefertigt, Lösungen A, B und C (vgl. Tab. 7), die sich aus den in Tabelle 6 aufgeführten Stammlösungen I, II und III herstellen lassen. Bei der Lösung $A$ handelte es sich um eine Kalzium-freie Lösung, die zur Entblutung der Leber eingesetzt wurde. Lösung $B$, eine kollagenasehaltige Lösung, diente der enzymatischen Verdauung der Zellverbände. Schließlich kam Lösung C zum Einsatz, die bei der Aufarbeitung der Zellsuspension als reine Waschlösung diente. Während der gesamten Prozedur wurden die Lösungen in einem Wasserbad konstant auf $37^{\circ} \mathrm{C}$ temperiert und zusätzlich mit einem Gemisch aus Sauerstoff und Kohlenstoffdioxid begast. 


\begin{tabular}{|c|c|c|}
\hline Stammlösung & $\begin{array}{c}\text { Substanz, } \\
\text { Endkonzentration in } \mathrm{mM}\end{array}$ & Menge für $500 \mathrm{ml}$ in $\mathrm{g}$ \\
\hline \multirow[t]{6}{*}{1} & $25 \mathrm{NaHCO} 3$ & 21 \\
\hline & $5,9 \mathrm{KCl}$ & 4,39 \\
\hline & 0,23 NaH2PO4 & 0,276 \\
\hline & $1.2 \mathrm{Na} 2 \mathrm{SO} 4$ & 1,7 \\
\hline & 5 HEPES & 11,9 \\
\hline & 5,5 Glucose & 9,9 \\
\hline \multirow[t]{2}{*}{ II } & $0,115 \mathrm{NaCl}$ & 67,21 \\
\hline & 0,5 EGTA & 1,9 \\
\hline \multirow[t]{3}{*}{ III } & $0,115 \mathrm{NaCl}$ & 67,21 \\
\hline & 2,5 CaCl2x2H2O & 3,68 \\
\hline & $1,18 \mathrm{MgCl} 2 \times 6 \mathrm{H} 2 \mathrm{O}$ & 2,4 \\
\hline
\end{tabular}

Tabelle 5: Stammlösungen für die Perfusionslösung 


\begin{tabular}{|cccc|}
\hline & Lösung A & Lösung B & Lösung C \\
\hline Stammlösung I & $25 \mathrm{ml}$ & $25 \mathrm{ml}$ & \\
\hline Stammlösung II & $25 \mathrm{ml}$ & - & - \\
\hline Stammlösung III & - & $25 \mathrm{ml}$ & $25 \mathrm{ml}$ \\
\hline Auffüllen mit & & & $500 \mathrm{ml}$ \\
\hline Aqua dest. auf & $500 \mathrm{ml}$ & $500 \mathrm{ml}$ & $30-50 \mathrm{mg} / 100 \mathrm{ml}$ \\
\hline Kollagenase & - & - & $7,8-7,9$ \\
\hline pH-Wert & 7,8 & 7,4 & \\
\hline
\end{tabular}

Tabelle 6: Herstellung der Perfusionslösung

\subsubsection{Gewinnung isolierter Hepatozyten}

Nach Einleitung der Narkose durch intramuskuläre Applikation eines Gemisches aus Rompun und Hostaket (6 mg Rompun + 75 mg Hostaket/kg KG) wurde die Ratte auf dem Präparationstisch fixiert, das Abdomen rasiert und mit Alkohol desinfiziert. Die Eröffnung der abdominellen Kavität der Spenderratte erfolgte entlang der Medianlinie. Es folgte die Darstellung der Vena cava inferior oberhalb der Abgänge der Nierenvenen. Anschließend wurde die Vena portae freigelegt und kurz vor dem Übergang zum Leberhilus ligiert. Über eine $22 \mathrm{G}$-Kanüle wurde $1 \mathrm{ml}$ frisch zubereitete Heparinlösung $(0,1 \mathrm{ml}$ Heparin [5000 IU/ml] / 2,4 $\mathrm{ml}$ physiologische Kochsalzlösung) in die Vena cava inferior injiziert. Anschließend wurde die Vena portae mittels Vasotomie ankanüliert. Mit einer Flussrate von $20 \mathrm{ml} / \mathrm{min}$ wurde über diesen Zugang die Leber etwa 10 min lang unter Verwendung der Lösung $A$ 
ausgespült. Anschließend erfolgte eine Sternotomie und eine retrograde Ankanülierung des rechten Herzvorhofes bis zur Vena cava inferior mit einer 17 G-Kanüle. Es erfolgt die Ligatur der Vena cava inferior. Hierdurch entstand ein geschlossenes Flusssystem, in dem Lösung A über die Pfortader in die Leber und darüber in den rechten Herzvorhof gelangte. Nachdem Lösung $A$ über etwa 15 min appliziert wurde, wurde die kollagenasehaltige Lösung $C$ bei gleicher Flussrate für weitere $10 \mathrm{~min}$ in das Perfusionssystem eingeleitet. Nach Abschluss der 10 min stellte sich die Leber marmoriert da und wies, als Ausdruck des nun aufgehobenen Gewebeverbandes, eines aufgeweichte Konsistenz auf. Es folgte die Organentnahme unter Durchtrennung der Hilusgefäße. Die Leber wurde als nächstes auf eine auf Eis gelagerte Petrischale aufgetragen, in der sich die vorgekühlte Lösung $B$ befand. Die Glisson'sche Kapsel wurde eröffnet und mit einem Plastikschaber das aufgeweichte Leberparenchym ausgestrichen. Die so gewonnene Zellsuspension bestand aus Hepatozyten, Stromal- und Blutzellen sowie partiell aufgelösten Gefäß- und Bindegewebsresten. Für die weitere Verwendung musste die Zellsuspension durch ein steriles Perlon-Filter (Maschengrösse von $250 \mu \mathrm{m}$ ) gefiltert und einem weiteren Zellreinigungsverfahren unterzogen werden.

\subsubsection{Reinigung der Zellsuspension}

Zur Gewinnung reiner Zellen musste eine weitere Prozessierung des vorhandenen Zellmaterials erfolgen. Dabei wurde zunächst die Zellsuspension auf $50 \mathrm{ml}$ FalconTubes verteilt und 5 min lang bei $500 \mathrm{U} / \mathrm{min}$ zentrifugiert. Der Überstand wurde verworfen und das Pellet mit 2-3 ml Lösung B resuspendiert. Nach wiederholter Suspension des Pellets erfolgte eine Schichtung mit $8 \mathrm{ml}$ einer Percollösung und wurde über 10 min bei $2000 \mathrm{U} / \mathrm{min}$ zentrifugiert. Das Pellet mit den Hepatozyten wurde erneut in die Lösung $B$ überführt, der Überstand mit Detritus wurde anschließend verworfen. Im vorletzten Schritt wurde die Hepatozytenlösung mit Lösung B auf ein Gesamtvolumen von $50 \mathrm{ml}$ aufgefüllt und erneut über $5 \mathrm{~min}$ bei 500 U/min zentrifugiert. Um die endgültige Hepatozytenlösung zu erhalten wurde das 
Sediment mit einer geringen Menge Lösung B (ca. 1-2 ml) resuspendiert, um letztlich eine hohe Zelldichte zu erhalten. Zur qualitativen und quantitativen Beurteilung der gewonnen Zellen wurden sie in einem letzten Schritt mit Trypanblau (0,1\%) gegengefärbt. Die anschließende lichtmikroskopische Auswertung erfolgte in einer Neubauerzählkammer. Mit Hilfe des Trypanblaus ließen sich in diesem letzten Schritt avitale von vitalen Zellen trennen, da sich bei dieser Färbemethode nur Bestandteile beschädigter Zellmembranen blau anfärben. Eine Zellvitalitätsrate innerhalb der hergestellten Lösung von mehr als $80 \%$ wurde als ausreichend betrachtet.

\subsubsection{Zytospin}

Mit Hilfe der Zentrifugalkraft ermöglichte das Zytospin-Verfahren das konzentrierte Auftragen einer Zelllösung auf ein definiertes Areal auf einem Objektträger. In unseren Versuchen wurden Zytospins mit einer Zelldichte von $1 \times 10^{5}$ Hepatozyten angefertigt. Anschließend wurden die Zellen bei $800 \mathrm{U} / \mathrm{min}$ zentrifugiert. Die darauf folgende zweistündige Trocknungsphase bei Raumtemperatur wurde mit einem 10 minütigen Fixierbad in $100 \%$ Aceton abgeschlossen.

\subsection{Leberteilresektion und intrasplenale Transplantation von Hepatozyten}

Bei den DPPIV-negativen Empfängertieren wurde 4 Tage nach Bestrahlung und unmittelbar vor der Hepatozytentransplantation eine 30-prozentige Hepatektomie durchgeführt, was dem linken Leberlappen entspricht. Bei diesem Verfahren wurden die Tiere zunächst mit Sevofluran narkotisiert und ihr Abdomen anschließend entlang der Medianlinie eröffnet. Hierbei wurde der oben genannte Anteil der Leber unter Einsatz von resorbierbarem Nahtmaterial Vicryl® 2,0 (Ethicon, Deutschland) basisnah ligiert und darüber abgesetzt. 
Für die intrasplenale Transplantation wurde die Milz mobilisiert. Anschließend erfolgte die Injektion von $15 \times 10^{6}$ frisch isolierter DPPIV-positiver Hepatozyten mithilfe von 2 ml Einmalspritzen Injekt® (Braun, Deutschland) über einen Zeitraum von 2 min in das Milzparenchym. Die der Laparotomiezugang wurde mit einer fortlaufenden Naht unter Verwendung von Vicryl® 3,0 (Ethicon, Deutschland) verschlossen. Die Tiere wurden bis zur vollständigen Erholung von der Anästhesie beobachtet.

\subsection{Histologische Aufarbeitung der Gewebeproben}

\subsubsection{Organentnahme}

Nach einer Messperiode von 16 Wochen wurden die transplantierten Tiere, wie unter 2.7.2.3 beschrieben, zunächst betäubt und anschließend ihre Lebern unter Durchtrennung der unteren Hohlvene entfernt. Die resezierte Leber wurde anschließend präpariert und in Gewebeproben einer Größe von ca. 0,5 x 0,5 cm zerteilt.

\subsubsection{Fixierung von Gewebeproben}

Für die Fixierung der Gewebeproben wurde das präparierte Lebermaterial zunächst in Kryocups aufgenommen. Anschließend folgte die Überführung in flüssigem Stickstoff gekühltem Methylbutanol, in dem die Kryocups schonend heruntergekühlt werden konnten. Die anschließende Lagerung der Proben erfolgte bei -70 ${ }^{\circ} \mathrm{C}$. 


\subsubsection{Kryoschnitte}

Zur weiteren Verarbeitung der gewonnenen Proben aus den Lebern der Empfängertiere wurden Kryoschnitte angefertigt. Dies erfolgte mit Hilfe eines Ultramikrotoms (Leica) bei $-20^{\circ} \mathrm{C}$. Die Schichtdicke betrug $5 \mu \mathrm{m}$. Im Anschluss wurden die Kryoschnitte auf Superfrost-Objektträger überführt und über Nacht lichtgeschützt getrocknet. Danach wurden die Schnitte in einem Fixierungsbad für 10 min in Aceton bei $-20^{\circ} \mathrm{C}$ eingelegt und anschließend luftgetrocknet. Die Lagerung der Schnitte erfolgte bei $-70^{\circ} \mathrm{C}$.

\subsection{Immunfluoreszenzfärbungen}

Für den Nachweis der DPPIV-positiven, transplantierten Zellen aus den Spendertieren wurden Immunfluoreszenzfärbungen der Kryoschnitte aus den Lebern der Empfängertiere der Messgruppe B (5 Tiere) und aus der histologischen Referenzgruppe (6 Tiere) angefertigt (vgl. Tab. 6). Eine detaillierte Darstellung des Färbeprotokolls findet sich in Abbildung 2. Bei dieser Nachweismethode wurde die spezifische Bindung eines primären Antikörpers (vgl. Tab. 1) an bestimmte Antigene genutzt. Um diese Bindung darzustellen, kam ein sekundärer Antikörper zum Einsatz, der gegen den primären Antikörper gerichtet und an ein spezifisches Detektionssystem, z.B. einen Fluoreszenzfarbstoff, gekoppelt war. In diesem Fall handelte es sich um einen gegen DPPIV gerichteten primären Antikörper, welcher das Antigen DPPIV auf den Spenderhepatozyten zu erkennen in der Lage war. Die an den Fluoreszenzfarbstoff gekoppelten Sekundärantikörper wiesen zwei Farbspektren auf und waren entweder an Alexa Fluor 488 oder Alexa Fluor 555 gekoppelt (vgl. Tab. 2).

\subsubsection{Fluoreszenzmikroskopische Untersuchung}

Für die weitere fluoreszenzmikroskopische Untersuchung der Kryoschnitte kam ein Zeiss-Fluoreszenzmikroskop (Axioskop, Zeiss) zum Einsatz. Zur Darstellung 
der DPPIV-positiven Zellen wurde ein Rhodamin-Filter (546 nm Bandpass Exzitation, $580 \mathrm{~nm}$ Farbteiler, > $590 \mathrm{~nm}$ Langpass Emission) verwendet. Die Betrachtung der Kernfärbung mit DAPI gelang mit einem DAPI-Filter (bei 350 nm). Für die Darstellung der Zelladhäsions- und Kommunikationsproteine wurde ein FITC-Filter (450-490 nm Bandpass Exzitation, $510 \mathrm{~nm}$ Farbteiler, 515-565 nm Bandpass Emission) eingesetzt.

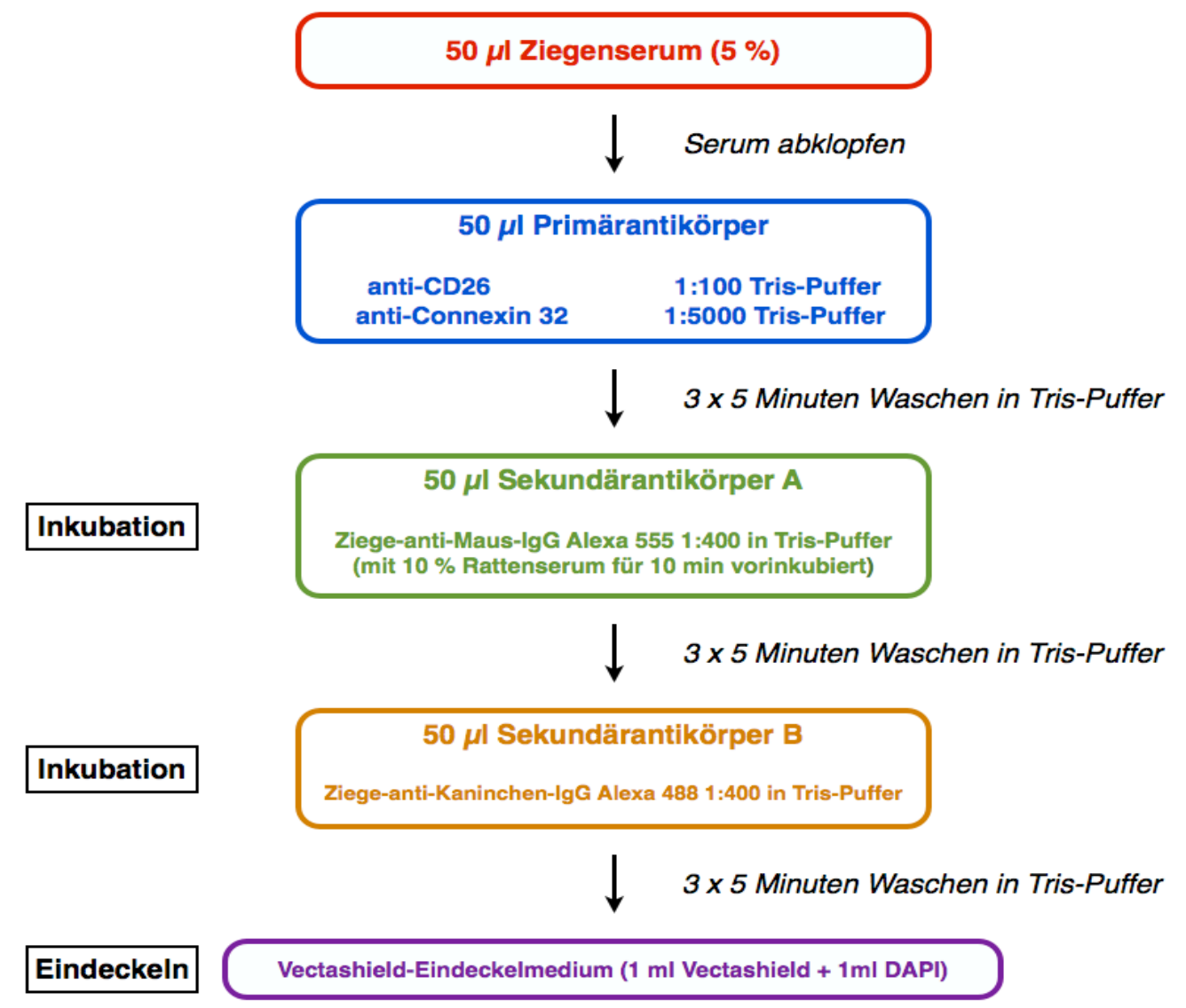

\section{Abbildung 2: Färbeprotokoll von Cx32 und DPPIV an Kryoschnitten}

Dargestellt ist das Färbeprotokoll der Doppelimmunfluoreszenzfärbung von Cx32 und DPPIV an Kryoschnitten. Im ersten Schritt erfolgte die Inkubation der Kryoschnitte mit beiden Primärantikörpern (Kaninchen-anti-Ratte-Connexin 32 und Maus-anti-Ratte-DPPIV). In einem zweiten Schritt erfolgte eine separate Inkubation mit dem Spezies-gerichteten Sekundärantikörper Ziege-antiKaninchen-Alexa488 bzw. Ziege-anti-Maus-Alexa555. DAPI und Vectashield-Medium wurden zum Eindeckeln verwendet. 


\subsubsection{Fotodokumentation}

Mit Hilfe einer computergesteuerten Kamera sowie eines entsprechenden Softwareprogrammes der Firma Leica (Leica DC100 Version 2.51) wurde eine Fotodokumentation der präparierten Kryoschnitte digital am Mikroskop durchgeführt. Die Nachbearbeitung erfolgte durch Adobe Photoshop CS3.

\subsection{Optical Imaging}

\subsubsection{Cy5.5-gekoppelte Antikörper}

Der verwendete Antikörper für die DPPIV-Detektion wurde über die Firma BD Pharmingen (Heidelberg, Deutschland) bezogen, ebenso der unspezifische IgGAntikörper. Die für die Visualisierung und Detektion durch das Optical-ImagingSystem notwendige Kopplung des spezifischen Antikörpers DPPIV an den Farbstoff Cy5.5-NHS wurde von der Firma Squarix (Marl, Deutschland) vorgenommen. Das erzeugte DPPIV-Cy5.5-Konjugat hatte eine Konzentration von $1174 \mu \mathrm{g} / \mathrm{ml}$ und wurde lichtgeschützt bei $4{ }^{\circ} \mathrm{C}$ gelagert. Die Kopplung des unspezifischen IgG an Cy5.5-NHS für die Kontrolltiere wurde ebenfalls durch die Firma Squarix (Marl, Deutschland) durchgeführt und hatte eine Konzentration von $1160 \mu \mathrm{g} / \mathrm{ml}$.

\begin{tabular}{cccc}
\hline Antikörper & Spezies & Konzentration & Bezugsquelle \\
$\begin{array}{c}\text { DPPIV } \\
\text { (spezifisch) }\end{array}$ & $\begin{array}{c}\text { Maus, } \\
\text { monoklonal }\end{array}$ & $1174 \mu \mathrm{g} / \mathrm{ml}$ & BD-Pharmingen \\
$\begin{array}{c}\text { Maus, } \\
\text { (unspezifisch) }\end{array}$ & $\begin{array}{c}\text { Manoklonal } \\
\text { mono }\end{array}$ & $1160 \mu \mathrm{g} / \mathrm{ml}$ & BD-Pharmingen \\
\hline
\end{tabular}

Tabelle 7: Cy5.5-gekoppelte Antikörper 


\subsubsection{Das Optix-MX2-System}

Die Optical-Imaging-Experimente wurden unter Verwendung des Systems Optix MX2 der Firma ART, Montreal, Canada (vgl. Abb. 3) durchgeführt. Dieses System führt eine zeitaufgelöste 2D-Fluoreszenzbildgebung im lebenden Tier durch. Im Gegensatz zu den meisten anderen auf dem Markt verfügbaren Systemen verwendet Optix MX2 dabei gepulste Laserdioden als Quellen für das Anregungslicht. Das System arbeitet in einem Raster-Scan-Modus, d.h. die ausgewählte, zu scannende Region wird mit Punkten in einem Raster von minimal 0,5 mm abgetastet. An jeder dieser Rasterpositionen wird eine Vielzahl von Messungen durchgeführt (8 Mio. pro Sekunde). Eine Messung besteht aus dem Aussenden eines Anregungsimpulses und der Messung der Zeit bis zur Detektion des ersten Fluoreszenzphotons (innerhalb von 8 ns). Dies wird durch Einsatz eines Time Correlated Single Photon Counter (TCSPC) erreicht, der sog. Zeitkorrelierten Einzelphotonenzählung. Der Detektor und die gepulste Erregung ermöglichen die Erstellung der Temporal Point Spread Function (TPSF), dem sog. Fluoreszenzphotonenlaufzeithistogramm. Diese Funktion beinhaltet nicht nur die Angabe der Intensität, sondern auch Informationen über die charakteristische Lebensdauer des Fluoreszenzübergangs, einen weiteren Parameter zusätzlich zu den spektralen Eigenschaften des Farbstoffes, mit dessen Hilfe sich unerwünschte Autofluoreszenz besser vom spezifischen Signal trennen lässt. Die Fluoreszenzlebensdauer kann mit Hilfe von konventionellen, ungepulsten Lichtquellen nutzenden Geräten nicht nachgewiesen werden. Alle Scans wurden mit einer Wellenlänge von $670 \mathrm{~nm}$ und einem 700 nm-Langpass-Detektionsfilter durchgeführt. Der an die Antikörper gekoppelte Fluoreszenzfarbstoff Cy5.5 hat sein Absorptionsmaximum bei $679 \mathrm{~nm}$ und sein Emissionsmaximum bei 702 nm (vgl. Abb. 5), entspricht daher den gewählten Einstellungen. 

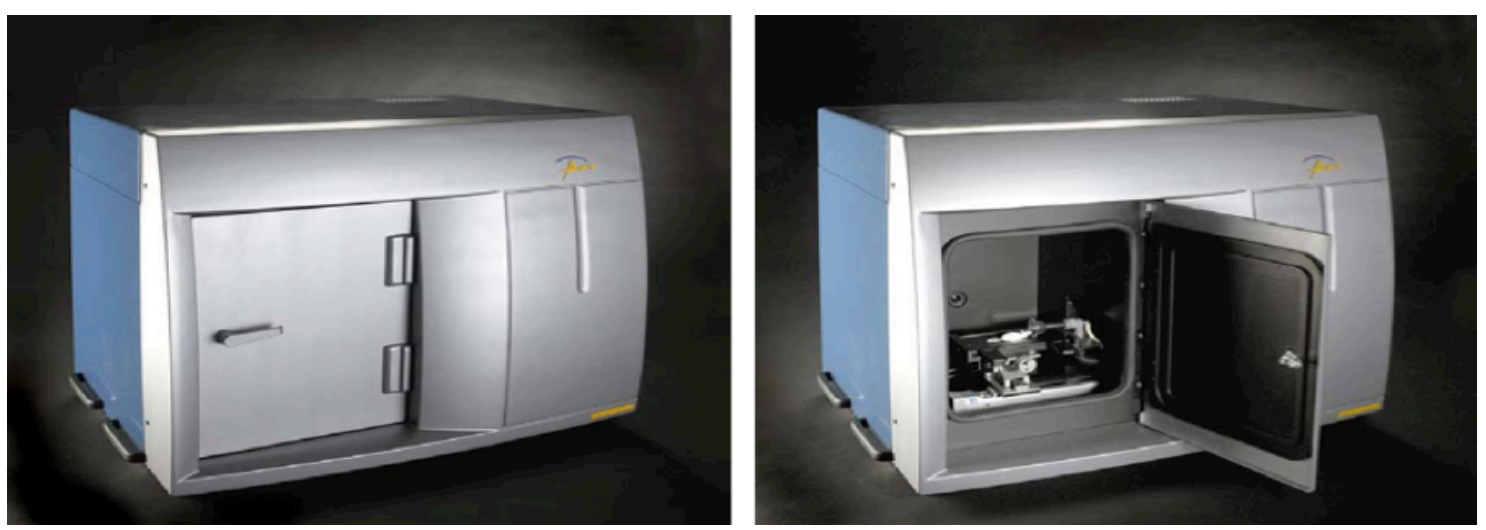

\section{Abbildung 3: Das Optix-MX2-System}

Bildquelle: Fa. ART, Montreal, Kanada.

Die Ergebnisse wurden als Overlay über einem Kamerabild dargestellt, das unmittelbar vor der Messung gemacht wurde. Zur Objektivierung der Fluoreszenzsignale, wurde als Maß die gemittelte Konzentration verwendet. Hierbei handelt es sich um die relative Fluoreszenzintensität, die über ein ausgewähltes Messfeld gemittelt und durch die im Messbereich befindliche Messpunktzahl geteilt wird. Dieses Maß ist einheitslos.

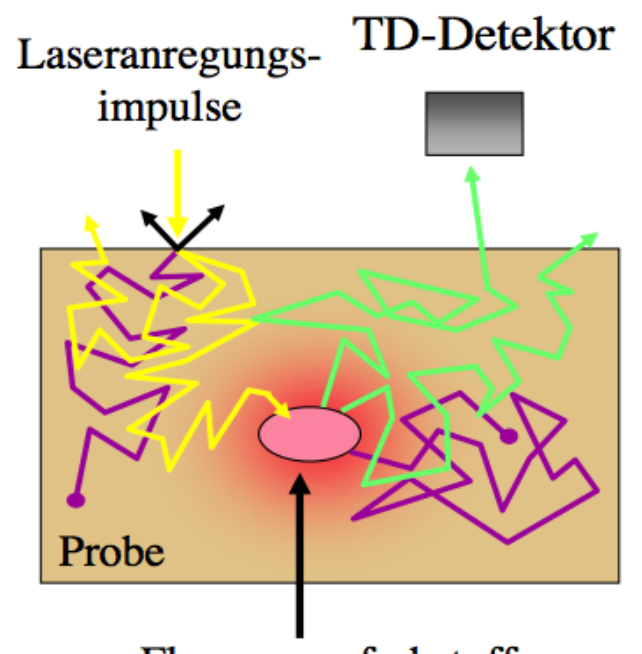

Fluoreszensfarbstoff

\section{Abbildung 4: Prinzip der Fluoreszenzfarbstoffmessung}

Bildquelle: Fa. ART, Montreal, Kanada, modifiziert. 
Alle Daten wurden jeweils in einer gemeinsamen Intensitätsskala (normalized counts $[\mathrm{NC}]$ ) unabhängig von der benutzten Anregungsintensität dargestellt und analysiert. Für jede Ratte wurden Scans durchgeführt, die die komplette Leberregion beinhalteten. Drei Wochen vor den Scans erhielten die Versuchstiere eine spezielle Futterdiät (GLP 3893 Nafag 890, Provimi Kliba, Kaiseraugst, Schweiz), um unspezifische Fluoreszenzsignale des Magen-Darm-Traktes durch vor allem den chlorophyllhaltigen Anteilen im normalen Futter zu vermeiden. Zusätzlich wurden die Ratten in der zu untersuchenden Region rasiert (Bauchseite des Abdomens), da das Fell eine unnötig starke Streuung und Absorption verursacht. Spezifische Cy5.5-konjugierte DPPIV-Antikörper und unspezifische Cy5.5-konjugierte IgG-Kontrollantikörper wurden intravenös über die Schwanzvene injiziert $(1,16$ $\mathrm{mg} / \mathrm{kg}$ ). Für die Durchführung der Messungen erhielten die Versuchstiere eine Inhalationsnarkose mit 2-3,5 prozentigem Sevofluran und wurden auf dem Untersuchungstisch in Rückenlage fixiert. Die Körpertemperatur der Ratten wurde durch den beheizten Untersuchungstisch konstant auf $37^{\circ} \mathrm{C}$ gehalten.

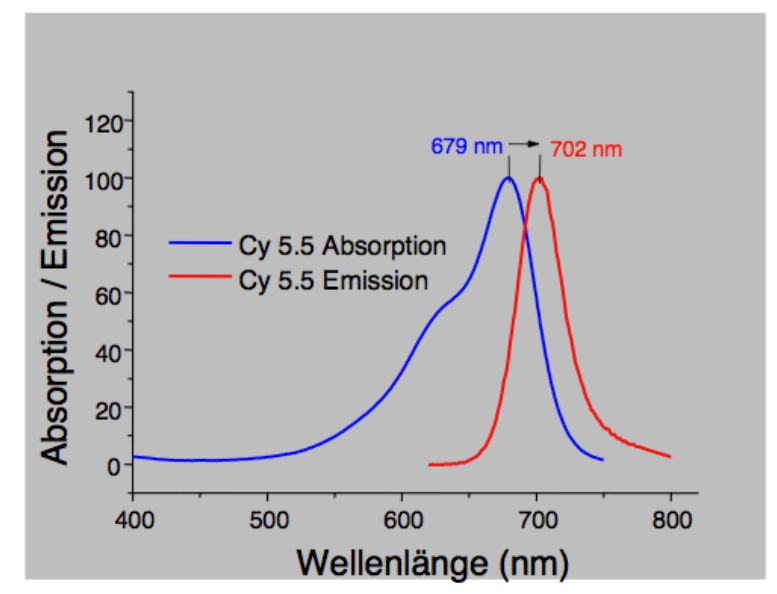

Laserwellenlänge : 670nm

Detektionswellenlänge : 700nm

\section{Abbildung 5: Absorptions- und Emissionsspektrum des Optix MX2}

Bildquelle: Fa. ART, Montreal, Kanada 
In ersten Messungen wurden mit Hilfe von insgesamt 3 Tieren aus der Evaluationsgruppe (vgl. Tab. 6) die Aufnahmebedingungen am Optix-MX2-System und der optimale Messzeitpunkt determiniert. Anschließend erfolgten die eigentlichen Untersuchungen an der Messgruppe mit insgesamt 5 Tieren (vgl. Tab. 6). Hierbei dienten ein nicht transplantiertes Tier, dem Cy5.5-konjugierter spezifischer Antikörper injiziert wurde, und ein weiteres transplantiertes Tier, welches unspezifischen, an Cy5.5 gekoppelten IgG-Kontroll-Antikörper erhielt, in allen Experimenten zur Kontrolle. Das Optical Imaging der Messgruppe wurde durchgeführt, indem zu den Zeitpunkten von 1, 4 und 11 Tagen sowie 4, 6, 12 und 16 Wochen nach der Hepatozytentransplantation jeweils eine Region of Interest (ROI) in der Größe von $54 \mathrm{~mm}^{2}$ im Bereich der größten Fluoreszenzintensität definiert wurde. Die Messungen wurden 7 Stunden nach der Antikörperinjektion durchgeführt. Um später eine Vergleichbarkeit zwischen unterschiedlichen Proben zu ermöglichen, ist die Kenntnis des Dye-To-Proteine-Verhältnisses wesentlich, d.h. wie viele Farbstoffmoleküle sich im Mittel an einem Antikörper befinden. Das Dye-To-ProteineVerhältnis für IgG beträgt 2, das von anti-DPPIV 3,5.

\subsubsection{Bestimmung der Gesamtleuchtkraft}

Die Gesamtleuchtkraft (GLK) ist ein Maß für die relative Menge der Zellen in der Leberregion und lässt sich aus der gemessenen Fluoreszenzstrahlung ableiten. Sie berechnet sich als Summe aller Intensitäten in der Messregion, die größer als $10 \%$ der vordefinierten Maximalintensität sind. Hintergrundbereiche zeigen typischerweise Signalintensitäten unter $10 \%$ und wurden nicht mit einbezogen. Die GLK ist direkt proportional zur Gesamtheit der von der Leber kommenden Fluoreszenzstrahlung und somit ein Maß für die relative Menge des gebundenen Antikörper-Farbstoffkonjugates und damit direkt proportional zur DPPIV-positiven Zellzahl unter der Voraussetzung einer konstanten Bindungsrate zwischen Antikörper und untersuchten Zellen. Um die Spezifität der Antikörperbindung als auch den Anteil der unspezifischen Anreicherung in der Leber nachzuweisen, wurden Kon- 
trollversuche mit einem unspezifischen Antikörper ( $(g G)$ bzw. Negativkontrollen mit Tieren ohne implantierte Zellen durchgeführt. Ein weiterer Parameter, der die Vergleichbarkeit der Ergebnisse mit unterschiedlichen Proben erschwert, ist das oben genannte Dye-To-Proteine-Verhältnis, also das Verhältnis von Farbstoffmolekülen zu Antikörper. Das Dye-To-Proteine-Verhältnis war für die gegeben Proben bekannt und wurde bei der Berechnung der GLK berücksichtigt (vgl. Kap. 2.11.2). 


\section{Ergebnisse}

\subsection{Nebenwirkungen und Toxizität der Vorbehandlung und des Optical Imaging}

Weder akute noch chronisch toxische Effekte waren als Folge der selektiven perkutanen Leberbestrahlung mit 25 Gy über einen Beobachtungszeitraum von etwa 16 Wochen sichtbar. Keine mit der Präkonditionierung in Beziehung stehende Morbidität oder Mortalität konnte bei den Ratten festgestellt werden, die dem Optical Imaging unterzogen wurden. Ferner zeigten die Anwendung des Optix-MX2Systems und die Applikation des Cy5.5-gebundenen Antikörpers innerhalb des Beobachtungszeitraums keine erkennbaren Nebenwirkungen.

\subsection{Beurteilung präparierter Spenderhepatozyten vor Transplan- tation}

Für die Bestimmung der Zellqualität sowie der Morphologie der gewonnen Spenderhepatozyten wurden Zytospins angefertigt. Die Suspension aus isolierten, DPPIV-positiven Spenderhepatozyten wies eine Zellvitalität von mehr als $90 \%$ auf. Stark deformierte Zellen fanden sich nur vereinzelt. Nach Inkubation der Zellsuspension mit anti-DPPIV zeigte sich, dass alle vitalen Hepatozyten erwartungsgemäß eine starke Immunoreaktivität für das Spenderzellantigen aufwiesen (Abb. $3)$. 


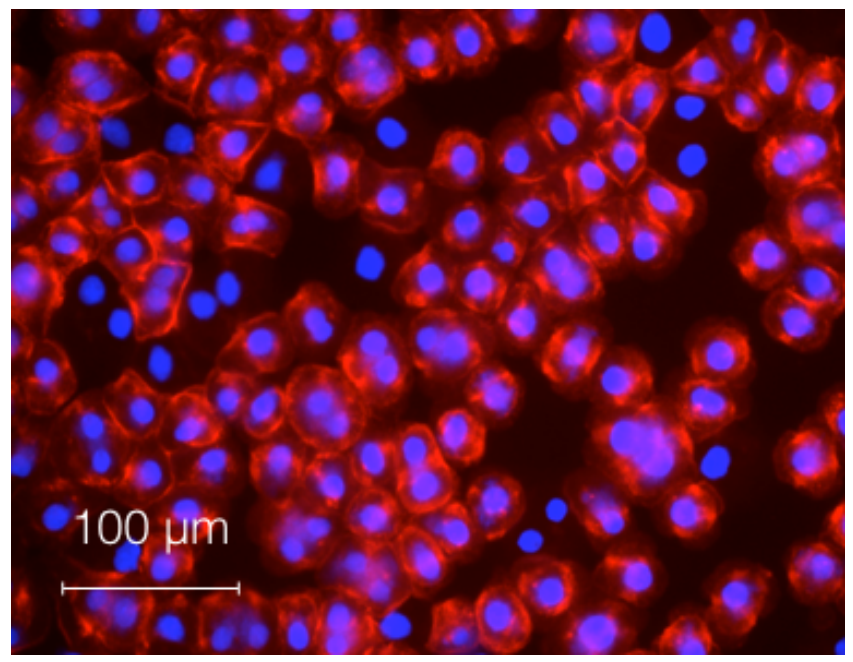

\section{Abbildung 6: Charakterisierung der Spenderhepatozyten}

Zur qualitativen Beurteilung der isolierten Spenderhepatozyten wurden Immunfluoreszenzfärbungen an Zytospins von Spenderzellen mit anti-DPPIV durchgeführt. Die Rotfärbung visualisiert das membranständige DPPIV und ist daher besonders kontrastreich. Die Färbung der Zellkerne erfolgte mit DAPI in Blau.

\subsection{Feststellung der optimalen Aufnahmebedingungen und des Messzeitpunktes im Optical Imaging}

In einem ersten Schritt mussten die Aufnahmebedingungen und Geräteeinstellungen bestimmt werden. Zu diesem Zweck wurde transplantierten Ratten aus der Evaluationsgruppe A nach zweimonatiger Repopulationsdauer (vgl. Tab. 6) Cy5.5konjugierter, spezifischer Antikörper über die Schwanzvene injiziert. Anschließend wurden sie dem Optical Imaging unterzogen. Hierbei stellte sich heraus, dass das Fell eine unnötig starke Streuung und Absorption verursachte. Eine zusätzliche Fehlerquelle lag im herkömmlichen Tierfutter, welches durch starke Autofluoreszenz in den Probemessungen unspezifische Signale im Verdauungssystem erzeugte und somit falsch-positive Werte lieferte. Die anschließend unter angepassten Messbedingungen, d.h. nach Rasur des Bauchfells unmittelbar vor dem Scan und Einführen einer speziellen, autofluoreszenzfreien Futterdiät 3 Wochen vor dem Messtermin (vgl. Kap. 2.11) festgestellte Fluoreszenz stellte sich als hochspezifisch heraus. Das Signal-Rausch-Verhältnis betrug 14,6. Es handelt sich 
hierbei um einen Wert, der eine klare Abgrenzung der gemessenen Signale im ROI und derer des inhärenten Hintergrundrauschens im erhaltenen Bild erlaubte.

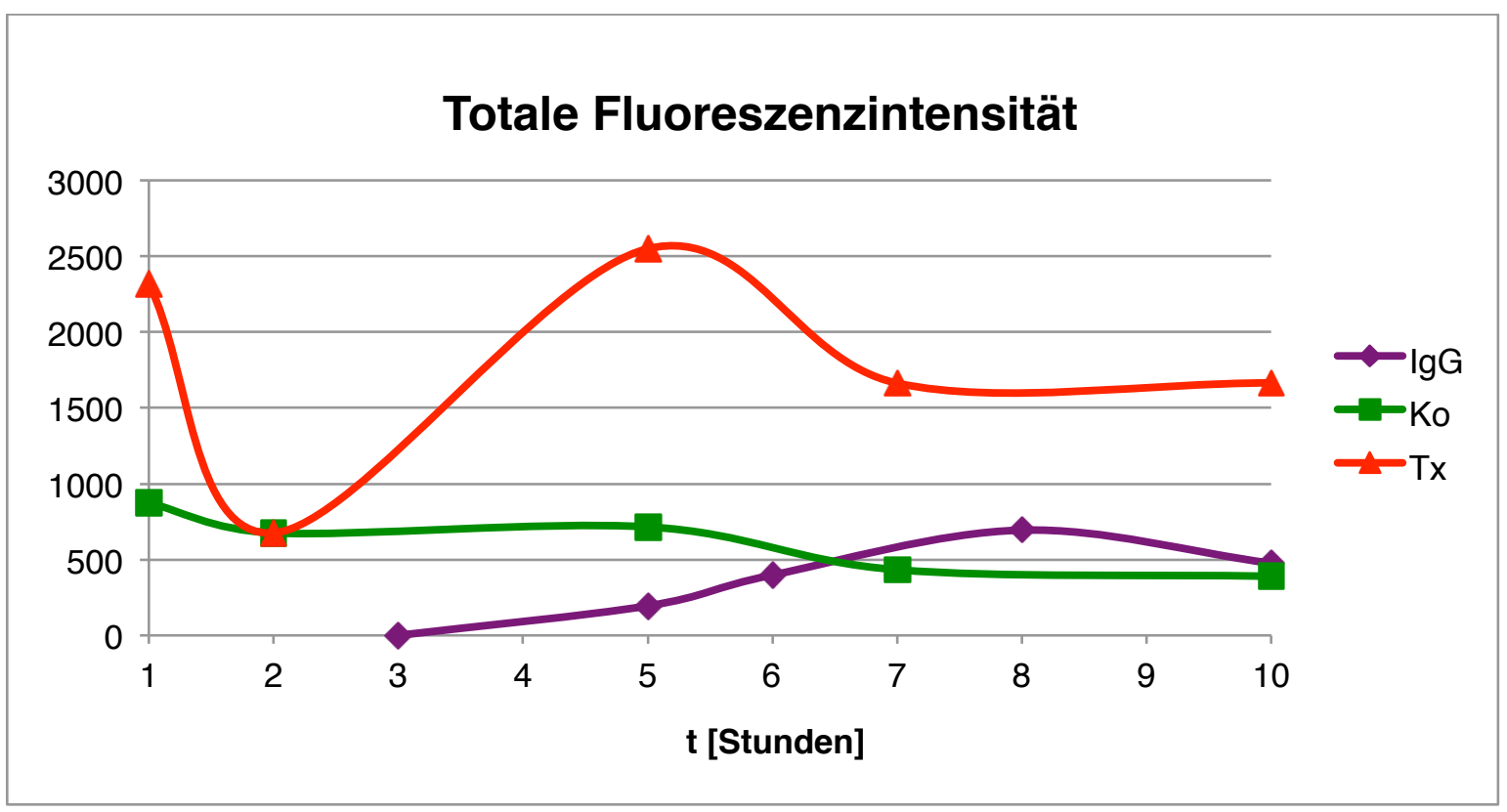

\section{Abbildung 7: Evaluation der Messbedingungen}

Nach Eliminierung des ungebundenen Farbstoffkonjugats stellte sich der optimale Messzeitpunkt zwischen Antikörperapplikation und Optical Imaging auf etwa 7 Stunden heraus. Die rote Kurve repräsentiert eine stetig hohe Fluoreszenzintensität des transplantierten Tieres. Die Kontrolltiere (nicht transplantiertes Tier mit spezifischem Cy5.5 Antikörper und transplantiertes Tier mit unspezifischem Antikörper lgG) zeigten flache Kurvenverläufe und somit keinen signifikanten Signalanstieg (grüne und violette Kurve).

Eine zeitliche Verzögerung zwischen Injektion des Fluoreszenzfarbstoffes und dem Optical Imaging erleichterte eine Differenzierung zwischen gebundenem und freiem Farbstoff. Zu diesem Zweck wurde einem transplantierten Tier spezifisches, Cy5.5-konjugiertes anti-DPPIV appliziert. Eine weitere transplantierte Ratte erhielt Cy5.5-gebundenes, unspezifisches IgG. Ferner wurde einem nicht transplantierten Tier, welches jedoch nach demselben Protokoll vorbehandelt wurde, Cy5.5konjugiertes anti-DPPIV appliziert. Daraufhin wurden die Tiere der Evaluationsgruppe A stündlich zwischen 1 und 10 Stunden nach der Antikörper-Injektion dem Optical Imaging unterzogen. 


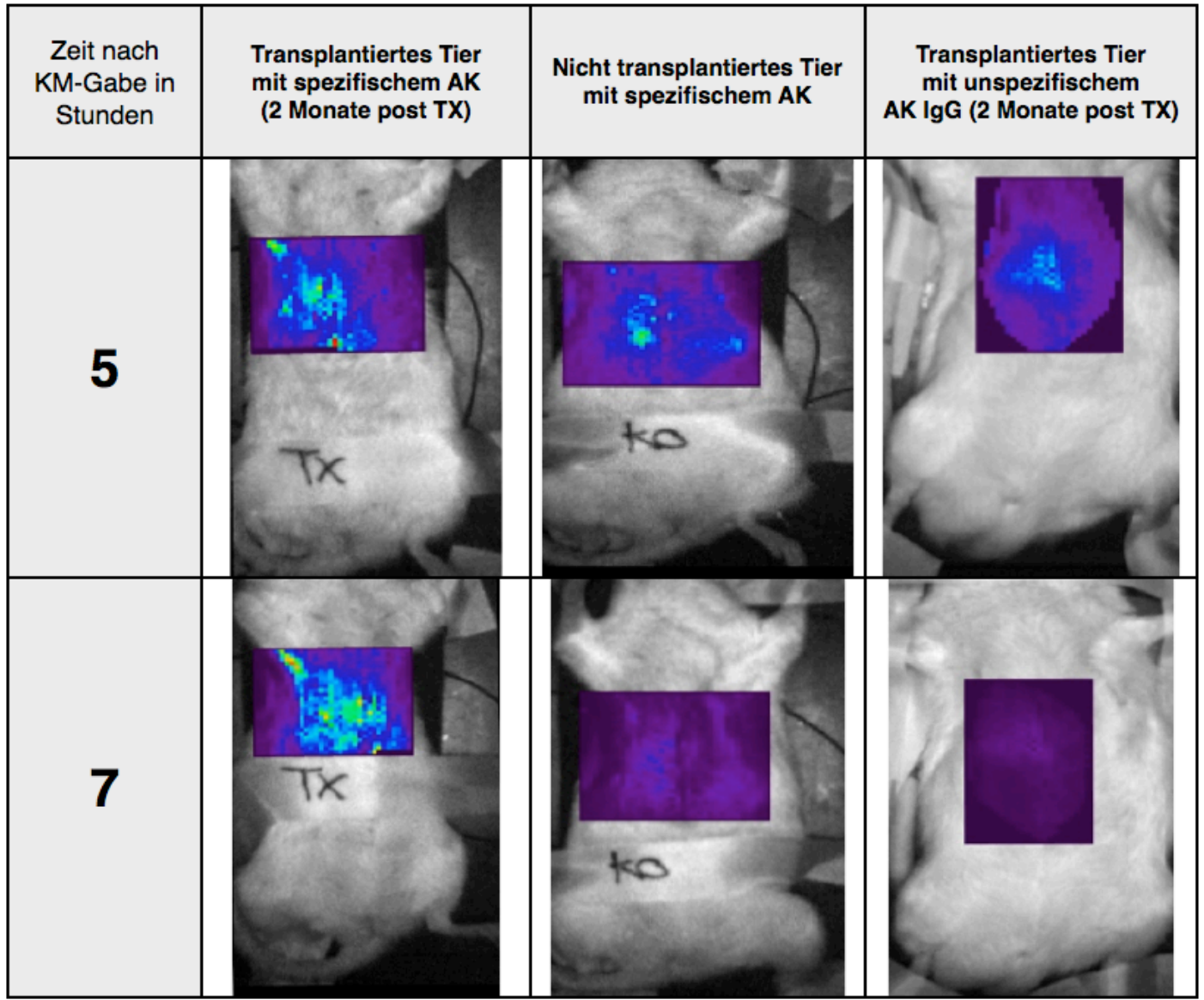

\section{Abbildung 8: Determinierung des optimalen Messzeitpunktes}

Die Tiere wurden stündlich zwischen 1 und 10 Stunden nach Antikörper-Injektion dem Optical Imaging zugeführt. Das transplantierte Tier (2 Monate nach Transplantation) mit spezifischem AK zeigte nach 7 bis 10 Stunden p.i. eine stabile Fluoreszenzintensität über der Leberregion. Die Kontrolltiere (nicht transplantiertes Tier mit spezifischem AK und transplantiertes Tier mit dem unspezifischem AK $\mathrm{IgG}$ ) zeigten über den gesamten Zeitraum deutlich niedrigere Fluoreszenzintensitäten, insbesondere 7 Stunden nach Applikation, zu einem Zeitpunkt an dem hohe Intensitäten im transplantierten Tier mit spezifischem AK nachweisbar waren.

Anfangs wurde ein hohes Niveau totaler Fluoreszenzintensität in der Leberregion der untersuchten Tiere mit spezifischem Antikörper festgestellt. Als Folge der Redistribution im Plasmaraum fiel die Emission nach zwei Stunden schnell auf das niedrigste Level ab. Danach zeigte sich, dass fluoreszente Konjugate in der Leberregion angereichert worden waren. Dies wurde als spezifische Aufnahme interpretiert (vgl. Abb. 4).

Dieses Signal konnte bis zu mindestens 10 Stunden nach Injektion deutlich vom umgebenden Hintergrundsignal unterschieden werden. Mit einem signifikanten 
Abfall der totalen Fluoreszenzintensität konnte dennoch gezeigt werden, dass der freie Farbstoff etwa 5 bis 7 Stunden nach Injektion in erheblichem Maße aus der Leber eliminiert wurde. Zusammenfassend konnte also ein gleichbleibendes Antikörper-Distributionslevel und eine stabile Emission in der Leberregion zwischen 7 und 10 Stunden festgestellt werden. Dieses Zeitfenster wurde daher für die folgenden Messversuche in Betracht gezogen (vgl. Abb. 5).

Obwohl der Cy5.5-konjugierte spezifische Antikörper pharmakokinetischen Regeln folgte, inklusive Exkretion im enterohepatischen Kreislauf, konnte bis zu 24 Stunden nach Injektion keine Interferenz mit den spezifischen Fluoreszenzsignalen in der Leber festgestellt werden. Jedoch trat eine deutliche Exkretion über das Harnsystem mit Fluophorakkumulation in der Harnblase ab dem Zeitpunkt von 5 Stunden nach Injektion auf (hierzu keine Abbildung gezeigt). Nicht transplantierte Tiere, die die vollständige Vorbehandlung mit Bestrahlung und partieller Hepatektomie durchlaufen hatten, dienten als Negativkontrolle. Auch innen wurde Cy5.5konjugierter spezifischer Antikörper injiziert. Die gemessenen Fluoreszenzintensitäten in der Leberregion waren während des gesamten Beobachtungszeitraums sehr gering und konnte ab 3 Stunden nach Injektion klar von den transplantierten Tieren unterschieden werden. In einem zweiten Kontrollversuch erhielten repopulierte Tiere eine Injektion mit konjugiertem, unspezifischem IgG. Hier konnten in der Leberregion zu jedem Zeitpunkt nur sehr geringe Intensitäten der Fluoreszenzsignale festgestellt werden. Zusammenfassend haben wir somit das optimale zeitliche Intervall zwischen Antikörper-Applikation und Messung der Fluoreszenzintensität für die folgenden Versuche auf 7 Stunden determiniert.

Auf eine besondere Eigenschaft des Farbstoffes muss an dieser Stelle noch hingewiesen werden. Die Sonde emittiert nicht unmittelbar dann, wenn markiertes Gewebe mit Kurzzeitlichtimpulsen bestrahlt wird, sondern über eine charakteristische Lebensdauer hinweg (Keren et al. 2008). Diese Eigenschaft kann in Kombination mit einer zeitaufgelösten Messung, wie sie im Optix-MX2-System realisiert ist, genutzt werden um Autofluoreszenz von der spezifischen Fluoreszenz unseres applizierten Antikörper-Farbstoff-Konjugat zu differenzieren. Die spezifische Lebensdauer für unser Antikörper-Cy5.5-Konjugat wurde in Vorversuchen in vitro 
determiniert (1,67 ns) und anschließend eingesetzt, um zu validieren, ob die in der Leber gemessenen Signale spezifisch für unser Antikörper-Cy5.5-Konjugat waren.

\subsection{Optical Imaging der Leberrepopulation in vivo}

1, 4 und 11 Tage sowie 4, 8, 12 und 16 Wochen nach der Leberteilresektion und Hepatozyten-Injektion erfolgte jeweils die qualitative Evaluation der 5 Empfängertiere aus der Messgruppe B (vgl. Tab. 6) durch Optical Imaging mit Bestimmung der relativen Konzentration der Fluoreszenzintensität im zuvor festgelegten ROI der Leberregion.

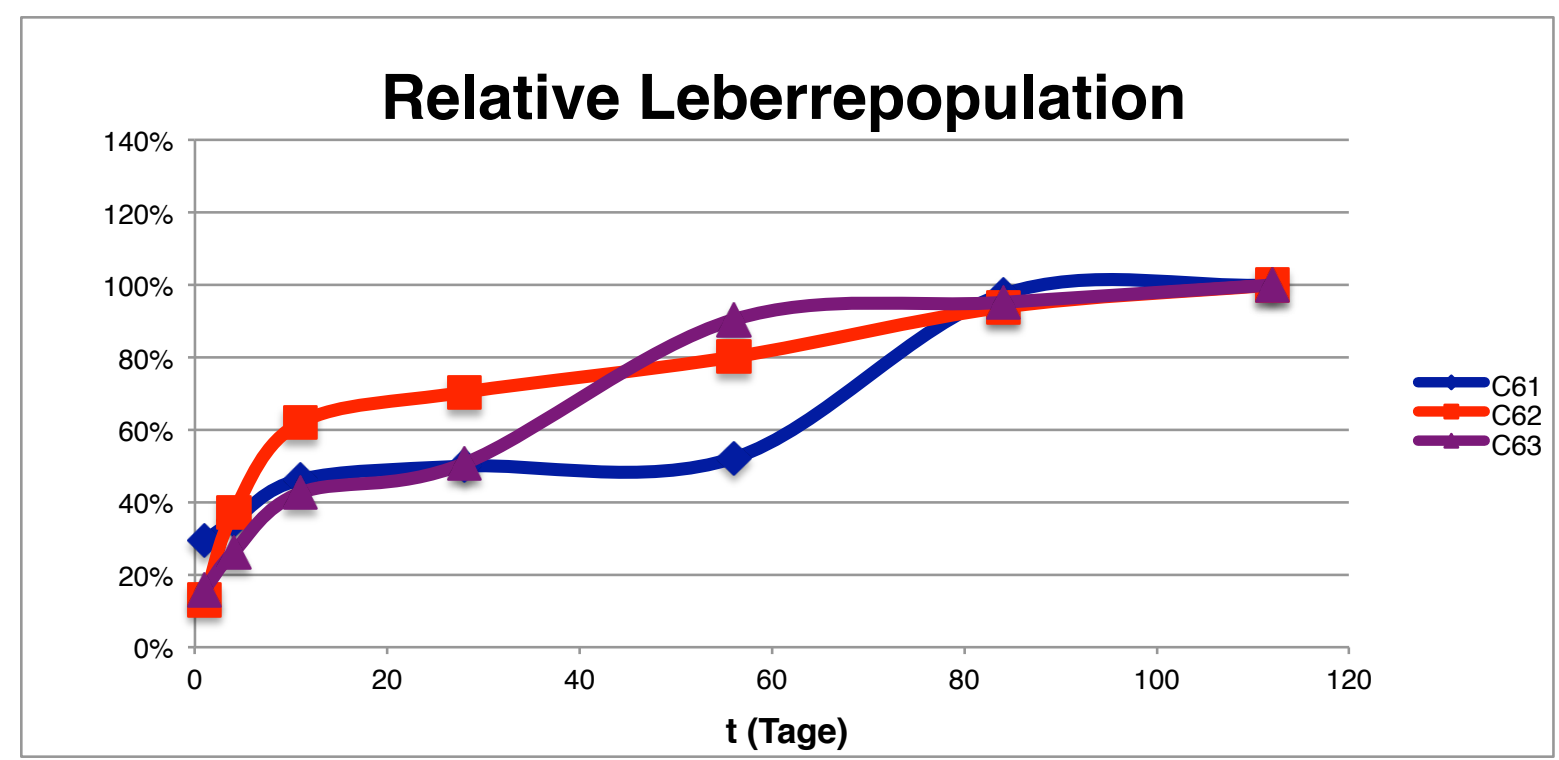

\section{Abbildung 9: Fluoreszenzintensität transplantierter Tiere über 16 Wochen}

Die im Optical Imaging akquirierten Fluoreszenzintensitäten wurden mit $100 \%$ auf ihren Endwert normiert und repräsentieren die verschiedenen Wachstumskurven der Spenderhepatozyten. Alle drei Kurvenverläufe zeigen einen zunächst schnellen Anstieg und erreichen nach ca. 12-16 Wochen eine Plateauphase. Das macht deutlich, dass innerhalb der ersten 20 Tage ein schnelles Wachstum vorlag und sich nach etwa 80 Tagen ein Sättigungsphänomen der Repopulationskapazität einstellte. Es ist anzunehmen, dass die Repopulation in Folge des gesetzten Regenerationsreizes nahezu abgeschlossen war. 

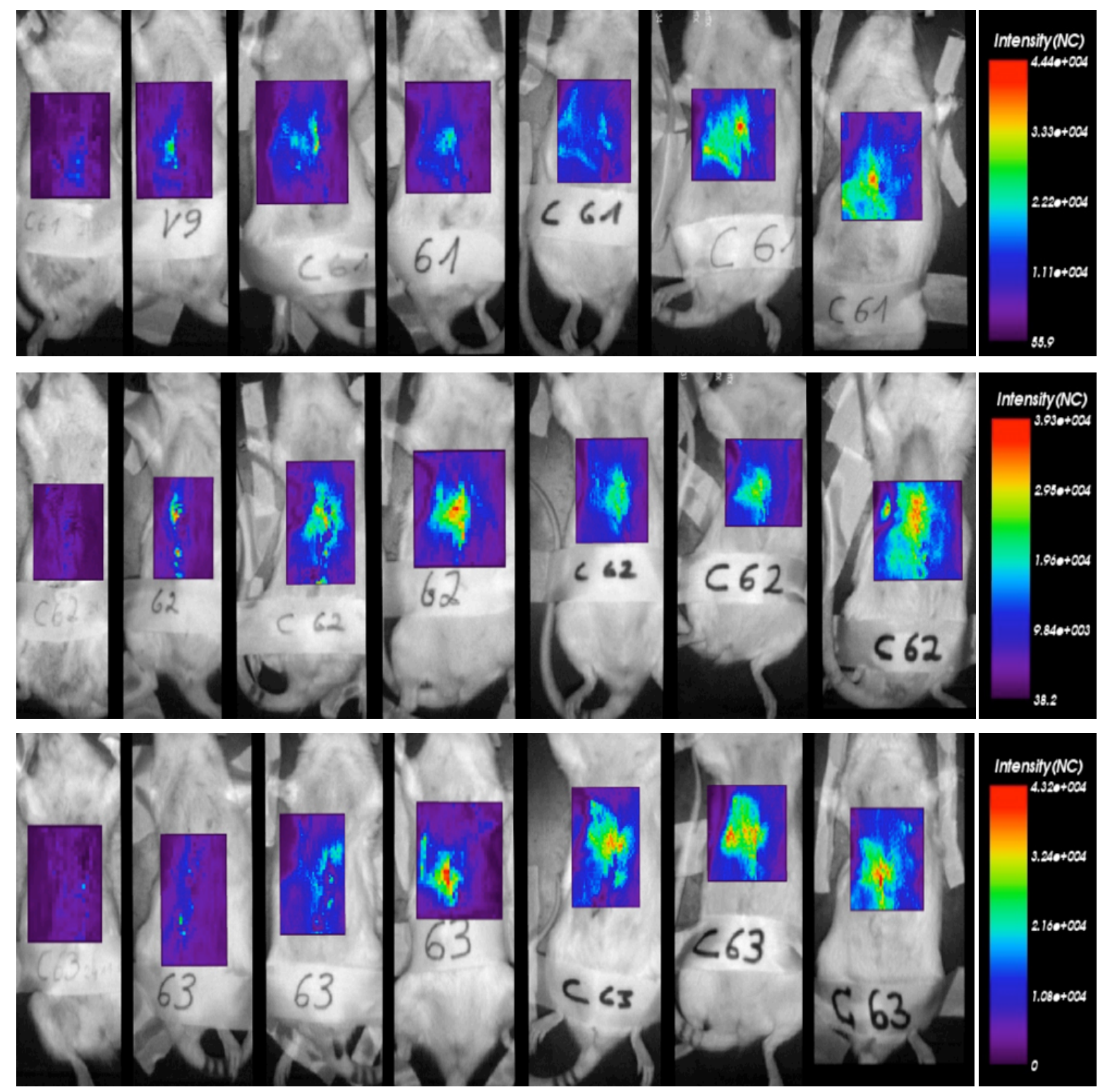

\section{$1 \mathrm{~d} \quad 4 \mathrm{~d} \quad 11 \mathrm{~d} \quad 4$ Wo 6 Wo 12 Wo 16 Wo}

\section{Abbildung 10: Kinetischer Verlauf der Leberrepopulation im Optical Imaging}

An den 3 transplantierten Tieren aus der Messgruppe B wurden 1, 4 und 11 Tagen sowie 4, 6, 12 und 16 Wochen nach Hepatozytentransplantation Optical-Imaging-Messungen durchgeführt. Die relativen Fluoreszenzintensitäten wurden nach 16 Wochen verglichen und zeigten in allen Tieren eine stetige Zunahme über den gesamten Untersuchungszeitraum. 
Nach intravenöser Injektion von konjugiertem Cy5.5-anti-DPPIV zeigten die Untersuchungen der transplantierten Tiere bereits nach einem Tag ein klar erkennbares, spezifisches Signal der Empfängerleber. Im Verlauf des Experiments wurden über 16 Wochen hinweg kontinuierlich steigende Fluoreszenzintensitäten in allen drei Tieren festgestellt, was die progressive Spenderzellvermehrung in den Lebern durch DPPIV-positive Hepatozyten und deren Abkömmlinge wiederspiegelte (vgl. Abb.11).

Die Abbildung 10 zeigt die Kinetik der Fluoreszenzintensität, die bei 16 Wochen auf dem jeweiligen höchsten Wert auf $100 \%$ normiert wurde. Für die Bestimmung der relativen Konzentration der Fluoreszenzintensität, wurde das Fluoreszenzsignal über ein ausgewähltes Messfeld gemittelt und durch die im Messbereich befindliche Messpunktzahl geteilt. Diese besitzt keine Maßeinheit. Obwohl die Vorbehandlungsprotokolle für die Empfängerlebern und die Zelltransplantation für alle drei Tiere identisch waren, zeigten die Datenunterschiede in der Höhe der absoluten Fluoreszenzintensität mit einer maximalen absoluten Variation von 191 NC (normalised counts). Am Endpunkt des Experiments beobachteten wir eine totale Fluoreszenzintensität von $1314 \mathrm{NC}$ in der Leberregion von Tier 1, $1386 \mathrm{NC}$ bei Tier 2 und 1195 bei Tier 3.

Die Auswertung der Daten zeigte insgesamt ständig steigende, jedoch variierende Fluoreszenzsignale, die repräsentativ für die unterschiedlichen Wachstumskurven der Spenderhepatozyten waren (vgl. Abb. 10). Jedoch konnte ein gemeinsames Muster entdeckt werden: Während der ersten 11 Tage war die Multiplikation der transplantierten Zellen relativ schnell. Danach schien sich die Leberrepopulation zu verlangsamen und erreichte nach ca. 12-16 Wochen eine Plateauphase. Ein repräsentativer Vergleich der transplantierten Tiere mit den beiden Kontrolltieren aus der Messgruppe B zum Zeitpunkt 12 Wochen nach Transplantation zeigte einen deutlichen Signalunterschied über der Leber (vgl. Abb. 11). Bei gleichem Vorbehandlungsprotokoll ist hierbei davon auszugehen, dass der dokumentierte Signalunterschied auf eine Proliferation der transplantierten Zellen zurückzuführen ist. 


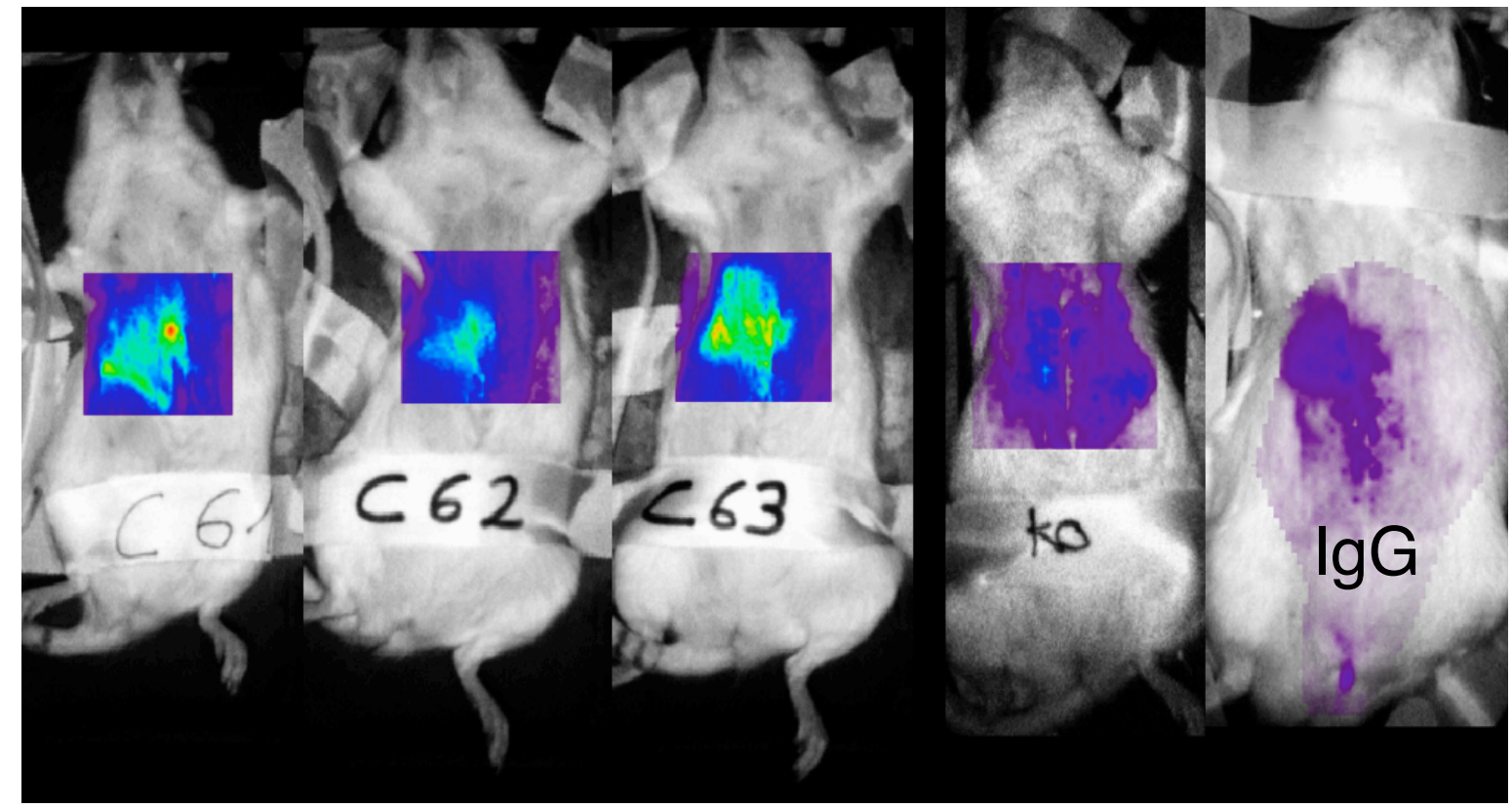

Abbildung 11: Fluoreszenzintensitäten über dem Leberareal 12 Wochen nach Hepatozytentransplantation

Bei den Tieren C61 - C63 handelte es sich um transplantierte Tiere, denen spezifisches DPPIVCy5.5 Antikörper-Konjugat injiziert wurde. Die KO-Kontrolle, ein nicht transplantiertes Tier, erhielt DPPIV-Cy5.5 Antikörper-Konjugat. Der IgG-Kontrolle, ein transplantiertes Tier, wurde unspezifisches IgG-Cy5.5 Antikörper-Konjugat appliziert. Die Messgruppe (C61 - C63) zeigte deutlich stärkere Signale als die KO- und IgG-Kontrolle. Die Abwesenheit von Signalen in der Kontrollgruppe bewies, dass das Signal in der Messgruppe von spezifisch gebundenem DPPIV-Cy5.5-Konjugat verursacht wurde und damit in Relation zu den transplantierten Zellen stand.

\subsection{Bestimmung der Gesamtleuchtkraft der Leber}

Um relative Menge der Zellen in der Leberregion mit der gemessenen Fluoreszenzstrahlung korrelieren zu können, haben wir die Daten aus dem generierten Bildmaterial umgerechnet und einen neuen Parameter eingeführt, die GLK (siehe Kap. 2.11.3). Die Abbildung 12 zeigt die gemessene Antikörpermenge der Tiere der Messgruppe B inklusive der Kontrolltiere (blaue Balken). Die Antikörpermenge ist dabei in einer linearen, aber einheitslosen Größe angegeben, da die Parameter wie Quanteneffizenz der Proben und Umwandlungsrate des Detektors nicht bekannt sind. Deutlich höhere Werte wurden bei dieser Messung für die drei transplantierten Tiere erzielt, die auch spezifische Antikörper erhielten (C61 - C63). Dies unterstrich die Spezifität der Antikörperbindung im Vergleich mit der IgG- 
Kontrolle. Auch konnte es sich dabei nicht um eine ungebundene Anreicherung des spezifischen Antikörpers in der Leber handeln, z.B. nach hepatischer Verstoffwechselung des Antikörpers, da das nicht transplantierte Tier, das den gleichen Antikörper verabreicht bekam, deutlich niedrigere Signale in der Leber zeigte.

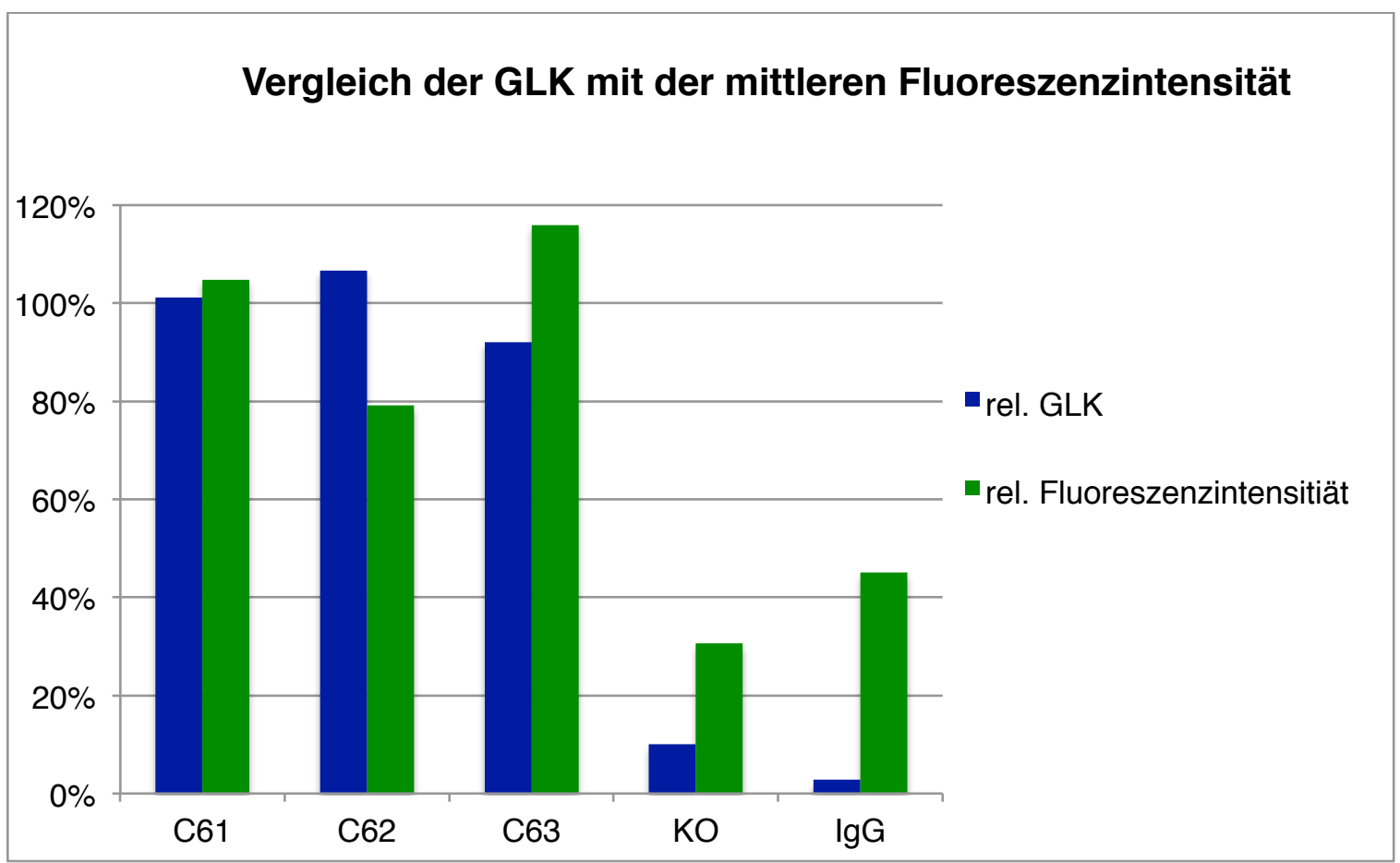

\section{Abbildung 12: Vergleich der GLK mit der mittleren Fluoreszenzintensität}

Die Gegenüberstellung der GLK mit der mittleren Fluoreszenzintensität (jeweils normiert auf den Mittelwert der Messgruppe um einen Vergleich zu ermöglichen) zeigte eine erhöhte Spezifität der GLK basierten Messungen, nachgewiesen durch eine geringere Variabilität in der Messgruppe (C61 - C63), und eine erhöhte Sensitivität, erkennbar am deutlicheren Unterschied zu der KO- und lgG-Kontrolle.

Der hier entwickelte Parameter GLK hat den Vorteil, dass er weitestgehend unabhängig von der Größe der Messregion ist und zusätzlich lokale Schwankungen im Messsignal toleriert, die durch Inhomogenitäten in der Verteilung der transplantierten Zellen hervorgerufen werden. Die Überlegenheit der GLK-Auswertung im Vergleich zum klassischen Ansatz der Analyse von mittleren Signalintensitäten in bestimmten Regionen (vgl. Abb. 10) wird in Abbildung 12 deutlich. Die GLK (blaue 
Balken) zeigt gegenüber der relativen Fluoreszenzintensität (grüne Balken) eine deutlich geringere Variabilität innerhalb der therapierten Tiere (C61 - C63) und einen größeren Unterschied zu den Werten von KO und IgG. Folglich ist die Auswertung basierend auf GLK sowohl in der Sensitivität als auch in der Spezifität überlegen.

Zur Ergebnisvalidierung wurden die Daten aus der GLK-Messung mit den immunhistochemischen Untersuchungen der explantierten Lebern verglichen (siehe Kap. 3.6).

\subsection{Nachweis der hepatischen Repopulation durch Immunfluo- reszenzmikroskopie}

Um die progrediente Leberrepopulation, die im Optical Imaging festgestellt wurde, histologisch zu bestätigen, wurden Immunofluoreszenz-Ko-Lokalisationsstudien an den Lebern der Tiere aus der Messgruppe B nach Beendigung der OpticalImaging-Messungen nach 16 Wochen durchgeführt (vgl. Abb. 12). Zudem kam eine weitere Gruppe, bestehend aus 6 Tieren, zum Einsatz, die die histologische Referenzgruppe $\mathrm{C}$ darstellte (vgl. Tab. 6). Alle 6 Tiere waren DPPIV-negativ, erhielten eine Hepatozytentransplantation und wurden in Analogie zur Messgruppe B (vgl. Abb. 1) vorbehandelt. Jeweils zwei von innen wurden nach 3 Tagen, respektive 4 und 16 Wochen, getötet und ihre prozessierten Lebern der Immunfluoreszenzmikroskopie zugeführt (vgl. Abb. 14).

Alle Leberlappen der insgesamt 11 Tiere wurden der Immunofluoreszenzmikroskopie unterzogen. Die Leberstruktur zeigte sich zu allen Untersuchungszeitpunkten unbeschädigt und ohne Hinweise auf Entzündung, Fibrose oder verdrängendes Wachstum. Große, teils konfluierende Cluster von Hepatozyten mit Expression des Spenderantigens DPPIV konnten in den Lebern der DPPIV-negativen Empfängertiere nachgewiesen werden ( $\mathrm{vgl}$. Abb. 9).

Die DPPIV-positiven Zellverbände schienen sich aus Portalfeldern zu entwickeln, wo die Spenderzellenintegration initial erfolgt war. Genauer gesagt, exprimierten die Spenderzellen und ihre Abkömmlinge DPPIV in der den Gallencanaliculi zuge- 
wandten Membranseite in einem für intakte und metabolisch aktive Hepatozyten typisches Muster. Der kombinierte Stimulus der Bestrahlung und der partiellen Hepatektomie haben eine kontinuierliche Leberrepopulation hervorgerufen, mit der Folge, dass sich die Spenderzellen zunehmend in das Parenchym vorwuchsen und ausdehnten. Schließlich bildeten sich Cluster, die im Laufe der Repopulationsdauer konfluierten. Nach 16 Wochen beinhalteten diese Bereiche im Durchschnitt maximal bis zu 500 Zellen (vgl. unten).

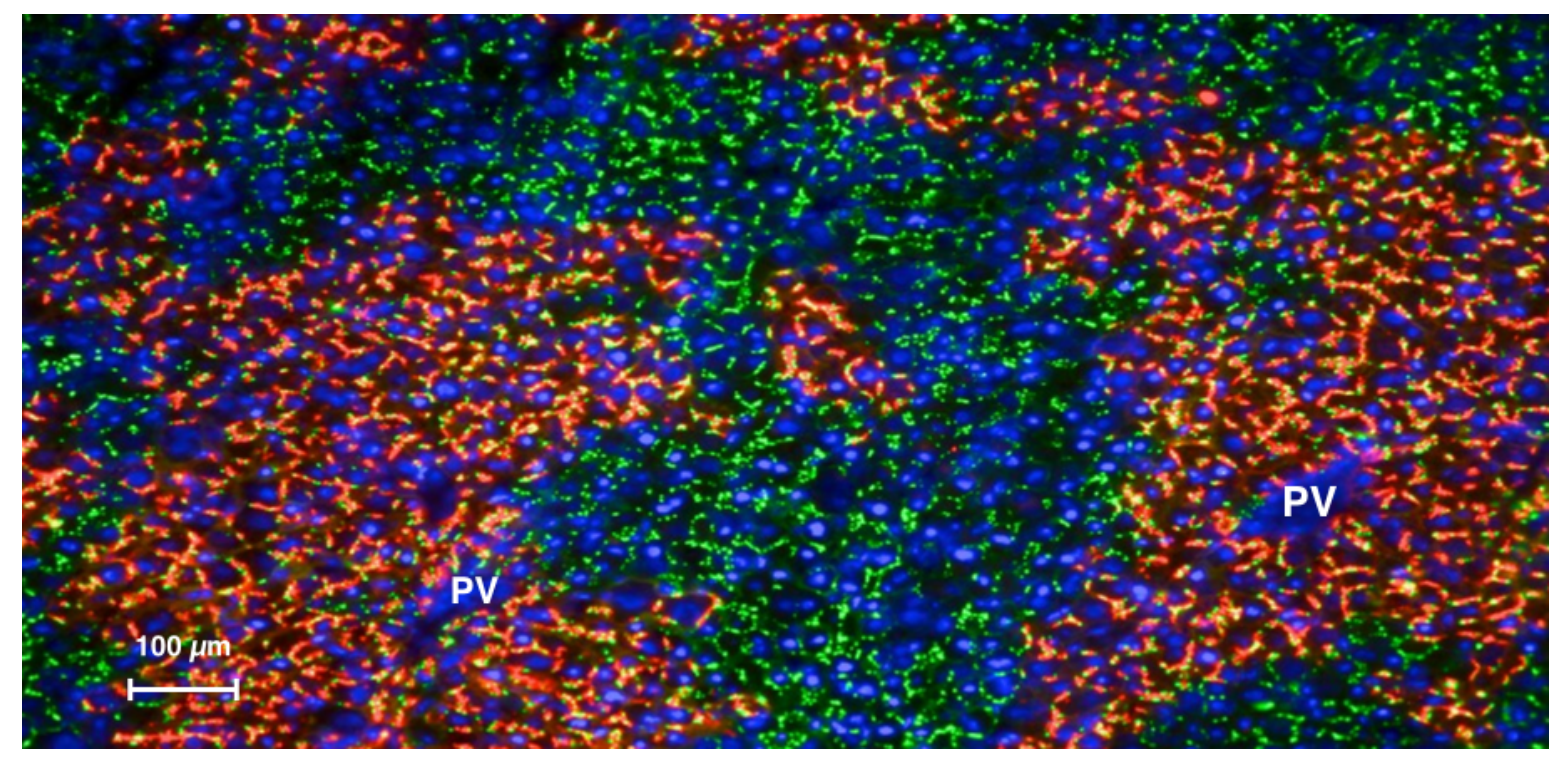

\section{Abbildung 13: Immunfluoreszenzfärbung der Empfängerleber nach 16 Wochen}

Dargestellt ist die repräsentative Immunfluoreszenzfärbung einer Empfängerleber aus der Messgruppe B nach 16 Wochen mit anti-DPPIV zur Markierung der transplantierten DPPIV-positiven Hepatozyten in Rot. Eine massive Repopulation der Empfängerleber wurde hiermit auch histologisch nachgewiesen. Die DPPIV-positiven Zellverbände schienen sich aus Portalfeldern zu entwickeln (PV = Portalvene), wo die Spenderzellenintegration initial erfolgt war. Das Gap-Junction-Protein Cx32 ist in Grün und die Zellkerne mit DAPI in Blau gefärbt. Die Übersichtsaufnahme zeigt zudem die homogene Architektur des repopulierten Leberläppchens und die gleichmäßige Verteilung von Cx32 auf der Zellmembran der Spenderzellen. Die Expression von Cx32 stellt einen Indikator für einen hochdifferenzierten Zellstatus dar.

Eine Korrelation der immunhistochemischen Auswertung mit den Ergebnissen aus der GLK-Messung zeigte korrespondierend zur Gesamtleuchtkraft eine ausgeprägte Besiedlung der Lebern mit DPPIV-positiven Zellen. In den nicht transplantierten Lebern, die in der GLK-Messung kein Signal aufwiesen konnten keine 
DPPIV-positiven Zellen dokumentiert werden. Ebenso konnte keine Färbung in Gewebeschnitten transplantierter Tiere nachgewiesen werden, die mit dem unspezifischen Antikörper lgG inkubiert worden waren (hierzu keine Abbildungen gezeigt).
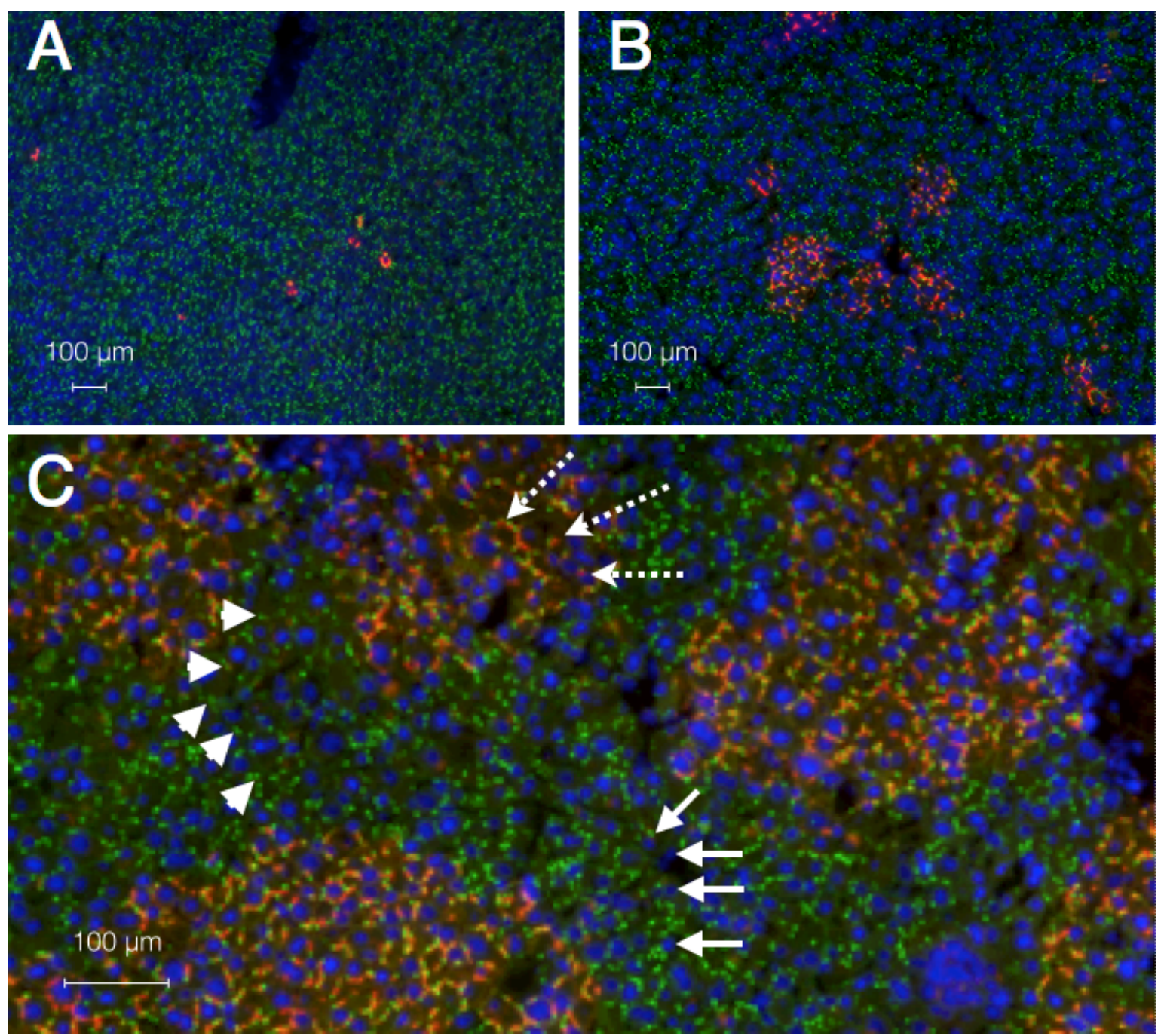

\section{Abbildung 14: Kinetik der Repopulation}

Zu unterschiedlichen Zeitpunkten der Repopulation wurden Immunfluoreszenzfärbungen der Tiere aus der histologischen Referenzgruppe $\mathrm{C}$ durchgeführt mit Färbung von anti-DPPIV zur Markierung DPPIV-positiver Hepatozyten in Rot (gestrichelte Pfeile), Gap-Junction-Protein Cx32 in Grün (Pfeilspitzen) und Zellkerne mit DAPI in Blau (Pfeile), 3 Tage (A), 4 Wochen (B) und 16 Wochen (C) nach Hepatozytentransplantation. Nach 16 Wochen konnte eine ausgedehnte Repopulation der Leber dokumentiert werden. Die Spenderzellcluster wuchsen ohne Zeichen der Raumforderung im Empfängerparenchym. 
Die Kinetik des Repopulationsprozesses ist im Detail in den Abbildungen $14 \mathrm{~A}-\mathrm{C}$ dargestellt. In Abbildung 14 A sind einige wenige DPPIV-positive Spenderhepatozyten 3 Tage nach Transplantation abgebildet. Es konnten Ansammlungen von etwa 10 DPPIV-positiven Hepatozyten in einer Schnittebene nachgewiesen werden. Im Verlauf vermehrte sich deutlich die Anzahl der transplantierten Zellen und erreichte nach 4 Wochen eine Zellzahl von etwa 100 DPPIV-positiven Hepatozyten pro Schnittebene (vgl. Abb. 14 B). Im Laufe des Beobachtungszeitraumes von 4 Monaten vergrößerten sich die Cluster zu konfluierenden Anhäufungen von bis zu 500 Zellen.

Ein weiterer Anhaltspunkt für eine erfolgreiche Integration und metabolische Kommunikation der DPPIV-positiven Zellen ist das Expressionsmuster des GapJunction-Proteins Connexin 32 (Cx32) (Koenig et al. 2005). Cx32 ist ein Transmembranprotein, das eine direkte Zell-zu-Zell-Kommunikation erlaubt und für die Migration und Differenzierung von Hepatozyten erforderlich ist. Es ist ferner für die Integrität des Leberparenchyms notwendig. Folglich dient Cx32 als Indikator für einen hochdifferenzierten Zellstatus. Im Rahmen der Gewinnung und Prozessierung der transplantierten Hepatozyten durch das In-Situ-KollagenaseperfusionsVerfahren werden in der Regel die Zell-zu-Zell-Verbindungen aufgebrochen und kommen im Zytospin der isolierten Zellsuspension entsprechend deutlich vermindert oder nicht zur Darstellung (dokumentiert durch fehlende Grünfluoreszenz des Cx32) (vgl. Abb. 6). In Studien konnte gezeigt werden, dass durch die Transplantation und in der frühen Post-Transplantationsphase es zu einer weiteren Reduktion von Cx32 kommt. Eine Reexpression des Proteins erfolgt i.d.R. über einen Zeitraum von 3 bis 5 Tagen nach Transplantation (Koenig et al. 2005). Unsere Immunfluoreszenzfärbungen der Empfängerlebern nach 16 Wochen zeigten neben der Rotfluoreszenz der DPPIV-positiven Zellen eine homogene punktförmige Verteilung der Grünfluoreszenz des Cx32, welche eine hohe Proteinexpression und stabile intrazelluläre Verbindungen zwischen transplantierten Zellen repräsentierte (vgl. Abb. 13).

Zusammenfassend konnte hier eine ausgedehnte Besiedlung der Empfängerleber durch die transplantierten Zellen innerhalb von 16 Wochen konstatiert werden. Zu 
diesem Zeitpunkt waren die Spenderzellen und ihre zahlreichen Abkömmlinge vollständig in das Leberparenchym des Empfängers integriert und zeigten sowohl strukturmorphologische als auch metabolische Eigenschaften von voll entwickelten und integrierten Hepatozyten. 


\section{Diskussion}

\subsection{Hepatozelluläre Transplantation im DPPIV-Fischer-344- Tiermodell}

Zahlreiche Tiermodelle entstanden über die letzten Jahre mit dem Ziel, Methoden und Strategien zu entwickeln, um das Engraftment der Hepatozyten sowie ihr Langzeitüberleben zu verbessern (Gilgenkrantz 2010). Dabei wurden Hepatozyten auf verschiedene Art und Weise markiert und dargestellt, z.B. durch Farbstoffe oder durch radioaktive Marker. Ebenso brachte der Einsatz von mutagenen Tiermodellen wesentliche Erkenntnisse auf dem Gebiet der Hepatozytentransplantation.

Das Tiermodell in der vorgelegten Dissertation verwendet Ratten aus genetisch identischen Inzuchtstämmen, wobei DPPIV-defiziente Fischer-344-Ratten als Empfängertiere und DPPIV-positive Wildtyp-Fischer-344-Ratten als Spendertiere dienten. Bei dieser sogenannten syngenen Transplantation ist eine Immunsuppression nicht erforderlich. Das Prinzip des DPPIV-Fischer-344-Tiermodells beruht auf dem Lokalisieren von genetisch markierten Zellen. Da es sich beim DPPIV um einen endogenen Marker handelt, ist die Grundlage für Langzeitversuche gegeben, im Falle des vorgelegten Dissertationsprojektes für solche von bis zu 16 Wochen. Im Gegensatz zu exogenen Markern, wie z.B. Fluoreszenzfarbstoffen (vgl. Kap. 1.2.1) oder radioaktiven Isotopen, die abbauenden Prozessen unterliegen (Rajvanshi et al. 1996), ist im vorgestellten Tiermodell eine konstante Nachweisbarkeit der Spenderhepatozyten gewährleistet. Ein durch somatische Mutation bedingter Verlust des DPPIV-Antigens wäre möglich, aber sehr unwahrscheinlich und wurde überdies bislang nicht in der Literatur beschrieben.

Eine Einschränkung haben syngene Tiermodelle dennoch. Sie reflektieren nicht in ausreichendem Maße die Umstände, die eine humane Anwendung betreffen, welche eine allogene Transplantation erfordert (Weber et al. 2009). Jedoch waren und sind sie besonders hilfreich bei der Untersuchung und Evaluierung der selektiven Hepatozytenrepopulation. 


\subsection{Optical Imaging}

\subsubsection{Optical Imaging im DPPIV-Fischer-344-Tiermodell}

Das DPPIV-Fischer-344-Tiermodell mit partieller Hepatektomie sowie RestleberBestrahlung ist eine geeignete Methode, um Mechanismen zu untersuchen, die zur Rekonstituierung der Leber durch DPPIV-positive Spenderzellen führen. Dieses Dissertationsprojekt hat gezeigt, dass die Leberrepopulation im experimentellen Tiermodell durch Optical Imaging und Cy5.5-konjugierte Antikörper einfach überwacht werden kann. Bisher repräsentieren Ex-Vivo-Techniken, wie etwa morphometrische Analysen, die auf Histochemie bzw. Immunolabeling oder der Feststellung von DPPIV in Gewebeproben, z.B. durch enzymatische oder molekulare Untersuchung und FACS-Analyse basieren, den Goldstandard für die Feststellung des Ausmaßes der Leberrepopulation im anerkannten DPPIV-Fischer-344Tiermodell (Koyama et al. 2007). Diese Methoden verlangen jedoch das Explantieren von Organen vor der Analyse. Darüber hinaus ist eine große Anzahl Tiere nötig, um Messungen zu verschiedenen Zeitpunkten durchführen zu können. Außerdem muss eine große Anzahl Proben von einer Leber prozessiert und analysiert werden, bevor die Extrapolation der Ergebnisse überhaupt die Effizienz der Leberrepopulation im gesamten Organ darstellen kann. Zudem kann die Kinetik der Spenderzellmultiplikation nur unzureichend dokumentiert werden, da während der Studie verschiedene Tiere beobachtet werden. Um die erfolgreiche Repopulation der Leber durch transplantierte Zellen repetitiv in einem einzigen Tier zu unterschiedlichen Zeitpunkten darstellen zu können, ist die Nadelbiopsie aus der Leber eine weitere denkbare Möglichkeit. Jedoch scheint dieser Ansatz zu anspruchsvoll, da es technisch schwierig ist, Biopsien an kleinen Tieren durchzuführen. Ferner können lediglich kleine Gewebeproben gewonnen werden, so dass das Risiko von erheblichen Stichprobenfehlern besteht (Plebani und Basso 2007).

Unter Berücksichtigung der o.g. Schwierigkeiten wird hier ein Optical-ImagingVerfahren präsentiert, das auf einem durch Fluoreszenzfarbstoff konjugierten, monoklonalen Antikörper basiert. Es liefert nicht nur exakte Daten, sondern ermöglicht zeitlich eine longitudinale Dokumentation der Leberrepopulation in einem ein- 
zigen Tier. Zudem beinhaltet es die Möglichkeit, die Anzahl der für die Experimente notwendigen Tiere in erheblichem Maße zu reduzieren.

Verglichen mit der Szintigraphie oder der MRT besitzen Fluoreszenzfarbstoffe nur eine geringe Eindringtiefe in das Gewebe (Cheng et al. 2005). Jedoch hat biologisches Gewebe ein minimales Absorptionsvermögen im NIR-Fenster (650-900 nm), was effiziente Photonenpenetration in und aus dem Gewebe mit niedriger Streuung im Gewebe ermöglicht (Koyama et al. 2007). In den einzelnen Messreihen konnte die Absorption und die Autofluoreszenz durch Rasur der Tiere im Scanbereich vor jeder Messung weiter verringert werden. Dadurch war eine tiefere und genauere Darstellung des Gewebes möglich. Zusätzlich wurde eine spezielle Futterdiät angewendet, um Hintergrundsignale zu reduzieren, die normalerweise im oberen Gastrointestinaltrakt erheblich sind.

Initiale Studien wurden zur Evaluation des optimalen Zeitintervalls für die Applikation des Fluoreszenzfarbstoffs durchgeführt. Sieben Stunden nach der intravenösen Injektion war der Antikörper im Empfängertier gut verteilt. In der Leberregion konnte eine starke Signalintensität nachgewiesen werden. Jedoch war es wichtig zu zeigen, dass die Fluoreszenz spezifisch für das Antikörper-Cy5.5-Konjugat war und durch die spezifische Bindung des Antikörpers an das Zielantigen verursacht wurde. Ein wichtiger Parameter, der bei dieser Unterscheidung helfen konnte war die Lebensdauer. Sie gibt die mittlere Zeit an, in der ein Farbstoffmolekül in einem angeregten Zustand verbleibt, bevor es ein Photon emittiert und damit in den Grundzustand zurückkehrt. Dieser Wert ist für jedes Antikörper-Farbstoff-Konjugat charakteristisch und kann daher herangezogen werden um spezifische Signale zu detektieren (Akers et al. 2007). Die Lebensdauer ist ferner so spezifisch, dass mit ihrer Hilfe nicht nur Autofluoreszenz von emittierter Fluoreszenz eines AntikörperFarbstoff-Konjugates unterschieden werden kann, sondern sie findet auch Anwendung um Signale von zwei simultan applizierten NIR-Fluophoren mit einem ähnlichen Spektrum in vivo voneinander zu differenzieren (Napp et al. 2010). Basierend auf In-Vitro-Messungen und Bestimmung der spezifischen Lebensdauer konnten wir zeigen, dass sich die Lebensdauer unseres gemessenen Signals über der Leberregion als spezifisch für das Antikörper-Cy5.5-Konjugat erwies. 
Des weiteren konnte die Möglichkeit ausgeschlossen werden, dass die gemessene Fluoreszenz durch unspezifische Antikörper-Bindungen verursacht wurde, indem zuvor zwei wichtige Kontrollexperimente durchgeführt wurden: Nicht transplantierten Tieren wurde Cy5.5-konjugierter spezifischer Antikörper injiziert und nur sehr niedrige Fluoreszenzlevel konnten in der Leber festgestellt werden. Darüber hinaus wurde kein ausreichend hohes Fluoreszenzsignal erreicht, wenn nicht transplantierten Tieren Cy5.5-konjugiertes IgG injiziert wurde. Überdies konnte eine hohe, zeitabhängige Aufnahme des Antikörper-Cy5.5-Konjugates in allen transplantierten Tieren bewiesen werden: Das Fluoreszenzsignal stieg parallel zur Leberrepopulation. Zuletzt konnte eine starke Korrelation zwischen der Cy5.5-bezogenen Fluoreszenz der repopulierten Leber und der Visualisierung von Spenderzellclustern auf Kryoschnitten durch Verwendung der Immunreaktionsfähigkeit von DPPIV gezeigt werden.

Das Optical Imaging erlaubte in der vorgelegten Studie zum ersten Mal, die Wachstumskurven von Spenderzellen in verschiedenen Tieren untereinander zu vergleichen. In der Tat erwies sich die Kinetik der Leberrepopulation als inhomogen. Trotzdem ergab sich ein einheitliches Muster der Spenderzellmultiplikation mit einer zunächst stark ansteigenden Wachstumskurve und einer späten Plateauphase.

\subsubsection{Messung der Gesamtleuchtkraft}

Ziel der Untersuchung war es, die gemessene Fluoreszenzintensität in der Leberregion mit der relativen Menge der dort vorhandenen Hepatozyten in Verbindung zu setzten. Dabei gab es mehrere systemimmanente Probleme zu bedenken:

1. Es wurde nicht die Anzahl der Spenderzellen gemessen, sondern die Signale, die von einer Menge an markierten Antikörper ausgehen. Um im Vergleich mit den Kontrollen Rückschlüsse über die vorhandenen Zellen ziehen zu können, musste nachgewiesen werden, dass der Antikörper spezifisch an die entsprechenden Zellen band. 
2. In den meisten Fällen war ein Antikörper mit mehr als einem Fluorophor markiert. Für die vergleichende Analyse musste daher das Fluorophor-zu-AntikörperVerhältnis für alle verwendeten Proben bekannt sein.

3. Da es sich bei den Antikörper-Farbstoff-Konjugaten um Makromoleküle handelte, wurden diese über die Leber verstoffwechselt, d.h. auch ungebundene Konjugate trugen in der Leber zum Entstehen des Fluoreszenzsignals bei. Um diesen Anteil schätzen und die Spezifität der Antikörperbindung nachzuweisen zu können, waren zwingend Kontrollversuche mit einem unspezifischen Antikörper (IgGCy5.5-Konjugat) bzw. Negativkontrollen mit Tieren ohne implantierte Zellen nötig, da diese nur ein unspezifisches Fluoreszenzsignal zeigen konnten. Die zuvor bestimmte GLK in der IgG-Isotypkontrolle entsprach daher weitestgehend dem unspezifischen Anteil der GLK-Werte der Versuchstiere C61 - C63. Um einen modelbedingten Einfluss durch die injizierten DPPIV-positiven Zellen auszuschließen wurde das KO-Tier in Kombination mit dem spezifischen DPPIV-Cy5.5-Konjugat analysiert. Die Ergebnisse zeigen in etwa die gleiche GLK wie im IgG-Tier (vgl. Abb. 12) und deuten daher darauf hin, dass die DPPIV-positiven Hepatozyten keinen direkten Einfluss auf die Messung haben. Somit ließe sich aus der Differenz der GLK-Werte der Versuchstiere C61 - C63 mit dem mittleren GLK-Wert aus dem IgG- und KO-Tier die GLK des spezifisch gebunden Anteils des DPPIV-Cy5.5Farbstoff-Konjugates bestimmen.

4. In den meisten Fällen basierte die Auswertung von Fluoreszenzsignalen einer In-Vivo-Messung auf der Bestimmung der mittleren Intensität für die ROI. In Falle des vorgestellten Tiermodells sollte aber die gesamte Intensität in der Leberregion mit der Zellrepopulation korreliert werden. Außerdem bestand die Möglichkeit, dass die Zellen inselartig in der Leber verteilt waren und somit ein Mittelwert auch von Regionen ohne Zellen beeinflusst worden wäre. Daher haben wir die Summe der Fluoreszenzintensität in einer Region bestimmt, die immer die gesamte Leber enthielt. Allerdings wäre dieses Ergebnis von der Körpergröße des Versuchstieres sowie von Variation bei der Lagerung abhängig gewesen, da nicht gesichert werden konnte, dass die Leber immer den gleichen Volumenanteil im Messfeld ausmacht. Wir haben daher für die Auswertung einen neuen Parameter Gesamt- 
leuchtkraft als Summe aller Intensitäten in der Messregion, die größer als $10 \%$ der bestimmten Maximalintensität sind, eingeführt. Der Wert der GLK war nur von der Konzentration des Antikörper-Farbstoffkonjugates abhängig und nach hinreichend langer Zeit, in der die ungebunden Anteile des Konjugates vollständig verstoffwechselt werden konnten, direkt proportional zur vorherrschenden Zellzahl (natürlich nur unter der Voraussetzung, dass das Konjugat im Überschuss appliziert wurde und in der Lage gewesen ist in vivo an alle Zellen zu binden).

In der vorgelegten Studie konnte gezeigt werden, dass der Parameter GLK gegenüber der Bestimmung der Fluoreszenzintensität eine höhere Spezifität und Sensitivität aufweist und ihr somit überlegen ist. Es ist daher zu vermuten, dass basierend auf der GLK-Messung, feinere Unterschiede zwischen transplantierten Tieren und den Kontrolltieren nachweisbar waren. Daher könnte das hier entwickelte Verfahren vermutlich eingesetzt werden, um zu einem deutlich früheren Zeitpunkt den Erfolg der Hepatozytentransplantation nachzuweisen.

\subsubsection{Derzeitiger Status und Perspektiven des Optical Imaging}

Die nichtinvasive Echtzeitanalyse molekularer Prozesse im lebenden Organismus ist ein aktiver Bereich der Forschung (Pittet und Weissleder 2011). SPECT, PET und die MRT wurden erfolgreich auf In-Vivo-Studien zur Detektion von Pathologien und der Evaluation von Regenerationsprozessen angewandt. Insbesondere die MRT wurde erfolgreich zum Nachweis von magnetisch markierten Zellen mit hoher anatomischer Auflösung verwendet (Weissleder et al. 1997). Jedoch ist die Empfindlichkeit von MRT-basierten Nachweisverfahren begrenzt (Daldrup-Link et al. 2005). Wenn man zudem berücksichtigt, dass diese Methode zeitaufwändig und technisch sehr kompliziert ist, muss die Realisierbarkeit von langfristig angesetzten, repetitiven Längsschnittstudien in Frage gestellt werden (Lecchi et al. 2007). Im Gegensatz zu den oben erwähnten Verfahren stellt Optical Imaging eine komfortable Methode zur Überwachung molekularer Prozesse in Echtzeit zur Verfügung. Sie ist schnell, einfach zu handhaben und kann innerhalb kurzer Zeit auf InVivo-Studien angewendet werden. Anders als bei der SPECT und PET hat z.B. 
das NIR-Fluoreszenz basiertes Optical Imaging den Vorteil, dass keine radioaktiven Substanzen benötigt werden. Außerdem ist die Technologie hochsensibel, miniaturisierbar und potenziell mobil (Koenig et al. 2009). Wie wir im vorgelegten Dissertationsprojekt zeigen konnten, ist sie zudem bestens als nichtinvasives Verfahren für die Überwachung von In-Vivo-Prozessen geeignet, in unserem Fall für den Nachweis der Hepatozytenrepopulation im Ratten-Transplantationsmodell.

Die Arbeitsgruppe von Landis hat ebenfalls eine hoch entwickelte, nichtinvasive Methode zur Bestimmung der Leberrepopulation vorgestellt (Landis et al. 2006). Sie haben ein transgenes Maus-Transplantationsmodell verwendet, in dem Spenderhepatozyten über die Produktion von Phosphokreatin mit Hilfe der Magnetresonanz-Spektroskopie überwacht wurden. Der größte Vorteil hierbei bestand darin, dass keine weitere Substanz zur Darstellung der Zielzellen im Repopulationsprozess benötigt wurde. Jedoch ist bei diesem Ansatz für die Bildgebung die Expression eines transgenen Proteins notwendig. Im vorgestellten Transplantationsmodell wurden die Spenderhepatozyten und deren Abkömmlinge visualisiert, indem konjugierte Antikörper an ein spezifisches Oberflächenantigen auf den Spenderzellen banden. Obwohl hier Fremdproteine (Antikörper) den Versuchstieren appliziert werden mussten, ist das Bildgebungsverfahren mit Optix MX2 im klinischen Umfeld durchaus denkbar (Koenig et al. 2009). Allerdings hat dieses Verfahren eine Einschränkung: Die geringe Eindringtiefe sowie die starke Lichtstreuung im Gewebe gestalten die Translation des Optical Imaging für eine breite klinische Anwendung schwierig.

Ziel weiterer Forschung sollte es sein, die Stellung des Optical Imaging in der präklinischen Kleintierbildgebung auszubauen. Derzeit ist ein Forschungsschwerpunkt die Entwicklung von besseren Scannern mit einer höheren Eindringtiefe (Deliolanis et al. 2007), von tomographischen Fluoreszenzbildgebungssystemen (Zavattini et al. 2006) sowie von photoakustischer Bildgebung (Ntziachristos 2011). 


\subsubsection{Intravitale Bildgebung im klinischen Kontext}

Im vorgelegten Dissertationsprojekt wurde gezeigt, dass Optical-ImagingVerfahren, die nach der Injektion eines Antikörper-Farbstoff-Konjugates angewendet werden, das Potenzial besitzt die Leberrepopulation nach Hepatozytentransplantation im Ratten-Transplantationsmodell zuverlässig nachzuweisen und die Kinetik der Leberrepopulation sicher darzustellen.

Optical Imaging ist auf selektive und aktivierbare Sonden angewiesen, um Zielstrukturen, biologische Prozesse und Zellen in vivo zu visualisieren und zu quantifizieren. Die Kombination aus molekularen Informationen, die durch Sonden gewonnen werden, und anatomischen Daten aus anderen Bildgebungsmodalitäten wie z.B. CT oder MRT, führt zu einer erhöhten Funktionalität. Der Bedarf und das Interesse nach solchen Verfahren wird es ermöglichen das Optical Imaging in den kommenden Jahren auszuweiten.

Die Verwendung von optischen, fluoreszenfarbstoff-gekoppelten Sonden im nahen infraroten Bereich ermöglicht, wie bereits oben beschrieben (vgl. Kap. 1.3), eine verbesserte Penetration des Gewebes durch Photonen und minimiert Artefakte durch Autofluoreszenz des Gewebes. Mehrere Parameter beeinflussen überdies die Effektivität der Sonden in vivo. Zu diesen Faktoren gehören das SondenTargeting, die Sondenaktivierung, die Pharmakokinetik der jeweiligen Sonden, ihre Biokompatibilität und ihre Photophysik. Nur wenige Sonden sind von der Food and Drug Administration für die klinische Verwendung freigegeben worden (Hilderbrand und Weissleder 2010). Indocyanin-Grün hat eine niedrige Toxizität, vernachlässigbare Nebeneffekte und wird für die Überwachung der Herzfunktion, der Leberausscheidung und für Angiographien der Retina verwendet (Owens 1996). Methylen-Blau, ein Fluophor mit dunkelroter Emission, ist als Farbstoff für die Sektion des Wächterlymphknotens (East et al. 2009) und die Identifikation von Kolonpolypen verwendet worden (Kiesslich et al. 2003). Viele neue Fluophore mit dunkelroter oder NIR-Emission sind nun auf dem Markt erhältlich und wurden bezüglich der Helligkeit, der Löslichkeit und ihrer Photostabilität optimiert (Hilderbrand und Weissleder 2010). 
In der Onkologie findet der diagnostische, aber auch der therapeutische Einsatz von Sonden bereits Anwendung. Die Wirksamkeit dieser Substanzen, wie etwa Antikörper, Peptide und Liganden, ist ausführlich untersucht worden und sie werden heute routinemäßig im klinischen Alltag eingesetzt (Press und Lenz 2007). So werden etwa für Rezeptoren auf Oberflächen von Krebszellen hochspezifische monoklonale Antikörper als Kontrastmittel in der PET-Bildgebung verwendet, z.B. Pentetreotide in neuroendokrinen Tumoren (Jacobsson et al. 2012). Zur Behandlung sowohl von Brustkrebs (Salouti et al. 2011) und Prostatakrebs (Bouchelouche et al. 2011) im Rahmen der sogenannten Radioimmuntherapie, als auch von fortgeschrittenem kolorektalen Karzinomen zur Blockierung der Zellsignale finden Cetuximab (Garrett und Eng 2011) und Bevacizumab Anwendung (Bagnasco et al. 2012).

Die Zukunft des Optical Imaging für einen potenziellen klinischen Einsatz hängt nicht unwesentlich von der Entwicklung geeigneter Sonden ab. Weitere Innovationen des Sondendesigns von klinisch anwendbaren Fluoreszenzfarbstoffen und Bildgebungsverfahren sowie ein angepasstes Toxizitäts-Screening werden zur Entwicklung von Sonden mit höherer Sicherheit und Einsatzflexibilität führen. Aufgrund der geringen Eindringtiefe von Fluoreszenzfarbstoffen sowie der starken Lichtstreuung im Gewebe erscheinen nur bestimmte Körperregionen für die humane Applikation des Optical Imaging sinnvoll. In Frage kämen z.B. Läsionen in oder knapp unterhalb der Haut, endoskopisch zugängliche Regionen z.B. Darmpolypen oder intraoperativ im Rahmen von laparoskopischen Eingriffen (Kim 2009). Somit erscheint eine reine nichtinvasive Anwendung von Optical Imaging beim Menschen derzeit nicht möglich.

\subsection{Hepatozytentransplantation als Perspektive}

Aufgrund ihres hohen regenerativen Potenzials gehörte die Leber zu den Organen, die für einen zelltherapeutischen Ansatz in Erwägung gezogen werden können (Gilgenkrantz 2010). Im Laufe der vergangenen 10 Jahre konnten bereits beachtli- 
che Erfolge auf dem Gebiet der klinischen Hepatozytentransplantation erzielt werden (Dhawan et al. 2010). Viele Ergebnisse aus grundlegenden, tierexperimentellen Studien konnten im Vorfeld auf den Menschen übertragen werden und zur steten Verbesserung beitragen. Dennoch stellt die OLT weiterhin die Standardtherapieoption für das fortgeschrittene Stadium des akuten und chronischen Leberversagens dar (Hughes et al. 2012). Obwohl die Ergebnisse aus den klinischen Studien bis zum heutigen Tage ermutigend sind, konnte zu keinem Zeitpunkt eine komplette Korrektur metabolischer Entgleisungen der Leber erzielt werden (Soltys et al. 2010). Es gibt daher noch viel Bedarf für Veränderungen und Verbesserungen auf dem Gebiet der zellulären Therapie in der Leber.

Heute sind die Eigenschaften und das Potenzial transplantierter Hepatozyten gut erforscht. Sie wurden erfolgreich zur Überbrückung der Zeit bis zu einer Organverpflanzung eingesetzt (Bilir et al. 2000). Auch sind sie in der Lage die Mortalität bei akutem Leberversagen signifikant zu senken (Ott et al. 2000) und sie sind einsetzbar für die Therapie von metabolischen Leberfunktionsstörungen (Puppi et al. 2008).

Die Hepatozytentransplantation weist gegenüber der Ganzorgantransplantation mehrere entscheidende Vorteile auf. Im Gegensatz zur OLT können aus einem Leberorgan gleich mehrere Empfänger mit Zellen versorgt werden, weil nur ein Bruchteil des Organs für eine Transplantation notwendig ist. Darüber hinaus ist eine Zelltransplantation logistisch weniger aufwendig und stellt einen weniger invasiven Eingriff für den Patienten dar (Markus und Becker 1999). Dadurch minimieren sich sowohl die Risiken als auch die Kosten einer solchen Therapie in erheblichem Maße (Mazaris et al. 2005). Zudem erfordert das geringe immunogene Potenzial reiner Zellen geringere Mengen immunsuppressiver Medikation gegenüber der OLT (Allen und Soriano 2001). Um bessere Ergebnisse beim Langzeitüberleben transplantierter Hepatozyten im Empfängerorganismus zu erzielen, wurde kürzlich ein Ansatz vorgestellt, bei dem Hepatozyten vor der Transplantation aufbereitet und entkapselt werden, eine sogenannte Immunoisolation (Mei et al. 2009). Die so hergestellten Hepatozyten-Microbeads weisen kein immunogenes Potenzial auf, so dass theoretisch auf eine Immunsuppression verzichtet werden 
könnte. In ersten In-Vitro-Versuchen konnte zudem gezeigt werden, dass in einer Lösung aus Aszites, welches von Kindern mit einer Leberinsuffizienz stammt, herangezüchtete Microbeads in der Lage waren, über eine Dauer von zwei Wochen die Albumin- und Faktor-VII-Produktion aufrechtzuerhalten (Hughes et al. 2012). In den letzten Jahren wurden erhebliche Fortschritte im Umgang mit Hepatozyten und den Techniken der Hepatozytentransplantation erzielt, die einen regelhaften klinischen Einsatz effizienter und sicherer gestalten. Die Zelltherapie mit Hepatozyten ist längst nicht mehr individuellen Heilversuchen vorbehalten. Seit 2008 wird in Deutschland und in weiteren europäischen Ländern die SELICA (Safety and Efficacy of Liver Cell Application)-Studie zur Leberzelltherapie bei Neugeborenen mit Harnstoffzyklusdefekten durchgeführt, inzwischen als Phase-V-Studie. Zudem wird seit 2010 im Rahmen der SELICA-III-Studie die Leberzelltherapie auch in den USA und seit 2011 in Kanada realisiert (Meyburg und Hoffmann 2010).

Trotz der offensichtlichen Vorteile einer zellulären Therapie bei Lebererkrankungen müssen einige fundamentale Fragen beantwortet werden, bevor eine standardisierte klinische Applikation durchgeführt werden kann, z.B. über die fehlende Vorhersagbarkeit für ein erfolgreiches Engraftment der Hepatozyten, ihrer Funktionalität und Expansion nach Transplantation oder über das offensichtliche Langzeitversagen der Zellen in den bislang durchgeführten klinischen Versuchsreihen (Puppi et al. 2011). Daher wird die Nachfrage nach einer nicht-invasiven Methode der Langzeituntersuchung und qualitativen Evaluation des Spenderzell-Engraftment, des Überlebens und der Proliferation von zentraler Bedeutung für die Verbesserung von experimentellen und ebenso von klinischen Strategien sein. 


\section{Zusammenfassung}

\section{Hintergrund}

Die Hepatozytentransplantation wird als vielversprechende Behandlungsoption für Patienten mit angeborenen Stoffwechselerkrankungen oder mit akutem Leberversagen betrachtet und könnte als Alternative zur orthotopen Lebertransplantation dienen. Aktuell gibt es noch kein etabliertes bildgebendes Verfahren, um das Schicksal der transplantierten Hepatozyten intravital zu verfolgen. Optical Imaging ist ein Bildgebungsverfahren für die Darstellung von in vivo Prozessen in präklinischen Tiermodellen. Ziel der hier vorgelegten Dissertation war es zu evaluieren, ob mittels intravitaler Bildgebung mit dem Optical-Imaging-System Optix MX2 (ART, Kanada) unter Einsatz von Fluoreszenzfarbstoff-gekoppelten Antikörpern transplantierte Hepatozyten im DPPIV-Fischer-344-Rattenmodell detektiert und quantifiziert werden können. Ferner wurde untersucht, ob die Wachstumskinetik der transplantierten Zellen in der Empfängerleber im zeitlichen Verlauf dargestellt werden kann.

\section{Methode}

Zur Vorbereitung des Transplantationsprozesses und zur Optimierung der Bedingungen für die Repopulation wurden Empfängertiere (DPPIV-defiziente Ratten) mit 25 Gy Einzeldosis-Bestrahlung der rechten Leberlappen vorbehandelt. Vier Tage später erfolgte eine 30-prozentige Leberteilresektion (Entfernung des linksanterioren Leberlappens). Anschließend wurden DPPIV-positive Spenderhepatozyten in das Milzparenchym der Empfängertiere implantiert, von wo aus deren Redistribution über das Pfortadersystem in die Empfängerleber erfolgte. In einem ersten Schritt wurden zunächst die optimalen Aufnahmebedingungen und Geräteeinstellungen sowie der ideale Zeitpunkt für die Messung bestimmt. AnschlieBend wurde die Repopulation der Leber durch die Spenderzellen an drei exemplarischen Tieren nach intravenöser Applikation von Cy5.5-gekoppelten DPPIVAntikörpern mit Hilfe des Optix-MX2-Systems nach 1, 4 und 11 Tagen sowie 4, 8, 
12 und 16 Wochen in vivo untersucht. Als Kontrolle dienten erstens nicht transplantierte Tiere, die das spezifische und transplantierte Tiere, zweitens Tiere, die ein unspezifisches Antikörper-Farbstoff-Konjugat (Cy5.5 gekoppelt an $\lg G$ ) erhalten hatten.

Um das Ausmaß der Neubesiedelung in der Leberregion mit der gemessenen Fluoreszenzstrahlung korrelieren zu können, wurde für die Auswertung die Gesamtleuchtkraft (GLK) definiert. Sie ist direkt proportional zur Gesamtheit der von der Leber kommenden Fluoreszenzstrahlung und somit ein Maß für die relative Menge des gebundenen Antikörper-Farbstoffkonjugates, ausgehend von einer konstanten Bindungsrate zwischen Antikörper und untersuchten Zellen.

Die Ergebnisse des Optical Imaging wurden anschließend nach 16-wöchiger Repopulationszeit mit Immunofluoreszenz-Ko-Lokalisationsstudien an Kryoschnitten validiert.

\section{Ergebnisse}

Die Vorversuche ergaben, dass der optimale Messzeitpunkt der Fluoreszenzintensität bei etwa 7 bis 10 Stunden nach Antikörper-Applikation lag.

Die Anhand der Fluoreszenzintensität ermittelten Wachstumskurven der Spenderhepatozyten zeigten zunächst einen schnellen Anstieg und erreichten im Verlauf des Beobachtungszeitraums von 12-16 Wochen eine Plateauphase. Die gemessenen Signale in der Leberregion waren spezifisch für die Antikörperbindung und waren ein Indiz für die Repopulation der Empfängerleber durch die transplantierten Hepatozyten. Im Gegensatz dazu konnten bei beiden Kontrolltieren keine spezifischen Signale festgestellt werden.

Im Vergleich zur mittleren Fluoreszenzintensität zeigte die GLK-Messung eine deutlich geringere Variabilität innerhalb der transplantierten Tiere und einen größeren Unterschied (Messabstand) zu den Kontrolltieren. Folglich war die Auswertung basierend auf der GLK in Hinblick auf Sensitivität und Spezifität überlegen.

Die Ergebnisse des Optical Imaging korrelierten in hohem Maße mit denen aus den Immunofluoreszenz-Ko-Lokalisationsstudien. Diese zeigten, dass sich DPPIVpositive Zellverbände aus den Portalfeldern entwickelten, wo die Spenderzellenin- 
tegration initial erfolgt war. Nach 16 Wochen fanden sich große Cluster aus Spenderhepatozyten und deren Abkömmlinge mit ca. 100-500 Zellen im Durchmesser.

\section{Schlussfolgerung}

Das Optix-MX2-System ist eine zuverlässige Methode zur in-vivo-Darstellung und Quantifizierung der Leberrepopulation im experimentellen Hepatozytentransplantationsmodell. Das Verfahren ist im zeitlichen Verlauf mehrfach anwendbar und ermöglicht somit die Beurteilung der longitudinalen Wachstumskinetik der transplantierten Zellen in einem Versuchstier und den Vergleich der Repopulation mehrerer Tiere untereinander. 


\section{Tabellen- und Abbildungsverzeichnis}

\section{Tabellenverzeichnis}

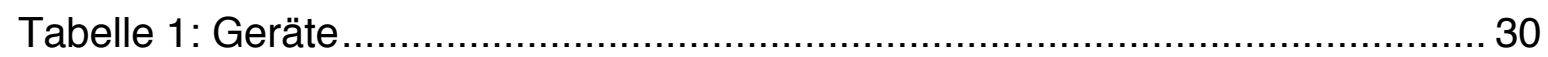

Tabelle 2: Verwendete Primärantikörper ....................................................... 31

Tabelle 3: Verwendete Sekundärantikörper ………........................................ 31

Tabelle 4: Verwendete Versuchstiere ………............................................ 33

Tabelle 5: Stammlösungen für die Perfusionslösung ………………………......... 37

Tabelle 6: Herstellung der Perfusionslösung................................................... 38

Tabelle 7: Cy5.5-gekoppelte Antikörper ....................................................... 44

\section{Abbildungsverzeichnis}

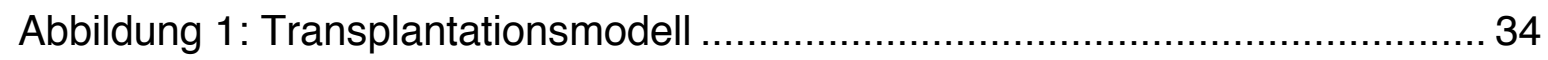

Abbildung 2: Färbeprotokoll von Cx32 und DPPIV an Kryoschnitten................... 43

Abbildung 3: Das Optix-MX2-System ............................................................. 46

Abbildung 4: Prinzip der Fluoreszenzfarbstoffmessung ........................................ 46

Abbildung 5: Absorptions- und Emissionsspektrum des Optix MX2 …............... 47

Abbildung 6: Charakterisierung der Spenderhepatozyten ................................... 51

Abbildung 7: Evaluation der Messbedingungen .............................................. 52

Abbildung 8: Determinierung des optimalen Messzeitpunktes............................ 53

Abbildung 9: Fluoreszenzintensität transplantierter Tiere über 16 Wochen .......... 55

Abbildung 10: Kinetischer Verlauf der Leberrepopulation im Optical Imaging ...... 56

Abbildung 11: Fluoreszenzintensitäten über dem Leberareal 12 Wochen nach

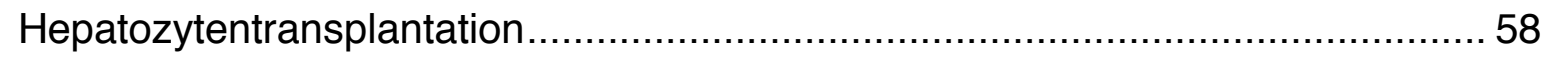

Abbildung 12: Vergleich der GLK mit der mittleren Fluoreszenzintensität ............ 59

Abbildung 13: Immunfluoreszenzfärbung der Empfängerleber nach 16 Wochen . 61

Abbildung 14: Kinetik der Repopulation ........................................................ 62 


\section{Literaturverzeichnis}

Agarwal S, Holton KL und Lanza R (2008): Efficient differentiation of functional hepatocytes from human embryonic stem cells. Stem Cells $\underline{26}, 1117-1127$

Akers W, Lesage F, Holten D und Achilefu S (2007): In vivo resolution of multiexponential decays of multiple near-infrared molecular probes by fluorescence lifetime-gated whole-body time-resolved diffuse optical imaging. Mol Imaging $\underline{6}$, 237246

Allen KJ und Soriano HE (2001): Liver cell transplantation: the road to clinical application. J Lab Clin Med 138, 298-312

Baccarani U, Sanna A, Cariani A, Sainz-Barriga M, Adani GL, Zambito AM, Piccolo G, Risaliti A, Nanni-Costa A, Ridolfi L (2003): Isolation of human hepatocytes from livers rejected for liver transplantation on a national basis: results of a 2-year experience. Liver Transpl 9, 506-512

Bagnasco L, Piras D, Parodi S, Bauer I, Zoppoli G, Patrone F und Ballestrero A (2012): Role of angiogenesis inhibitors in colorectal cancer: sensitive and insensitive tumors. Curr Cancer Drug Targets 12 , 303-315

Banas A, Teratani T, Yamamoto Y, Tokuhara M, Takeshita F, Osaki M, Kawamata M, Kato T, Okochi H und Ochiya T (2008): IFATS collection: in vivo therapeutic potential of human adipose tissue mesenchymal stem cells after transplantation into mice with liver injury. Stem Cells $\underline{26}, 2705-2712$

Berry MN und Friend DS (1969): High-yield preparation of isolated rat liver parenchymal cells: a biochemical and fine structural study. J Cell Biol $\underline{43}, 506-520$

Bilir BM, Guinette D, Karrer F, Kumpe DA, Krysl J, Stephens J, McGavran L, Ostrowska A und Durham J (2000): Hepatocyte transplantation in acute liver failure. Liver Transpl $\underline{6}$, 32-40

Bouchelouche K, Tagawa ST, Goldsmith SJ, Turkbey B, Capala J und Choyke P (2011): PET/CT Imaging and Radioimmunotherapy of Prostate Cancer. Semin Nucl Med 41, 29-44 
Boumaza S, Arribas SM, Osborne-Pellegrin M, McGrath JC, Laurent S, Lacolley P und Challande P (2001): Fenestrations of the carotid internal elastic lamina and structural adaptation in stroke-prone spontaneously hypertensive rats. Hypertension 37, 1101-1107

Cai J, Ito M, Nagata H, Westerman KA, Lafleur D, Chowdhury JR, Leboulch $\mathrm{P}$ und Fox IJ (2002): Treatment of liver failure in rats with end-stage cirrhosis by transplantation of immortalized hepatocytes. Hepatology 36, 386-394

Cheng Z, Wu Y, Xiong Z, Gambhir SS und Chen X (2005): Near-infrared fluorescent RGD peptides for optical imaging of integrin alphavbeta3 expression in living mice. Bioconjug Chem 16, 1433-1441

Choy G, O'Connor S, Diehn FE, Costouros N, Alexander HR, Choyke P und Libutti SK (2003): Comparison of noninvasive fluorescent and bioluminescent small animal optical imaging. BioTechniques $\underline{35}$, 1022-1026, 1028-1030-1022-1026, 1028-1030

Christiansen H, Koenig S, Krause P, Hermann R, Rave-Frank M, Proehl T, Becker $\mathrm{H}$, Hess $\mathrm{C}$ und Schmidberger $\mathrm{H}$ (2006): External-beam radiotherapy as preparative regimen for hepatocyte transplantation after partial hepatectomy. Int $\mathrm{J}$ Radiat Oncol Biol Phys 65, 509-516

Daldrup-Link HE, Meier R, Rudelius M, Piontek G, Piert M, Metz S, Settles M, Uherek C, Wels W, Schlegel J (2005): In vivo tracking of genetically engineered, anti-HER2/neu directed natural killer cells to HER2/neu positive mammary tumors with magnetic resonance imaging. Eur Radiol 15, 4-13

Dang NH, Torimoto Y, Sugita K, Daley JF, Schow P, Prado C, Schlossman SF und Morimoto C (1990): Cell surface modulation of CD26 by anti-1F7 monoclonal antibody. Analysis of surface expression and human $\mathrm{T}$ cell activation. $\mathrm{J}$ Immunol $\underline{145}, 3963-3971$

Deliolanis N, Lasser T, Hyde D, Soubret A, Ripoll J und Ntziachristos V (2007): Free-space fluorescence molecular tomography utilizing 360 degrees geometry projections. Opt Lett 32, 382-384

Dhawan A, Puppi J, Hughes RD und Mitry RR (2010): Human hepatocyte transplantation: current experience and future challenges. Nat Rev Gastroenterol Hepatol. ㄱ, 288-298 
East JM, Valentine CS, Kanchev E und Blake GO (2009): Sentinel lymph node biopsy for breast cancer using methylene blue dye manifests a short learning curve among experienced surgeons: a prospective tabular cumulative sum (CUSUM) analysis. BMC Surg $\underline{9}, 2$

Fisher RA und Mas VR (2009): Cell transplant techniques: engraftment detection of cells. Methods Mol Biol 481, 97-105

Fitzpatrick E, Mitry RR und Dhawan A (2009): Human hepatocyte transplantation: state of the art. J Intern Med 266, 339-357

Fleischer B (1994): CD26: a surface protease involved in T-cell activation. Immunology Today 15, 180-184

Fox IJ, Chowdhury JR, Kaufman SS, Goertzen TC, Chowdhury NR, Warkentin PI, Dorko K, Sauter BV und Strom SC (1998): Treatment of the Crigler-Najjar syndrome type I with hepatocyte transplantation. N Engl J Med 338, 1422-1426

Fujioka H, Hunt PJ, Rozga J, Wu GD, Cramer DV, Demetriou AA und Moscioni AD (1994): Carboxyfluorescein (CFSE) labelling of hepatocytes for short-term localization following intraportal transplantation. Cell Transplant $\underline{3}, 397-408$

Garcea G und Maddern GJ (2009): Liver failure after major hepatic resection. J Hepatobiliary Pancreat Sci 16, 145-155

Garrett CR und Eng C (2011): Cetuximab in the treatment of patients with colorectal cancer. Expert Opin Biol Ther 11, 937-949

Gilgenkrantz H (2010): Rodent models of liver repopulation. Methods Mol Biol 640 , 475-490

Gossrau R (1981): Investigation of proteinases in the digestive tract using 4methoxy-2-naphthylamine (MNA) substrates. J Histochem Cytochem 29, 464-480

Grompe M (2001): Liver repopulation for the treatment of metabolic diseases. J Inherited Metab Dis 24, 231-244 
Grossman M, Raper SE, Kozarsky K, Stein EA, Engelhardt JF, Muller D, Lupien PJ und Wilson JM (1994): Successful ex vivo gene therapy directed to liver in a patient with familial hypercholesterolaemia. Nat Gen $\underline{6}$, 335-341

Groth CG, Arborgh B, Björkén C, Sundberg B und Lundgren G (1977): Correction of hyperbilirubinemia in the glucuronyltransferase-deficient rat by intraportal hepatocyte transplantation. Transplant Proc $\underline{9}$, 313-316

Gupta S, Aragona E, Vemuru RP, Bhargava KK, Burk RD und Chowdhury JR (1991): Permanent engraftment and function of hepatocytes delivered to the liver: implications for gene therapy and liver repopulation. Hepatology 14, 144-149

Gupta S, Chowdhury NR, Jagtiani R, Gustin K, Aragona E, Shafritz DA, Chowdhury JR und Burk RD (1990): A novel system for transplantation of isolated hepatocytes utilizing HBsAg-producing transgenic donor cells. Transplantation 50, 472-475

Gupta S, Lee CD, Vemuru RP und Bhargava KK (1994): 111Indium labeling of hepatocytes for analysis of short-term biodistribution of transplanted cells. Hepatology 19, 750-757

Gupta S, Rajvanshi P und Lee CD (1995): Integration of transplanted hepatocytes into host liver plates demonstrated with dipeptidyl peptidase IV-deficient rats. Proc Natl Acad Sci USA 92, 5860-5864

Habibullah CM, Syed IH, Qamar A und Taher-Uz Z (1994): Human fetal hepatocyte transplantation in patients with fulminant hepatic failure. Transplantation $\underline{58}$, 951952

Hilderbrand SA und Weissleder R (2010): Near-infrared fluorescence: application to in vivo molecular imaging. Curr Opin in Chem Biol 14, 71-79

Hopsu-Havu VK und Glenner GG (1966): A new dipeptide naphthylamidase hydrolyzing glycyl-prolyl-beta-naphthylamide. Histochemie $\underline{7}, 197-201$

Howard RB, Christensen AK, Gibbs FA und Pesch LA (1967): The enzymatic preparation of isolated intact parenchymal cells from rat liver. J Cell Biol 35, 675-684

Huang G, Diakur J, Xu Z und Wiebe LI (2008): Asialoglycoprotein receptor-targeted superparamagnetic iron oxide nanoparticles. Inter J Pharm 360, 197-203 
Hughes RD, Mitry RR und Dhawan A (2012): Current status of hepatocyte transplantation. Transplantation 93, 342-347

Jacobsson H, Larsson P, Jonsson C, Jussing E und Gryback P (2012): Normal Uptake of 68Ga-DOTA-TOC by the Pancreas Uncinate Process Mimicking Malignancy at Somatostatin Receptor PET. Clin Nucl Med 37, 362-365

Joseph B, Kumaran V, Berishvili E, Bhargava KK, Palestro CJ und Gupta S (2006): Monocrotaline promotes transplanted cell engraftment and advances liver repopulation in rats via liver conditioning. Hepatology $\underline{44}, 1411-1420$

Ke S, Wen X, Gurfinkel M, Charnsangavej C, Wallace S, Sevick-Muraca EM und Li C (2003): Near-infrared optical imaging of epidermal growth factor receptor in breast cancer xenografts. Cancer Res $\underline{63}, 7870-7875$

Keren S, Gheysens O, Levin CS und Gambhir SS (2008): A comparison between a time domain and continuous wave small animal optical imaging system. IEEE Trans Med Imaging 27, 58-63

Kiesslich R, Fritsch J, Holtmann M, Koehler HH, Stolte M, Kanzler S, Nafe B, Jung M, Galle PR und Neurath MF (2003): Methylene blue-aided chromoendoscopy for the detection of intraepithelial neoplasia and colon cancer in ulcerative colitis. Gastroenterology 124, 880-888

Kim HL (2009): Optical imaging in oncology. Urol Oncol 27, 298-300

Koenig S, Krause P, Hosseini AS, Dullin C, Rave-Fraenk M, Kimmina S, Entwistle AL, Hermann RM, Hess CF, Becker H (2009): Noninvasive imaging of liver repopulation following hepatocyte transplantation. Cell Transplant $\underline{18}, 69-78$

Koenig S, Stoesser C, Krause P, Becker H und Markus PM (2005): Liver repopulation after hepatocellular transplantation: integration and interaction of transplanted hepatocytes in the host. Cell transplantation 14, 31-40

Koyama Y, Barrett T, Hama Y, Ravizzini G, Choyke PL und Kobayashi H (2007): In vivo molecular imaging to diagnose and subtype tumors through receptor-targeted optically labeled monoclonal antibodies. Neoplasia 9, 1021-1029 
Lagasse E, Connors H, Al-Dhalimy M, Reitsma M, Dohse M, Osborne L, Wang X, Finegold M, Weissman IL und Grompe M (2000): Purified hematopoietic stem cells can differentiate into hepatocytes in vivo. Nat Med $\underline{6}, 1229-1234$

Landis CS, Yamanouchi K, Zhou H, Mohan S, Roy-Chowdhury N, Shafritz DA, Koretsky A, Roy-Chowdhury J, Hetherington HP und Guha C (2006): Noninvasive evaluation of liver repopulation by transplanted hepatocytes using 31P MRS imaging in mice. Hepatology 44, 1250-1258

Le Blanc K, Tammik C, Rosendahl K, Zetterberg E und Ringden O (2003): HLA expression and immunologic properties of differentiated and undifferentiated mesenchymal stem cells. Exp Hematol 31, 890-896

Lecchi M, Ottobrini L, Martelli C, Del Sole A und Lucignani G (2007): Instrumentation and probes for molecular and cellular imaging. $Q \mathrm{~J}$ Nucl Med Mol Imaging 51, 111126

Lee WK, Bell J, Kilpatrick E, Hayes M, Lindop GB und Dominiczak MH (1993): Collagen-linked fluorescence in human atherosclerotic plaques. Atherosclerosis $\underline{98}$, 219-227

Leevy WM, Gammon ST, Jiang H, Johnson JR, Maxwell DJ, Jackson EN, Marquez M, Piwnica-Worms D und Smith BD (2006): Optical imaging of bacterial infection in living mice using a fluorescent near-infrared molecular probe. J Am Chem Soc 128, 16476-16477

Luker GD und Luker KE (2008): Optical imaging: current applications and future directions. J Nucl Med 49, 1-4

Lysy PA, Campard D, Smets F, Najimi M und Sokal EM (2008): Stem cells for liver tissue repair: current knowledge and perspectives. World J Gastroenterol 14, 864875

Markus PM und Becker H (1999): Hepatocellular transplantation--from the beginning to clinical application. Chirurg $\underline{70}, 162-168$

Markus PM, Krause P, Fayyazi A, Honnicke K und Becker H (1997): Allogeneic hepatocyte transplantation using FK 506. Cell Transplant $\underline{6}, 77-83$ 
Matas AJ, Sutherland DE, Steffes MW, Mauer SM, Sowe A, Simmons RL und Najarian JS (1976): Hepatocellular transplantation for metabolic deficiencies: decrease of plasms bilirubin in Gunn rats. Science 192, 892-894

Mazaris EM, Roussos CT und Papalois VE (2005): Hepatocyte transplantation: a review of worldwide clinical developments and experiences. Exp Clin Transplant $\underline{3}$, 306-315

Mei J, Sgroi A, Mai G, Baertschiger R, Gonelle-Gispert C, Serre-Beinier V, Morel P und Buhler LH (2009): Improved survival of fulminant liver failure by transplantation of microencapsulated cryopreserved porcine hepatocytes in mice. Cell Transplant $18,101-110$

Meyburg $\mathrm{J}$ und Hoffmann GF (2010): Liver, liver cell and stem cell transplantation for the treatment of urea cycle defects. Mol Genet Metab 1, S77-83

Mito M, Kusano M und Kawaura $Y$ (1992): Hepatocyte transplantation in man. Transplant Proc 24, 3052-3053

Moore A, Medarova Z, Potthast A und Dai G (2004): In vivo targeting of underglycosylated MUC-1 tumor antigen using a multimodal imaging probe. Cancer Res 64, 1821-1827

Morimoto C und Schlossman SF (1998): The structure and function of CD26 in the T-cell immune response. Immunol Rev $\underline{161}, 55-70$

Morimoto C, Torimoto Y, Levinson G, Rudd CE, Schrieber M, Dang NH, Letvin NL und Schlossman SF (1989): 1F7, a novel cell surface molecule, involved in helper function of CD4 cells. J Immunol 143, 3430-3439

Muller J, Wunder A, Licha K (2013): Optical imaging. Recent Results. Cancer Res. 187, 221-246

Muraca M, Gerunda G, Neri D, Vilei MT, Granato A, Feltracco P, Meroni M, Giron G und Burlina $A B$ (2002): Hepatocyte transplantation as a treatment for glycogen storage disease type 1a. Lancet 359, 317-318 
Napp J, Dullin C, Muller F, Uhland K, Petri JB, van de Locht A, Steinmetzer T und Alves $F$ (2010): Time-domain in vivo near infrared fluorescence imaging for evaluation of matriptase as a potential target for the development of novel, inhibitorbased tumor therapies. Int J Cancer 127, 1958-1974

Nikolaou K, Cyran CC, Lauber K, Reiser MF und Clevert DA (2012): [Preclinical imaging in animal models of radiation therapy]. Radiologe 52, 252-262

Nonome K, Li XK, Takahara T, Kitazawa Y, Funeshima N, Yata Y, Xue F, Kanayama M, Shinno E, Kuwae C (2005): Human umbilical cord blood-derived cells differentiate into hepatocyte-like cells in the Fas-mediated liver injury model. Am $\mathrm{J}$ Physiol Gastrointest Liver Physiol 289, G1091-1099

Ntziachristos V (2011): Clinical translation of optical and optoacoustic imaging. Philos Transact A Math Phys Eng Sci 369, 4666-4678

Otsuka Y, Duffy JP, Saab S, Farmer DG, Ghobrial RM, Hiatt JR und Busuttil RW (2007): Postresection hepatic failure: successful treatment with liver transplantation. Liver Transpl 13, 672-679

Ott M, Schmidt HH, Cichon G und Manns MP (2000): Emerging therapies in hepatology: liver-directed gene transfer and hepatocyte transplantation. Cells Tissues Organs 167, 81-87

Owens SL (1996): Indocyanine green angiography. Br J Ophthalmol 80, 263-266

Papalois A, Arkadopoulos N, Pataryas TH, Papadimitriou J und Golematis B (1994): Combined hepatocyte-islet transplantation: an allograft model. Transpl Int $\underline{7}$, Suppl 1, S432-435

Pittet MJ und Weissleder R (2011): Intravital imaging. Cell 147, 983-991

Plebani M und Basso D (2007): Non-invasive assessment of chronic liver and gastric diseases. Clin Chim Acta 381, 39-49

Ponder KP, Gupta S, Leland F, Darlington G, Finegold M, DeMayo J, Ledley FD, Chowdhury JR und Woo SL (1991): Mouse hepatocytes migrate to liver parenchyma and function indefinitely after intrasplenic transplantation. Proc Natl Acad Sci USA 88, 1217-1221 
Press MF und Lenz HJ (2007): EGFR, HER2 and VEGF pathways: validated targets for cancer treatment. Drugs $\underline{67}, 2045-2075$

Puppi J, Strom SC, Hughes RD, Bansal S, Castell JV, Dagher I, Ellis EC, Nowak G, Ericzon BG, Fox IJ (2011): Improving the Techniques for Human Hepatocyte Transplantation: Report from a Consensus Meeting in London. Cell Transplant

Puppi J, Tan N, Mitry RR, Hughes RD, Lehec S, Mieli-Vergani G, Karani J, Champion MP, Heaton N, Mohamed R (2008): Hepatocyte transplantation followed by auxiliary liver transplantation--a novel treatment for ornithine transcarbamylase deficiency. Am J Transplant $\underline{8}, 452-457$

Raghuveer TS, Garg U und Graf WD (2006): Inborn errors of metabolism in infancy and early childhood: an update. Am Fam Physician 73, 1981-1990

Rajvanshi P, Kerr A, Bhargava KK, Burk RD und Gupta S (1996): Studies of liver repopulation using the dipeptidyl peptidase IV-deficient rat and other rodent recipients: cell size and structure relationships regulate capacity for increased transplanted hepatocyte mass in the liver lobule. Hepatology 23, 482-496

Räty JK, Liimatainen T, Unelma Kaikkonen M, Gröhn O, Airenne KJ, Jumani Airenne K und Ylä-Herttuala S (2007): Non-invasive Imaging in Gene Therapy. Mol Ther 15, 1579-1586

Ray P, Bauer E, lyer M, Barrio JR, Satyamurthy N, Phelps ME, Herschman HR und Gambhir SS (2001): Monitoring gene therapy with reporter gene imaging. Semin Nucl Med 31, 312-320

Rhim JA, Sandgren EP, Degen JL, Palmiter RD und Brinster RL (1994): Replacement of diseased mouse liver by hepatic cell transplantation. Science 263, 1149-1152

Rugstad HE, Robinson SH, Yannoni C und Tashjian AH (1970): Transfer of bilirubin uridine diphosphate-glucuronyltransferase to enzyme-deficient rats. Science 170 , 553-555

Salouti M, Babaei MH, Rajabi H und Rasaee M (2011): Preparation and biological evaluation of (177)Lu conjugated PR81 for radioimmunotherapy of breast cancer. Nucl Med Biol 38, 849-855 
Schmelzer E, Zhang L, Bruce A, Wauthier E, Ludlow J, Yao HL, Moss N, Melhem A, McClelland R, Turner W (2007): Human hepatic stem cells from fetal and postnatal donors. J Exp Med 204, 1973-1987

Seglen PO (1976): Preparation of isolated rat liver cells. Methods Cell Biol 13, 29-83

Seppen J, Filali EE und Elferink RO (2009): Small animal models of hepatocyte transplantation. Methods Mol Biol 481, 75-82

Serra MP, Marongiu F, Sini M und Laconi E (2012): Hepatocyte senescence in vivo following preconditioning for liver repopulation. Hepatology $\underline{56}, 760-768$

Singh S und Watt KD (2012): Long-term medical management of the liver transplant recipient: what the primary care physician needs to know. Mayo Clin Proc 87, 779790

Smets F, Najimi M und Sokal EM (2008): Cell transplantation in the treatment of liver diseases. Pediatr Transplant 12, 6-13

Sokal EM (2006): Liver transplantation for inborn errors of liver metabolism. J Inherit Metab Dis 29, 426-430

Solomon M, Liu Y, Berezin MY und Achilefu S (2011): Optical imaging in cancer research: basic principles, tumor detection, and therapeutic monitoring. Medical Princ Pract 20, 397-415

Soltys KA, Soto-Gutierrez A, Nagaya M, Baskin KM, Deutsch M, Ito R, Shneider BL, Squires R, Vockley J, Guha C (2010): Barriers to the successful treatment of liver disease by hepatocyte transplantation. J Hepatol 53, 769-774

Starzl TE, Marchioro TL und Faris TD (1966): Liver transplantation. Ann Intern Med $\underline{64}, 473-477$

Stephenne X, Najimi M, Sibille C, Nassogne MC, Smets F und Sokal EM (2006): Sustained engraftment and tissue enzyme activity after liver cell transplantation for argininosuccinate lyase deficiency. Gastroenterology 130, 1317-1323

Strom SC, Chowdhury JR und Fox IJ (1999): Hepatocyte transplantation for the treatment of human disease. Semin Liver Dis 19, 39-48 
Strom SC, Fisher RA, Thompson MT, Sanyal AJ, Cole PE, Ham JM und Posner MP (1997): Hepatocyte transplantation as a bridge to orthotopic liver transplantation in terminal liver failure. Transplantation $\underline{63}, 559-569$

Tanaka T, Camerini D, Seed B, Torimoto Y, Dang NH, Kameoka J, Dahlberg HN, Schlossman SF und Morimoto C (1992): Cloning and functional expression of the $T$ cell activation antigen CD26. Journal Immunol 149, 481-486

Thompson NL, Hixson DC, Callanan H, Panzica M, Flanagan D, Faris RA, Hong WJ, Hartel-Schenk S und Doyle D (1991): A Fischer rat substrain deficient in dipeptidyl peptidase IV activity makes normal steady-state RNA levels and an altered protein. Use as a liver-cell transplantation model. Biochem J 273 ( Pt 3), 497-502

Watt KD, Pedersen RA, Kremers WK, Heimbach JK und Charlton MR (2010): Evolution of causes and risk factors for mortality post-liver transplant: results of the NIDDK long-term follow-up study. Am J Transplant 10, 1420-1427

Weber A, Groyer-Picard MT, Franco D und Dagher I (2009): Hepatocyte transplantation in animal models. Liver Transplant 15, 7-14

Weissleder R, Cheng HC, Bogdanova A und Bogdanov A, Jr. (1997): Magnetically labeled cells can be detected by MR imaging. JMRI $\underline{7}, 258-263$

Weissleder R und Pittet MJ (2008): Imaging in the era of molecular oncology. Nature 452, 580-589

Yamanouchi K, Zhou H, Roy-Chowdhury N, Macaluso F, Liu L, Yamamoto T, Yannam GR, Enke C, Solberg TD, Adelson AB (2009): Hepatic irradiation augments engraftment of donor cells following hepatocyte transplantation. Hepatology $\underline{49}, 258-$ 267

Yuan RH, Ogawa A, Ogawa E, Neufeld D, Zhu L und Shafritz DA (2003): p27Kip1 inactivation provides a proliferative advantage to transplanted hepatocytes in DPPIV/Rag2 double knockout mice after repeated host liver injury. Cell Transplant 12, 907-919

Zavattini G, Vecchi S, Mitchell G, Weisser U, Leahy RM, Pichler BJ, Smith DJ und Cherry SR (2006): A hyperspectral fluorescence system for 3D in vivo optical imaging. Phys Med Biol 51, 2029-2043 
Die Ergebnisse aus der vorgelegten Dissertation wurden in der folgenden Publikation veröffentlicht:

Noninvasive imaging of liver repopulation following hepatocyte transplantation.

Koenig S, Krause P, Seif Amir Hosseini A, Dullin C, Rave-Fraenk M, Kimmina S, Entwistle AL, Hermann RM, Hess CF, Becker H, Christiansen H. / Cell Transplant. 200 


\section{Danksagung}

Viele Kollegen, Freunde und Experten haben mich auf unterschiedlichste Art unterstützt und zum Gelingen dieses Dissertationsprojekts beigetragen. Ihnen gilt mein aufrichtiger Dank.

Zuallererst danke ich Prof. Dr. med. Heinz Becker, dem ehemaligen Leiter der Abteilung Allgemein- und Viszeralchirurgie. Unter seiner Leitung ermöglichte er mir das experimentelle Arbeiten und stellte mir ausgezeichnete Arbeitsbedingungen zur Verfügung.

Ganz besonders danke ich PD. Dr. med. Sarah König und Prof. Dr. med. Hans Christiansen für die Umsetzung meines interessanten und hochaktuellen Themas, für das angenehme Arbeitsklima und die schnelle Integration in deren Arbeitsgruppen. Die kritische und immer prompte Durchsicht dieser Arbeit und ihre motivierenden Worte waren mir eine unschätzbare Hilfe.

Ferner danke ich herzlich Dr. rer. nat. Petra Krause, meiner Laborleiterin, für die Hilfestellung bei allen labortechnischen Fragen und Methoden. Neben ihrer großen theoretischen und praktischen Kompetenz sorgte sie stets für mein eigenverantwortliches Arbeiten und für eine sehr angenehme Arbeitsatmosphäre im Labor.

Die reibungslose und stets unkomplizierte Kooperation mit der Abteilung Strahlentherapie und Radioonkologie für die Vorbereitung der Experimente hat einen erheblichen Beitrag zum Gelingen dieser Arbeit geleistet. Dafür danke ich Prof. Dr. med. Dr. rer. nat. Clemens F. Hess und Dr. rer. nat. Margret Rave-Fränk.

Für seine unkomplizierte Art, die zahlreichen kreativen Anregungen und Ideen sowie seine wissenschaftliche Begeisterungsfähigkeit möchte ich Christian Dullin aus dem Institut für Diagnostische und Interventionelle Radiologie danken. 